\title{
Merz Magic:
}

\section{Kurt Schwitters and his Millenarian Art of Protection}

\author{
by
}

Ian Reddy, B.A. (Hons).

\author{
A thesis submitted to the Faculty of \\ Graduate Studies and Research in partial fulfillment \\ of the requirements of the degree of \\ Master of Arts \\ in Art History
}

Carleton University

OTTAWA, Ontario

(C) 2009, Ian Reddy 


\section{Library and Archives} Canada

Published Heritage

Branch

395 Wellington Street Ottawa ON K1A ON4 Canada
Bibliotheque et

Archives Canada

Direction du

Patrimoine de l'édition

395, rue Wellington

Ottawa ON K1A ON4

Canada
Your file Votre reférence
ISBN: $978-0-494-58431-6$
Our file Notre référence
ISBN: $978-0-494-58431-6$
NOTICE:

The author has granted a nonexclusive license allowing Library and Archives Canada to reproduce, publish, archive, preserve, conserve, communicate to the public by telecommunication or on the Internet, loan, distribute and sell theses worldwide, for commercial or noncommercial purposes, in microform, paper, electronic and/or any other formats.

The author retains copyright ownership and moral rights in this thesis. Neither the thesis nor substantial extracts from it may be printed or otherwise reproduced without the author's permission.
AVIS:

L'auteur a accordé une licence non exclusive permettant à la Bibliothèque et Archives Canada de reproduire, publier, archiver, sauvegarder, conserver, transmettre au public par télécommunication ou par l'Internet, prêter, distribuer et vendre des thèses partout dans le monde, à des fins commerciales ou autres, sur support microforme, papier, électronique et/ou autres formats.

L'auteur conserve la propriété du droit d'auteur et des droits moraux qui protège cette thèse. Ni la thèse ni des extraits substantiels de celle-ci ne doivent être imprimés ou autrement reproduits sans son autorisation.
In compliance with the Canadian Privacy Act some supporting forms may have been removed from this thesis.

While these forms may be included in the document page count, their removal does not represent any loss of content from the thesis.
Conformément à la loi canadienne sur la protection de la vie privée, quelques formulaires secondaires ont été enlevés de cette thèse.

Bien que ces formulaires aient inclus dans la pagination, il n'y aura aucun contenu manquant. 


\begin{abstract}
This thesis examines themes of millenarianism and protection in the Merz art of $20^{\text {th }}$ century German artist Kurt Schwitters. Merz was a one-man avant-garde art movement based on the blending of all materials and styles. Primarily such blending involved materials found by the artist on the streets of his place of residence, and the styles of German Expressionism and Dada. Taking as cues statements made by Schwitters at the inception of Merz following World War One, various degrees of millenarianism and protective magic are discerned in Schwitters work with regards to its iconology and materials. Merz is considered as a response to traumatic events in Schwitters life, and in the second chapter this theory is advanced through an iconological analysis of three works. These works, Das Kreisen (1919), Merzpicture with Rainbow (1939), and Carefree (1947), respond positively to traumatic events - both global and personal - with themes of millennial change. In the third chapter, Merz is broadly analyzed for its metaphorically protective properties. Such properties include a ritualistic-alchemical use of materials and a deployment of playful humour. In this chapter Mary Douglas' research on rituals regarding impurity and purity are referenced, as well as Mikhail Bakhtin's ideas of the carnivalesque and the grotesque to argue how a humorous use of found materials may serve protective ends.
\end{abstract}




\section{Acknowledgements}

I would like to thank my thesis advisor, Roger Mesley, whose enthusiasm for his lecture material motivated me during my undergraduate years to pursue an M.A. in art history. As an advisor he was always helpful in tempering my ideas and providing guidance to my project. I am also very appreciative of his ability to rapidly correct and return my work, even while taking refuge at his island cottage. I would also like to thank Roger's partner, Cathy, who was always friendly to Meredith and me on our visits to their home or cottage and was often offering useful words of wisdom of her own.

I would like to thank my parents and to my late grandfather 'Pops', for supporting me through my undergraduate years.

Thanks goes to my Ottawa field agents, Michel, Hamish, and Chris, for giving me a place to stay when a visit to Carleton was required, and for delivering printed materials to the proper drop points. I am especially thankful to Chris who was willing to help me from afar, sometimes on very short notice. The assistance Chris provided helped to overcome the difficulties in going to school in one city, and living in another for which I am grateful.

Thank you Huxley and Finny. Your therapeutically calming, furry presences helped me relax after long, tense hours of working at the computer. Furthermore, our wordless play helped to unravel the knots that would develop in my thought during periods of work.

Above all I would like to thank my best friend and wife, Meredith, without whose support I would surely have degenerated into an incoherence. Our long discussions about ideas helped to clarify my thoughts enough that they were worth developing into these chapters. 


\section{Table of Contents}

Abstract......................................................ii

Acknowledgements.............................................ii

List of Figures.................................................

Introduction: Themes of Protection in Kurt Schwitters' Merz...............1

Chapter One: “A Prayer About the Victorious End of the War"..............7

Chapter Two: "New Things Had to Be Made Out of Fragments"..........39

Chapter Three: “A Game we Play with Serious Matters. That is Art”.....77

Conclusion......................................................111

Figures.....................................................113

Bibliography................................................. 137 


\section{List of Figures}

(fig 1) Kurt Schwitters - Das Kreisen - 1919 - assemblage

(fig 2) Kurt Schwitters - Merzpicture With Rainbow - 1939 - assemblage

(fig 3) Kurt Schwitters - Carefree - 1947 - assemblage

(fig 4) Kurt Schwitters - Mountain Graveyard - 1918 - oil on canvas

(fig 5) Franz Marc - The Unfortunate Land of Tyrol - 1913 - oil on canvas

(fig 6) Kurt Schwitters - Merzbild 01 - 1919 - assemblage

(fig 7) Kurt Schwitters - Das Sternenbild - 1919 - assemblage

(fig 8) Kurt Schwitters - Merzpicture IA, The Alienist - 1919 - assemblage

(fig 9) Caspar David Friedrich - Cross in the Mountains - 1808 - oil on canvas

(fig 10) Kurt Schwitters - Das Arbeiterbild - 1919 - assemblage

(fig 11) George Grosz - Early Morning at 5 O'Clock - 1921 - drawing

(fig 12) Kurt Schwitters - Picture With Light Centre - 1919 - assemblage

(fig 13) Kurt Schwitters - The Cherry Picture - 1920 - assemblage

(fig 14) Kurt Schwitters - Grünflek - 1920 - assemblage

(fig 15) Kurt Schwitters - The Great Ich Picture - 1919 - assemblage

(fig 16) Athanasius Kirchner - astrological diagrams from Iter Extaticum - 1671

(fig 17) William Blake - Ancient of Days - 1794 - watercolour etching

(fig 18) Masonic Seal

(fig 19) Kurt Schwitters - Untitled Rubber-Stamp Drawing - 1919

(fig 20) Kurt Schwitters - Untitled Rubber-Stamp Drawing - 1919

(fig 21) Johannes Molzahn - Star Movements -1919 - woodcut

(fig 22) Joseph Anton Koch - Noah's Thanksoffering - 1803 - oil on canvas 
(fig 23) Caspar David Friedrich - Cross by the Baltic - 1815 - oil on canvas

(fig 24) Wassili Kandinsky - Murnau With Rainbow - 1909 - oil on canvas

(fig 25) Wassili Kandinsky - Cossacks - 1911 - oil on canvas

(fig 26) Kurt Schwitters - Picture with Spatial Growth/Picture with 2 Little Dogs 1920/1939 - assemblage

(fig 27) Kurt Schwitters - Aerated VII - 1942 - assemblage

(fig 28) Kurt Schwitters - Untitled (Merz Box) - 1920 - inlaid box

(fig 29) Kurt Schwitters - Untitled (Merz Hand-Mirror) - 1922 - assemblage

(fig 30) Kurt Schwitters - (detail) Untitled (Collage in Interior of Trunk Lid) - 1926 assemblage

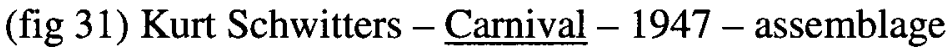

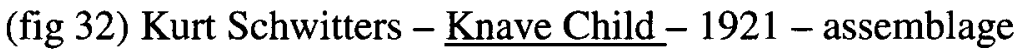

(fig 33) Kurt Schwitters - Correggio - 1947 - assemblage 


\section{Introduction}

\section{Themes of Protection in Kurt Schwitters' Merz}

In 1920 Kurt Schwitters (1887-1948) wrote that his Merz art "was a prayer about the victorious end of the war, victorious as once again peace had won in the end; everything had broken down in any case and new things had to be made out of fragments: and this is Merz." Merz was an artistic idiom aimed at rebuilding the world after its destruction by World War One. This art was primarily composed of found materials, in which the fragments of the past - fragmented by the apocalyptic event of the war - could be reassembled into new structures for a new world. The language Schwitters used to explain Merz was millenarian, positing Merz art as a spiritually inflected art of fragments - both material and conceptual - taken from the past. Merz was thus the cosmic return to peaceful origins after society had crumbled, an art which could assimilate every stylistic innovation and material, and be expanded to cover any object or structure.

At the root of Schwitters' millenarian art was a desire for protection, both metaphorical and actual. Schwitters responded to the post-war peace by saying, "I felt I had to shout my joy to the world," even though Germany was thrown into a severe state of economic and social instability that lasted approximately five years after the war's end. For Schwitters Weimar Germany was a great period, and many art historians concerned with the quality of Schwitters' work, place this five-year period of social turbulence as the peak of Merz. The vague millenarian rhetoric Schwitters used in his 1920 manifesto, Merz, takes an optimistic, jubilant tone regarding the peace and his art and establishes Merz as a kind of protective shield for the artist. Issues of post-apocalypse are found in

\footnotetext{
${ }^{1}$ Kurt Schwitters, as cited in Werner Schmalenbach, Kurt Schwitters, (1967) 32
} 
his art as well as his writing, but other protective forms and strategies are also deployed in his work.

I will argue that Schwitters sought protection through art from a variety of threats, both personal (epileptic seizure, Nazi persecution) and global (World War One), and he did so through art. Art's literal ability to provide a subject with protection from danger is, of course, limited. Art can provide metaphorical protection, analogous to how religious ritual (including prayer) may provide spiritual and psychological protection to those who invoke it, and I believe that Kurt Schwitters credited Merz with some kind of magical/talismanic power in this regard. Furthermore, millenarian rhetoric, such as that used by Schwitters to describe Merz's role in the post-World War One environment, has a protective function in that it divides time between catastrophe and peace, and fortifies the concept of peace as divinely sanctioned and utopian. As Schwitters stated, Merz art is an elaboration on such rhetoric, and serves as a kind of renewal ritual. As well, Schwitters uses apocalyptic symbolism as well as symbolism pertaining to esoteric traditions of renewal and transcendence, such as astrology and alchemy.

The serious invocations of spiritual protection in Schwitters' work are obscured by a facade of humour and play. As will be discussed in the third chapter, Merz is humourous art, and it bears many playful elements. The role humour played in Schwitters' art was more complex than simply concealing its serious elements, as later I will discuss how humour and play have protective elements as well. The utilization of humour has psychologically protective benefits to its user and its use in Merz complements the art form's more spiritual aspects. Furthermore, humour has the benefits of being immediately protective, while the spiritual elements, Merz as a "prayer", are 
ritualistically protective by way of metaphor. Thus Merz is protective in a number of interesting and interconnecting ways.

I will prove my argument that Merz is an art meant to be protective of Schwitters and, to some extent, his friends and family, over the course of three chapters. In the first chapter I contextualize my thesis by describing the social, political, and cultural climate of Weimar Germany, and I situate Schwitters within this milieu. There has been much writing published on Schwitters' art, but perhaps the most valuable source of biographical information is Gwendolyn Webster's 1994 book, Kurt 'Merz' Schwitters: A Biographical Study, which gives a detailed account of Schwitters' life. ${ }^{2}$ Schwitters will be discussed as an artist whose work arose from the tensions between Expressionism and Dada that followed World War One. I will elaborate a discussion of apocalyptic rhetoric and its relation to the avant-garde and the First World War. Kurt Schwitters was not the first to make apocalyptic allusions to the catastrophic conflict, as a number of artists before and during the war already considered it an apocalypse. Franz Marc and Wassili Kandinsky, before the war, wanted an apocalypse to bring about cultural renewal. During the conflict, Ludwig Meidner painted scenes of urban devastation as part of a series of paintings all titled Apocalypse. Scholarship by Richard Cork, Frederick S. Levine, and Rose Carol Washton-Long explored relationships between the war, abstraction, millenarianism and spiritual life. Schwitters was virtually unique in his project of following the war's end with apocalyptic rhetoric. The ideas of Apocalypse and Post-Apocalypse will also be analyzed in the first chapter by drawing upon the ideas of millenarian scholars such as Adela Yarbro Collins, Stephen O'Leary and Dan Berger.

\footnotetext{
${ }^{2}$ Gwendolyn Webster. Kurt Merz Schwitters: A Biographical Study, (Cardiff: University of Wales Press, 1997)
} 
Their analyses of apocalyptic thought will be put at the service of the theory that Schwitters' art was millenarian.

The second chapter will analyze three Merz collages by Schwitters with regard to their iconography. The iconography of Merz works has been discussed by earlier Schwitters scholars like Annegreth Nill, Kurt Germundson, John Elderfield and Werner Schmalenbach, all of whom have suggested in their writing that Schwitters has used the materials he finds to construct images that convey meaning through a symbolic use of objects and a poetic use of words. Also the scholars mentioned all considered Schwitters to be an artist whose work contained spiritual resonance and affirmed Schwitters' devotion to the Expressionist use of symbols. I am building upon the work of these scholars with interpretations of Schwitters' Das Kreisen (1919) (fig. 1), Merzpicture With Rainbow (1939) (fig. 2), and Carefree (1947) (fig. 3). Each work expresses the theme of renewal by a different set of signifiers, and each will be described in relation to a major, life-altering event that occurred to Schwitters. I intend to examine these works with regards to their affinities to various forms of apocalyptic rhetoric, but also to bolster my interpretations of the works by connecting them to related esoteric symbolism.

Schwitters employed iconography derived from such sources as alchemy, Theosophy, astrology, magic and Christianity. What these diverse esoteric and exoteric sources have in common is the pursuit of a more perfect world for their adherents. I have no evidence that Schwitters was uniquely affiliated with any one of these doctrines, but I will contend that he freely mixed iconography derived from them to signify the implicit postapocalyptic meaning of Merz. 
The third chapter will explore the number of metaphorically protective strategies deployed by Schwitters in Merz. In this chapter a variety of issues that more broadly pertain to protection and Merz will be investigated. These will include memory and collecting, which will draw upon the ideas of Leah Dickerman and Roger Cardinal, both of whom wrote directly about Schwitters and these matters. Schwitters' use of refuse will be examined as well, as I will draw upon the ideas of Mary Douglas regarding rituals of impurity and purity to bring a protective interpretation to his materials.

Furthermore, Schwitters' use of materials engages themes of humour, play, carnival and the grotesque. An analysis of his work as such will depend on a variety of scholarly sources. The thesis that humour is protective will draw upon psychological research done by humour researchers, including foundational work by Sigmund Freud, but more recent work by University of Waterloo psychologist Herbert M. Lefcourt will also be useful. The issue of play in Merz will be examined using the seminal theories of J. Huizinga and Roger Caillois, but the work of Christian Janecke will also be considered as he discussed directly the interrelationship of play and chance with Merz. An understanding of the concepts of carnival and the grotesque, which relate to a number of the ideas already discussed (including cultural renewal and humour) will necessitate utilizing Russian literary theorist Mikhail Bakhtin's ideas regarding these concepts. Bakhtin's ideas about carnival will help to articulate and synthesize some of the protective undercurrents active in Schwitters' work.

Ultimately I will postulate that Kurt Schwitters, through his art, was a kind of conflation of the archetypal shaman and trickster figures that are often posited as opposites. In Schwitters' art, numerous opposing tendencies are in operation: the sacred 
and the profane are implied, as solemn prayer and joyful play are simultaneously active in his works. This argument relies on Mircea Eliade's writings on global shamanism, as well as Lewis Hyde's analysis of the trickster figure in various mythical traditions. This concept of Schwitters as a unity of opposing spiritual figures postulates that he himself used Merz art as a form of metaphorical mastery over his environment that protected him from traumatic events. Many artists of early modernity cast themselves as priests, prophets, gurus or Christs. Schwitters, however, was the 'wise fool', who, as trickster and shaman combined, sought to save himself and his world with a serious millenarian vision camouflaged with humour and visual appeal. 


\section{Chapter One}

\section{"A Prayer About the Victorious End of the War"}

On the $28^{\text {th }}$ of June, 1919 , Germany officially ended the First World War when it signed the Treaty of Versailles with the Allied Powers, concluding an extended period of devastation and planting the seeds of another. Weimar Germany was a concept in statecraft, for the pre-war Germany of strong tradition and warfare was mortally wounded by the war, and killed at the treaty signing. The bloody results of war were a signal to many Germans that it was time to deemphasize the nation as a military power and emphasize its cultural prowess. ${ }^{1}$ Weimar, the seat of the new government, was also the birthplace of Goethe, one of Germany's greatest writers, and therefore a symbolically suitable location for a new German realm's center of government. ${ }^{2}$ This effort to force a cultural renewal in a war-torn nation was, to some extent, successful. Weimar Germany was very accommodating to the arts and other forms of cultural expression and exploration. But the Republic, threatened from the start, never found stability. Ultimately, the consequences of failure in The Great War were too great, as the signing of the Treaty of Versailles set off a chain reaction that gave rise to the Third Reich.

The Weimar Republic was built on compromise; the Treaty of Versailles forced the German people to accept sole responsibility for the ruin caused by World War I, a position the war-torn population found unacceptable as they too were coping with enormous losses. Germany was forced by the treaty to place heavy restrictions on its

\footnotetext{
${ }^{1}$ Peter Gay, Weimar Culture: Outsider as Insider, (1968: Harper Torchbooks) 2

${ }^{2}$ According to Peter Gay, Weimar was also chosen as a site for a new government because the previous capital, Berlin, had become too dangerous, due to rioting and street violence, to host the National Assembly, as post-war strife began immediately in Germany.
} 
populace and make exorbitant reparations to France for the damage done during the war, which led directly to the rise of massive inflation in the early 20s, with Germany receiving nothing in return other than scorn.

Despite the problems the Weimar era faced at its outset, the period was one of relative freedom. Even before the war, Germany was a country known for its Bohemianism - vegetarianism, nudism and various strains of religious mysticism thrived in pre-war Germany and were nurtured through the Weimar period. During this period of artistic and social experimentation, Kurt Schwitters developed his Merz project: a oneman art-movement that involved assemblage, painting, poetry and performance. Before and during the war, Schwitters was an unexceptional artist with Expressionist predilections. He came from an upper-middle-class background, inherited a home from his father (in which his parents continued to live) and lived a respectable family life with a wife, Helma, and a son, Ernst. ${ }^{3}$ For Schwitters the Weimar Republic was a paradise, a moment of renewal for the arts in Germany, as well as for German society and, especially, for himself. Schwitters' Merz, an approach to artmaking that sought to balance every possible source of material and idea, with a particular emphasis on foundobjects, bespeaks Germany's post-war period, with its diverse art scene, abundance of printed matter, and turbulent social climate. It was also, in fact, the war that gave Schwitters the requisite inspiration for his Merz idiom.

Schwitters' experience of the war was much different from many of his contemporaries, be they artists or not. Many artists of the pre-war avant-garde fought in the conflict and were afflicted by its excesses of violence and carnage. After developing

\footnotetext{
${ }^{3}$ Schwitters' parents were Hanover landlords who lived off tenants' rents. His parents provided him and his family with rooms in the same building they occupied, assuring Schwitters a secure, middle-class home and lifestyle.
} 
positive theories regarding war, the Expressionist co-leader of the group, Der Blaue Reiter, Franz Marc (from whom Schwitters derived a Cubist-inflected painting style) died as an officer in the German army in 1916, much as prominent Italian Futurist painter and sculptor Umberto Boccioni died fighting for Italy. During the conflict, Hugo Ball (who was rejected by army recruiters) and Richard Huelsenbeck, who went on to found the Dada movement, made a visit to the German front with expectations of observing valour in wartime, the Futurist ideal, only to witness a sickening carnage that influenced their subsequent anti-war and anti-culture activities. ${ }^{4}$ Many of the avant-gardes from before and during the Great War developed complex sets of theories and ideas about its merits: from the Futurists aestheticization of combat, ${ }^{5}$ to Franz Marc's millennial expectation of the war as a cleansing apocalypse, ${ }^{6}$ to the Dadaists' concept of the war as the de facto justification for rejecting Western Civilization and its values, ${ }^{7}$ World War One was an event that inspired extreme responses in art. Schwitters however, had no first-hand experience of the war. He suffered from epilepsy and was therefore found medically unfit by army recruiters to participate in the conflict, as many of his contemporaries had. As the conflict continued and the German military became desperate for fresh soldiers, Schwitters was, in 1917, again called in to be examined and this time the threshold for eligibility was lowered. Pressure on the doctors and enlistment officers to find new men compelled them to recruit Schwitters despite his disability, but he was stationed in Hanover, in a military industrial design office far from the front. ${ }^{8}$

\footnotetext{
${ }^{4}$ Leah Dickerman, Dada, (2005: National Gallery of Art), 21

${ }^{5}$ Richard Cork, A Bitter Truth: Avant-Garde and the Great War (New Haven CT: Yale University Press, 1994) 16

${ }^{6}$ Frederick S. Levine, The Apocalyptic Vision, The Art of Franz Marc as German Expressionist, (1979: Harper \& Row, Publishers) 138

${ }^{7}$ Dickerman, 2005, 17

${ }^{8}$ Schmalenbach, 32
} 
Many of Schwitters' German avant-garde contemporaries viewed the war and its outcome negatively, with the conflict acting as a radicalizing catalyst. For Schwitters, who never experienced first-hand the large-scale and indiscriminate violence the war offered its participants, the end of war was a victory, despite Germany's loss to the allies and the widespread destruction.

..in the war, it fermented horribly. I could not use what I had brought from the academy and the useful new ideas were still unready, while an imbecilic struggle raged around me about things that have never concerned me. Then suddenly the glorious revolution was upon us. I don't think highly of revolutions; mankind has to be ripe for such things. It is as though the wind shakes down the unripe apples, such a shame. However, the whole swindle that men call war, was finished by this. I left my place of work, without giving any notice, and things really started happening. Now the fermentation began in earnest. I felt myself freed and had to shout my jubilation out to the world. Out of parsimony I took whatever I could to do this, because we were now a poor country. One can even shout through refuse, and this is what I did, nailing it and gluing it together. I called it 'Merz', it was a prayer about the victorious end of the war, victorious as once again peace had won in the end; everything had broken down in any case and new things had to be made out of fragments: and this is Merz. It was like an image of the revolution within me, not as it was, but as it should have been. ${ }^{9}$

Schwitters' uniquely vague eschatology is thus encoded into such a statement, which was later reaffirmed by a statement made by his son, Ernst. Ernst Schwitters said his father "saw the great weariness and ruin which surrounded him everywhere after the war, and also how, by making use of the qualities associated with these characteristics, he could rebuild a better, sounder, more honest culture."10 Schwitters clearly ignored the depressed nationalism of the common folk, who considered the loss of the war and the signing of the Treaty of Versailles to be a stinging disgrace. Schwitters also apparently accepted the large number of casualties and the massive destruction done to German towns as the cost of proceeding through an eschatological event. He viewed the success of the survivors as the ultimate achievement at the end of World War I: they were

\footnotetext{
${ }^{9}$ Kurt Schwitters, as cited in Werner Schmalenbach, Kurt Schwitters, (1967) 32

${ }^{10}$ Ernst Schwitters, as cited in Elderfield, 90
} 
'apples' left on the tree after the wind had shaken the 'unripe' ones. ${ }^{11}$ Although relief over the war's conclusion was widespread among Germans, Schwitters' ideas regarding its results were exceptional. His understanding of the war's end as a success for humankind is integral to a perception of Schwitters' views of the Weimar Republic as a post-millennial milieu. The basic notion behind Millenarianism is that an event of neartotal devastation, often eliminating those whom the celestial force deems unsuitable for paradise, will be followed by a golden age of divine providence, thus rewarding those who remained true to their faith. In the Christian tradition (the source of the quintessential 'Apocalypse', as well as for the vocabulary used in discussing the apocalypse as archetypal event), the Millennium is the final stage of the Apocalypse. ${ }^{12}$ In 'Revelation', it is the period of one thousand years in which Christ returns to rule over a divine kingdom established on Earth for the faithful. This period invariably follows a long-lasting and complex struggle between good and evil forces, in which good triumphs. ${ }^{13}$

Schwitters' repeated reference to fermentation necessitates some comment. Fermentation is the breakdown of organic matter due to exposure to oxygen, and most often the term is used with regards to fruit sugars breaking down into alcohol. The use of this term can also be associated with alchemy, particularly with the step of putrefaction the step at which a material is brought to its most base state. Putrefaction precedes the step of purification, which, in alchemy, is the process of distillation that produces the

\footnotetext{
${ }^{11}$ Such allusions to natural forces separating good from bad are rooted in traditional apocalyptic rhetoric.

${ }^{12}$ It should be noted that millenarianism is quite pervasive in world religions as well as numerous smaller derivations of Christianity, including Cargo Cult groups in Melanesia, Jamaican Rastafarianism and the American Mormons. Eric Hobsbawm's book Primitive Rebels as well as the book Cargo Cults and Millenarian Movements delve in depth into the phenomenon of millenarianism among a number of groups.

${ }^{13}$ Stephen O'Leary, Arguing the Apocalypse, (New York: Oxford University Press, 1994) 32
} 
aqua vitae, and in Merz may be the manipulating of the found materials Schwitters worked with. ${ }^{14}$ The step of fermentation may also be fit into a pattern of cultural renewal, where, according to Mircea Eliade, often culture is renewed after it has reached its most corrupt and degraded point. ${ }^{15}$ Arguably Schwitters references both apocalypse and alchemy as metaphors for his art's relation to cultural renewal.

Millennial rhetoric operates as a protective force that functions along an intellectual-spiritual axis. To those who invest themselves spiritually in millenarianism, the outcome of the apocalyptic event is already known - good vanquishes evil, but at a terrible cost to the world as it was known. The apocalyptic event violently cleanses the world of sinners and adversaries so as to produce a new world that matches the divine order that descends upon it to rule. This mode of belief has an archetypal role in many cultures and is particularly effective in helping downtrodden groups cope with difficult times (periods of persecution or conflict) as it proclaims the ultimate doom of assailing forces and the divinely sanctioned eventual dominance of the group in question. With a basic conceptual framework of desire for mass change, and a prophetic expectation of this desire's fulfillment by a higher power, apocalypse has taken many different forms in human culture. Often millenarian groups and other visionary agents (such as artists) will respond to watershed events like World War One with such apocalyptic desires, developing theories and expectations of massive utopian renewal following a state of actual disaster or social upheaval.

The notion of the apocalypse cleaving away negative social forces and cleansing the world for true believers is a consistent feature of apocalyptic rhetoric and essential to

\footnotetext{
${ }^{14}$ Allison Coudert, Alchemy: The Philosopher's Stone, (Boulder CO: Shambhala Publications, Inc. 1980), 195

${ }^{15}$ Mircea Eliade, Myth and Reality, New York: (Harper \& Row Publishers, Inc. 1963) 63
} 
its protective capabilities. The Old and New Testaments' eschatology was largely contained in screeds written against the dominant power of the Roman Empire. Such writings were shrouded in prophetic language, but also stated as a divine threat. ${ }^{16}$ The visions presented in the Book of Daniel, Ezra 4, and Revelation all prophesy a reversal of the existing order that occurs through a battle between good and evil, in which good prevails, wiping out evil. ${ }^{17}$ In the modern world, marked by a decline in religious orthodoxy and a rise in syncretic movements and personal spiritual vision, World War One became an event interpreted by a number of eschatological notions from a variety of sources. In advance of the war, Franz Marc, a major influence on Schwitters, as well as casualty of the conflict, expected the war to purify the world into a realm of spiritual bliss, suitable for artists such as himself. He wrote in March 1914:

We know that everything can be destroyed if the germination of a spiritual race does not endure the test of the greed and impurity of the masses. We struggle for pure ideas, for a world in which pure ideas can be thought and can be expressed without becoming impure. ${ }^{18}$

A month earlier, he had written for the unpublished second volume of the Blaue Reiter Almanach the claim that: "The World gives birth to a new age: there is only one question: has the time yet arrived today in which the old world will be dissolved? Are we ready for the vita nuova? ${ }^{19}$ This is the most anxious question of our day." ${ }^{20}$ At the dawn of war, Marc's desire was for the war to be the apocalypse he had yearned for throughout his career and to which he had alluded in his art. His sentiments follow those of the Italian

\footnotetext{
${ }^{16}$ Adela Yarbo Collins Crisis and Catharsis: The Power of the Apocalypse, (1984: The Westminster Press) 99

${ }^{17}$ The Apocalyptic vision of Ezra 4 is thoroughly described and interpreted in Alastair Hamilton's The Apocryphal Apocalypse: The Reception of the Second Book of Esdras (4 Ezra) from the Renaissance to the Enlightenment.

${ }^{18}$ Levine, 166

${ }^{19}$ La Vita Nuova is the title of a work by medieval Italian poet, Dante Alighieri. The title translates to 'the new life' and refers to Dante's own "transformation into a poet of divine love by virtue of his pure love for the deceased Beatrice." Dante was, in effect, 'born again' into a vita nuova.

${ }^{20}$ Levine, 138
} 
Futurists whose leader, Filippo Tommaso Marinetti, wrote in the 1909 Futurist manifesto that the group celebrated war as the "sole cleanser of the world", a precursor to Marc's view of the war as a spiritual purifier. ${ }^{21}$ Furthermore, in 1911 Marinetti wrote Electric

War: A Futurist Visionary Hypothesis in which he predicted a future wherein:

Hunger and need have disappeared. Bitter social problems have been obliterated. Financial problems have been reduced to the simple accountancy of production. Freedom for all to make gold and mint their own gleaming coins.... Physical labour has finally ceased to be servile, for it has but these three purposes: health, pleasure, and perfection. - No longer having to toil in order to acquire food, man has at last conceived the pure notion of endlessly breaking records. His will and his ambition know no bounds. Boundless energy is at work in every soul.... The anarchy of a perpetual striving for perfection. ${ }^{22}$

Marinetti envisions a utopian future of competitive play rather than struggle. The

Futurist noted, however, that to achieve his vision, a war was needed; thus he

immediately followed a description of his utopian world of the future by stating "and for this reason we are at last witnessing the first electrical war." ${ }^{, 23}$ Marinetti's text was first published in French in 1911, and did not appear in Italian until the eve of Italy's entry into war, in 1915. His statements were profoundly millenarian, in that they predict a glorious future once a catastrophic event is navigated. Marinetti and Marc's attitude towards the war establishes a pre-conflict set of ideals concerning a world battle.

The Futurists and Expressionists both hoped that a transformative catastrophe could change the world to the benefit of art; conversely, they believed that art could change the world for the better. Franz Marc wanted the war to purify society to a spiritual essence, and have this matched by a spiritual refining in art. The Futurists, too, desired such a shift in art through an apocalypse. The Futurists were raging against the weight of the Italian peninsula's illustrious history, particularly its art history, and needed

\footnotetext{
${ }^{21}$ F.T. Marinetti, "The Foundation and Manifesto of Futurism", Critical Writings, ed. Günter Berghaus, trans. Doug Thompson, (2006) 15.

${ }^{22}$ F.T. Marinetti, "Electric War: A Futurist Visionary Hypothesis", Critical Writings, 223

${ }^{23}$ Marinetti, 224
} 
a break from Italy's past with which to establish their own brand of violent, modern art. The first tenet of Marinetti's Futurist manifesto was: "We want to sing about the love of danger, about the use of energy and recklessness as common, daily practice." ${ }^{24}$ Such a quote outlines the Futurist desire for a more dangerous world that rejects the rational peace of the present and the exaltation of the past. Ultimately, their views were somewhat aligned with the Dadaists, who established a semi-apocalyptic movement contemporaneous with the war.

The Dadaists, who influenced Schwitters profoundly, held eschatological views of the war as well, but theirs were significantly more nihilistic than Marc's persistent optimism. The Dadaists perceived the war as the self-destruction of Western civilization. The war was a culmination of all of the stupid military posturing and compartmentalized nationalist supremacy of the European states. The major Dadaists - Hugo Ball, Hans Arp, Richard Huelsenbeck, Tristan Tzara, Emmy Hennings, and other assorted artists found themselves in Zurich, the centre of neutral Switzerland, for a variety of reasons, and proceeded to construct a confounding internationalist ideology of ritualized destruction through anti-aesthetic attacks on artistic traditions. The Dadaists came from across Europe (Ball, Hennings and Huelsenbeck were German; Arp was Alsatian; Tzara and Marcel Janco were Romanian; Sophie Tauber was Swiss), fleeing from the brutalities of the decade. They thus found national boundaries to be one of their targets for destruction. They had no true group ideology (hence their numerous individual manifestoes). They were only unified in their contempt for the war and the culture that gave rise to it. Marcel Janco had written: "We had lost confidence in our culture. Everything had to be demolished. We would begin again after the 'tabula rasa'. At the

\footnotetext{
${ }^{24}$ Marinetti, 13
} 
Cabaret Voltaire we began by shocking common sense, public opinion, education, institutions, museums, good taste - in short, the whole prevailing order."25 Taking influence from the Cubists, Futurists (although eschewing their pro-war sentiments), and Expressionists, the Dadaists developed a number of strategies for providing an analogue to the war in the realm of art. Unlike Marc and the Futurists (who merely viewed war as an ideal condition for the art), the Dadaists posed as agents of apocalypse, doing away with the rational and civilized, and replacing them with nonsense and chaos.

Hugo Ball, author of the first Dada Manifesto, had tried to enlist in the German military before emigrating to Switzerland, and he was rejected from military service on the grounds that he was physically unfit to serve. ${ }^{26}$ Stung by this rejection, he had actually made an unauthorized, personal visit to the front with Richard Huelsenbeck, to witness the "glory" of battle for himself. What they saw was appalling: the image of dirt and carnage that characterized the trench war fought along the western front changed their approach to art afterwards, as well as their view of western civilization. ${ }^{27}$ The vision of the front struck the Dadaists as a form of cruelly sublime stupidity, especially in an age that vaunted rationality and technological progress. Hence, the Dadaists began to see the war as the logical end of western civilization, an affront to its own pretensions of being a realm of civility and intellect given its capability of entering such violent depravity. The battle externalized an underlying barbarism that ran beneath Western Civilization and, for the period of 1914-1918, came to the surface as a brutal spectacle willingly entered into by the most technologically advanced nations in the world. The

\footnotetext{
${ }^{25}$ Marcel Janco "Dada at Two Speeds" 36-38 Dadas on Art, (Englewood Cliffs, NJ: Prentice-Hall, 1971) 36

${ }^{26}$ Leah Dickerman, Dada: Zurich, Berlin, Hanover, Cologne, New York, Paris. (Washington DC: National Gallery of Art, 2005) 21

${ }^{27}$ Hugo Ball, Flight out of Time: A Dada Diary, (New York: The Viking Press, 1974) 10
} 
Dadaists' goal was thus to develop a variety of strategies that ridiculed the higher forms of a Western culture that caused incredible destruction in war. The Dada view of the war was similar to that of the Expressionists, in that it was as an apocalypse. But for the Dadaists, it was an apocalyptic moment in the sense that it was culturally damaging to the past. It was not a divine apocalypse cleansing the world, but rather a human discrediting of a spurious ideal.

For the Dadaists, Europe during the war was a dystopia that held no promise of a glorious future. Above all else, they did not want to see a continuation of western culture from the pre-war years as though a significant rupture had not taken place. Hence, they took aim at everything that preceded the hostilities. While the Futurists struggled to break from a culture they felt was held in the grip of a historical past, the Dadaists railed against the undercurrents of thought they considered to be the basis for their entire cultural environment. Ultimately, the Dadaists wanted a destruction of culture as it was known, and a renewal as something else from a tabula rasa. In Zurich, the Dadaists evaded artistic traditions by exploring elements of chance, transgression, and primitivism in their work. Hans Arp famously produced collages made from torn pieces of heavy paper dropped onto a backing surface, and glued where they fell. Meanwhile Hugo Ball and Richard Huelsenbeck experimented with sound. Huelsenbeck was fascinated by African drumming rituals and attempted to emulate them in performance. ${ }^{28}$ Hugo Ball, influenced by what he believed to be primitive chanting, composed sound poems like Karawane, a poem made up of sublingual vocalizations, conceived of as a sort of primitivist prayer, to be performed before an audience in costume. Also, under the

\footnotetext{
${ }^{28}$ Richard Huelsenbeck, Memoirs of a Dada Drummer, trans. Joachum Neugroschel. (Berkeley: University
} of California Press, 1969) 
direction of Tristan Tzara, many of the performances provoked the audience into rioting and brawls. Indeed, such performances often consisted of simply provoking the audience. ${ }^{29}$ It was through such hostile anti-art tactics that the Dadaists sought to bring about a cultural apocalypse parallel to the politico-military one.

The Dadaists, many of whom wrote prolifically, issued many statements, both as individual artists and as groups, in manifesto form. Their goals and program may be difficult to assess, as they were willfully evasive of having a single goal. The variety of their art reflected this plurality in their ideas. They can be said to have had, at their core, a desire to negate reason as a way of achieving a renewal in culture. Tzara wrote in 1916:

Dada is a great clownery. Since the age aims at the destruction of all that is noblest and best in life, the Dadaist courts the absurd, loves every kind of disguise, game or deception. The Dadaist fights against the agony of the times and the intoxication of death. ${ }^{30}$

Tzara's statement suggests a kind of renewal that is at once consonant and dissonant with contemporary events. He suggests that despite the age of reason being the foundation for the modern, "noble" civilization, the zeitgeist of the teen years of the twentieth century is destruction. This was the essence of the Dada millennium. They attempted to bring about a cultural renewal they felt was appropriate for a world that engaged in a conflict as absurd as the First World War. Ultimately however, the Dadaists burned out through their own action. Annabelle Mezler, author of Latest Rage the Big Drum, notes how figures such as Hugo Ball ultimately could not continue with their frequent assaults. ${ }^{31}$

\footnotetext{
${ }^{29}$ Anabelle Henkin Melzer, Latest Rage the Big Drum: Dada And Surrealist Performance, (Baltimore: John Hopkins University Press, 1976) 73

${ }^{30}$ Tristan Tzara, as cited in Matthew Josephon, Life Among the Surrealists, (New York: Holt, Rinehart and Winston. 1962) 111

${ }^{31}$ Melzer, 82
} 
Ball had written in his journal how stressful the nightly cabaret performances were. ${ }^{32}$ For two reasons, these performances were becoming a strain upon the performers. The first was the trouble of, almost nightly, developing new material to perform that was in accordance with the kind of ideological program the Dadaists espoused. The second was that the sheer danger of these performances became wearying upon the artists. According to Ball, the frequent performance nights were often plagued by violence, with the audience of AWOL soldiers and exiles often responding to the Dada taunts by brawls and otherwise vicious behaviour. ${ }^{33}$ Although this kind of irrational behaviour was precisely what the Dadaists were attempting to nurture through their works and performance, it was also what ended their efforts.

In 1917, Huelsenbeck returned from Zurich to Berlin and began the Berlin group, Club Dada. Huelsenbeck's vision for the group was a compromise between Zurich Dada anti-cultural hostility and a constructive, positive renewal of culture. The Berlin Dada group included Hannah Höch, Raoul Haussman, Richard Huelsenbeck and George Grosz - a more politically oriented group than the nihilist Zurich Dadaists - and they were largely hostile to Schwitters, who approached them in 1917 for friendship. ${ }^{34}$ Still, they continued with many of the same conceits as the Zurich Dadaists, albeit with an infusion of Marxist ideology and social critique. Once the war ended, Club Dada members, like many war-time millenarian artists, were focused explicitly on political revolution. This is

\footnotetext{
${ }^{32}$ Ball, 57

${ }^{33}$ Melzer, 73

${ }^{34}$ Richard Huelsenbeck's memoir recants an often repeated anecdote about how Schwitters approached him in Berlin for Club Dada membership and was rejected. Gwendolyn Webster, however, argues that this anecdote is exaggerated. Webster suggests that Schwitters was too individualistic to join one of the avantgarde groups. Furthermore Schwitters was opposed to politics in art while Club Dada members were overtly political: and finally, according to Webster, Club Dada was a closed group that one could not just apply to, and Schwitters knew this. Regardless of Schwitters' trouble with Club Dada, he maintained lifelong friendships with Hannah Höch and Raoul Haussman.
} 
a form of millenarianism, according to historian Eric Hobsbawm, but one invested in concepts of incremental social change rather than a violent catastrophe with transformative properties. ${ }^{35}$ This focus on political change rather than catastrophic renewal was the dominant trend among both Dadaists and Expressionists after the war's end.

The desire for cultural renewal extended well beyond Europe's artists in early twentieth-century Europe; and once the Great War had ended, Germany's politicians saw a need for reforming German culture, softening its emphasis on battlefield heroics. The end of war resulted in the Weimar Republic, which would shift Germany's capital to Weimar, the birthplace of Goethe, and place reward on cultural achievement rather than upon excellence in combat. The intention of Weimar was to make the artist the nation's vaunted representative archetype. Unfortunately, this concept for a paradisical artistic nation never truly materialized, as Weimar Germany was fraught with trouble from its inception.

The war left Germany traumatized and riddled with problems that a shift in emphasis could not resolve. First, Germany had experienced a loss of approximately one-million young men in the Great War. Approximately another 2.5 million young men were severely injured, and virtually all who returned from the front were psychologically scarred by their experiences. ${ }^{36}$ Shortages of food and other staples of daily life led to rioting, especially in Berlin. Labour unrest was widespread across Germany as the war

\footnotetext{
${ }^{35}$ E.J. Hobsbawm Primitive Rebels, (Manchester: Manchester University Press, 1959) 57

${ }^{36}$ Eric D. Weitz Weimar Germany: Promise and Tragedy, (Princeton, NJ: Princeton University Press, 2007) 9
} 
effort had taken men from their jobs, at which they were replaced by women who were now reluctant to return to their domestic roles. ${ }^{37}$

The new parliamentary government was fragile from its beginning. The public had been told by media and an outgoing aristocracy that the war effort was undermined at home by weakness from within the nation. ${ }^{38}$ The argument was made that Germany lost the war because of how communists and anti-war protestors at home prevailed. This successful argument led to the rise of the National Socialists, who began to build power almost immediately after the war's end. The size of the official German military was heavily restricted, so angry young men and disgruntled returning soldiers joined paramilitary units called Freikorps, which engaged in frequent street fighting and suppression of communist uprisings. ${ }^{39}$ Furthermore, the returned soldiers frequently displayed contempt for authority that involved violence. ${ }^{40}$

Morality became one of the central issues of the Weimar period. The war effort gave German society a moral centre, and its absence left a vacuum filled by more libertine pursuits - nudism, sexual fetishism, and pornography - which approached mainstream status. ${ }^{41}$ With large-scale unemployment, prostitution became commonplace, with thousands of prostitutes in Berlin alone. ${ }^{42}$ This sort of newfound cultural freedom

\footnotetext{
${ }^{37}$ Weitz, 21

${ }^{38}$ Panikos Panayi, "Continuities and Discontinuities in German History, 1919-1945" 4-33, Weimar and Nazi Germany: Continuities and Discontinuities, ed. Panikos Panayi, (Essex, UK: Pearson Education Limited, 2007) 10

${ }^{39}$ Jeffrey R. Smith, in his essay "The First World War and the Public Sphere in Germany" describes the public space of war-time Germany as a treacherous realm, infested with spies and dangerous elements indicating that the strife of Weimar Germany pre-dated the war's conclusion and contributed to the collapse of Germany's monarchy. Also Jan Vatlin, in his memoir of operating as a Communist agitator, Out of the Night, described in depth street fighting with Freikorps and Nazi SA.

${ }^{40}$ Weitz, 23

${ }^{41}$ Mel Gordon's book Voluptuous Panic: The Erotic World of Weimar Berlin, thoroughly explores this side of Weimar Culture.

42 Mel Gordon, Voluptuous Panic: The Erotic World of Weimar Berlin, (Los Angeles: Feral House, 2000) 30
} 
was, in a sense, what was expected in the founding of the Weimar Republic, and was largely what characterized the Weimar Republic as a period of cultural renewal. The consequence to nurturing an unfettered cultural milieu, however, was widespread moral backlash, which caused a tilt towards conservative cultural polices. ${ }^{43}$

The prevailing attitude among German citizens - that the German war-time culture had been weakened from within - intersected with a popular perception of Bohemia, as the public often associated artists with immoral, libidinous behavior. Many German artists, both before and after the war, were engaged in behaviour perceived as immoral (from Die Brucke's free-love experiments of well before the war, to the drunken riots occurring at Dada nights in Berlin) and it was perhaps inevitable that the new artpositive Weimar Republic came to be identified with overt sexuality and drug use. ${ }^{44}$ Also, the politically volatile environment drove many artists to take up political radicalism as subject matter, often aligning them with Communism. Furthermore, long before the war began, Max Nordau's caustic book, Degeneration (1892), which criticized avant-garde modern art as the product of deranged minds, was widely read and had a lasting influence. This was the nature of the cultural renewal of Germany after the war: a hopeful beginning quickly twisted painfully into a shift towards repression.

All of the approaches to cultural renewal listed, particularly with regards to their symbolic forms (such as the moving the national capital to Weimar), bear some association with what Stephen O'Leary posits in his book Arguing the Apocalypse as the fundamental importance of the role apocalyptic thinking plays in culture and society. O'Leary argues that apocalypticism was primarily a form of rhetoric used by a culture to

\footnotetext{
${ }^{43}$ Adolph Hitler had, in part, built his popularity upon promises to clean up what was perceived as an immoral and permissive culture according to Voluptuous Panic.

${ }^{44}$ Gordon, 242
} 
negotiate through trying times and manage periods into before and after. ${ }^{45}$ It is used to navigate through periods in which an element coded as evil must be overcome or dealt with in some way. Apocalyptic rhetoric provides an intellectual framework for a culture to deal with such events and forces, helping the culture's individual members cope with difficult events. Hence, even the real-world efforts of Germany's post-war parliament required some forms of millenarian rhetoric to navigate all of the tensions Germans faced in trying to heal a war-torn country.

O'Leary writes of apocalypse as a social narrative structured in a circular pattern. It begins with a catalyst of evil, followed by rhetoric about a divine intervention leading to a dissipation of the evil and then a disappointment at the conclusive lack of actual divine intervention. ${ }^{46}$ Typically, millenarian movements are dissolved when a conclusion comes without divine intervention, but this allows for the cycle to begin again, and the potential for this pattern to repeat in endless permutations is inexhaustible ${ }^{47}$. There are cases, however, wherein, despite the fact that the divine was absent, the millennium has been interpreted as having arrived. ${ }^{48}$ These efforts occur occasionally, often in periods wherein social structures face extreme external threats. Apocalyptic rhetoric's primary function is to cope with evil, and the function of establishing a millennial milieu is one of protection. This basic concept serves as an archetypal mode that is rarely actualized. Schwitters' Merz project is an example of such post-millennial potential. Schwitters'

\footnotetext{
${ }^{45}$ O'Leary, 50

${ }^{46}$ O'Leary, 34

${ }^{47}$ O'Leary, 195

${ }^{48}$ The early Mormons in the United States are an example. They began to form communities of Mormons that functioned as predicted in The Book of Mormon. Mormon settlements, for example, had been driven out of a number of states before they established their millennial stronghold in Utah.
} 
Merz idiom - I will argue - employs a number of strategies that serve as a kind of personal protection through art, and all under the sign of post-millennial rhetoric.

Schwitters' own form of eschatology is somewhat convoluted, as it serves as a backdrop for a matrix of cultural tropes and forms that function as symbolic protection. At its root is Schwitters' sense of the spiritual, which the artist never clearly defined. Unlike many of his contemporaries (e.g. Marc, Kandinsky, Kupka, Mondrian), Schwitters was rarely explicit about his spirituality. Schwitters made numerous statements that suggest an attraction to the mystical, although throughout his life he considered himself a non-practising member of the Lutheran church. ${ }^{49}$ He did seem to consider art to be a spiritual affair, however. In addition to referring to Merz as a "prayer" in 1920, he also wrote, "self-absorption in art is like service to the divine..."50 As a young man, he was an adherent of the Expressionist painters, particularly Kandinsky. Schwitters read "Concerning the Spiritual in Art" and attended lectures by the poet Theodor Däubler, who, like Kandinsky, spoke on the spiritual value of abstraction in modern painting. ${ }^{51}$ Before and during the war, Schwitters explored expressionist-style abstraction and the accompanying spirituality espoused by many of its adherents. ${ }^{52}$ These early expressionist works were marked by mystical overtones that demonstrated the influence of Caspar David Friedrich, as well as of Kandinsky and Marc. ${ }^{53}$ Works such as Mountain Graveyard (fig.4) (which shares content and stylistic similarities with Franz Marc's preapocalyptic landscape The Unfortunate Land of Tyrol (fig.5)) show the jagged

\footnotetext{
${ }^{49}$ Webster, 11

${ }^{50}$ Schwitters as cited in Schmalenbach, 103

${ }^{51}$ Webster, 28

${ }^{52}$ Curt Germundson, "Montage and Totality: Kurt Schwitters' Relationship to "Tradition" and "avantgarde"" 156-183 Dada Culture: Critical Texts on the Avant-Garde, ed. Dafydd Jones (Amsterdam: Rodopi, 2006) 160

${ }^{53}$ Germundson, 161
} 
expressionist landscape with three crosses, while other images are filled with references to a church. His images tend to focus on the object of the cross or church spire, indicating an interest in expressing spirituality through the cross, but also through exploring the intersections of form, colour and spirit outlined by Kandinsky, who crossed Christian and Theosophical iconographies.

When Schwitters began his Merz project, it is of great significance that he called Merz a form of prayer. ${ }^{54} \mathrm{~A}$ prayer is, perhaps, the most basic and common form of religious ritual, significant for being a personal method for accessing the divine, as well as a re-enactment of the contact made between Biblical figures and their divine power. For Schwitters to classify Merz art as prayers is to code them as spiritual manifestations of a personal nature, inasmuch as they provide Schwitters with a personal link to a spiritual realm, and, like other forms of ritual, access to a kind of magical power.

For Schwitters, Merz was prayer, but a prayer for a new world. The apocalyptic event had passed and the world had been transformed. From Schwitters' statements, we see that he had not viewed the war as a glorious national effort for victory and honour, nor did he view Germany's loss as a point of national disgrace and collective sorrow. Schwitters is declaring the peace that followed the war to be a time of peace without nations rather than between nations - a period defined by the universal peace, and hence a millennial epoch.

Schwitters also evokes the millennium through a sense of renewal encoded into his use of discarded materials. His statement that "Everything was destroyed anyway and new things had to be made from the fragments" clearly expresses his post-apocalyptic

\footnotetext{
${ }^{54}$ Kurt Schwitters, "Merz" The Dada Painters and Poets, ed. Robert Motherwell, (Cambridge MS: The Belknap Press of Harvard University, 1979) 55-67
} 
sentiments. The world has been reduced to rubble and a new culture must be made from it. His art of fragments is an approach to making art that is fully appropriate to this vision of cultural renewal. Merz art is, in effect, both a symbol and a direct expression of this kind of millennial viewpoint. Schwitters asserted that the fragments of the previous era needed to be reformed into new things. For this Merz art is necessary and it is, in a sense, the image of the millennium - ordered, harmonious and beautiful; discarded fragments aesthetically unified.

Were one to attempt categorizing, Kurt Schwitters' Merz would be somewhere between Dada and Expressionism. Rudi Fuchs wrote of Schwitters that he "worked on the margins of all movements."55 Merz was vaguely spiritual, vaguely anti-art, and it blended stylistic and conceptual elements from the two prominent German avant-garde movements. Schwitters' work combines the apocalyptic mysticism of Expressionist painters like Marc and Kandinsky with the sense of anarchy and play of the Dadaists. Furthermore, as an artist whose work prior to the war showed a strong Expressionist sensibility with overt Christian iconography, he treats post-1918 millenarian themes despite the fact that it was obvious that the Biblical millennium had not arrived, and even despite evidence that the Weimar Republic was not an unqualified utopia. O'Leary notes how apocalyptic rhetoric, regardless of its context, consistently displays a few key features. Apocalypticism typically emerges at a time when a society is faced with evil in some form that is so great that its defeat is inconceivable by normal means. ${ }^{56}$ The rhetorician typically forms a scenario where some greater power will intervene to protect an elect. This rhetoric serves as a kind of protection to its people and, as Adela Yarbro

\footnotetext{
${ }^{55}$ Rudi Fuchs, Conflicts with Modernism or the Absence of Kurt Schwitters. (Berlin: Verlag Gachnang \& Springer, 1991) 15

${ }^{56}$ O'Leary, 25
} 
Collins describes it, brings about a cathartic release from the torments of the culture that brings them strife. ${ }^{57}$ O'Leary states that with every iteration of apocalyptic rhetoric there is a period of thankful fervour for the coming of divine providence, ending with disappointment when the desires of the faithful are not sated, and the divine does not adhere to the schedule. ${ }^{58}$ For the vast majority of artists, World War One had, as it progressed to its conclusion, lost its mystic allure. There was no question that it was transformative - but not in the sense that was desired by artists before it occurred, as leading to a period of cultural purity. Schwitters was one of the few artists who responded to the conflict's conclusion with a positive attitude.

Schwitters' reasons for turning to assemblage and detritus are undocumented, although there is much to indicate that they are integral to his views regarding the end of the First World War. Gwendolyn Webster infers a number of different reasons for Schwitters' turn to rubbish as art material. Schwitters had come under the wing of Herwarth Walden in 1916, the wealthy leader of the Expressionist Der Sturm movement. Walden's Sturm organization was a major force of German Expressionism, involving events around Europe, gallery exhibitions (including showings of works by major figures like Kandinsky), and a journal. Schwitters had been, prior to his meeting with Walden, a lackluster artist who had produced academic landscapes and experimental works in a quasi-expressionist style emulative of Kandinsky and Marc. ${ }^{59}$ Webster describes Schwitters as a man under a great pressure to develop his own ideas at this point in his career; or, at the very least, to justify his placement among the artists who had found favour with Walden. Schwitters had, through mutual connections to Der Sturm, also

\footnotetext{
${ }^{57}$ Collins, 153

${ }^{58} \mathrm{O}$ 'Leary, 72

${ }^{59}$ Webster, 29
} 
come under the influence of the Zurich Dadaists, whose exploration of nonsense and abstraction Schwitters found to be of extreme interest. ${ }^{60}$ He was particularly taken with Hans Arp's use of non-traditional materials, such as coloured paper, to produce abstract images. Furthermore, due to wartime scarcity of resources and an atrophied post-war economy, the procurement of oil paints and other traditional art materials was a luxury, while rubbish was easily picked up from the streets.

However the most important reason for Schwitters' transition to the use of detritus as an art material, and to collage as a technique for image-making, was a quasi-mystical concept of renewal. Schwitters stated in 1919: "Suddenly the Glorious revolution was there. I think little of such revolutions...but with it came the end of the whole swindle that people call war... I felt myself free and had to shout out my joy into the world. For the sake of thrift I took what I found, for we were a poor country. One can also shout out through refuse and that's what I did... everything was destroyed anyway and new things had to be made from fragments..."61 These statements, first made by Schwitters in his Merz journal in 1920, demonstrate both Schwitters' reasons for turning to assemblage and clear evidence of a post-millennial worldview.

Merz was Schwitters' personal idiom. Initially the term was a label he applied to his unique collages; later Schwitters extended the term to everything he did.

Fundamentally, Merz was works of collage and assemblage, made from found objects Schwitters collected on his frequent lengthy, meandering walks through Hanover. Merz was also, however, a blending of all of Schwitters' artistic influences: primarily Dada and

\footnotetext{
${ }^{60}$ Several of the Dadaists had published poetry in Walden's Sturm journal and shown in his gallery before Schwitters became involved with it.

${ }^{61}$ Kurt Schwitters, "Merz" 55-67 The Dada Painters and Poets, ed. Robert Motherwell, (Cambridge MS:

The Belknap Press of Harvard University, 1979) 56
} 
Expressionism, but other movements such as Futurism, Cubism and Orphism show their effect as well. Schwitters' works were composed of fragments, both conceptual and material - and this figures heavily into Schwitters' concept of a millennial afterworld. Even the term, "Merz", is a fragment. First seen included in Merzbild 01, (fig 6) of 1919, the word was taken from a scrap of newspaper bearing the text kommerz, the German word for commerce. The word merz thus enters the world not through chance or through its affinities with the language of children (as with $d a d a$ ), but through a play of making language into fragments (à la Cubism) and assigning them new meanings. Merz began as a proper noun applied to Schwitters' work, and progressed into being used as a verb as well, when the artist began to refer to his techniques of making art as 'merzing' materials. ${ }^{62}$ Eventually 'Merz' simply became a name Schwitters used for himself: he was Merz and all Merz artwork is him. The term has two appropriate associations for its usage. The first is its origin as a word fragment, perfectly suitable for Schwitters' artistic vision; and the second is its affinities to the French word 'Merde' (shit) which is appropriate because of Schwitters' use of trash (another form of human waste) in his artwork. Merz simultaneously implies an interest in play with images, words and language, as well as with rituals of purification and renewal, as I will argue in chapter three.

Schwitters' vision of Weimar Germany as a post-apocalyptic milieu is a traumatic response to the conflict. James Berger, author of After the End: Representations of PostApocalypse, discusses a pattern of significance to Schwitters' Merz. Berger, drawing from Slazov Zizek, says that the transformative event occurs, renewing the symbolic

\footnotetext{
${ }^{62}$ Hereafter, I will not italicize $\underline{\underline{\text { merz }}}$
} 
order, but traces of the previous order persist, ultimately to disrupt the new order. ${ }^{63}$ Schwitters' work is a response to trauma: the apocalyptic event. Merz functions ritualistically to preserve the post-apocalyptic milieu until the forces of the outer world break through his defenses and Schwitters is forced to react drastically - often to flee from a new trauma. This event causes a renewal in Merz, which re-assumes its role as a form of post-apocalyptic art, personally protective of Schwitters. It is significant that Kurt merged his personality with his art, sometimes signing letters as "Merz" or using the name "Kurt 'Merz' Schwitters" in Merz materials, and dissolving his image into his assemblage works. Psychologist Herbert F. Waldhorn stated that the traumatized subject may blur the inner and outer self. ${ }^{64}$ Merz was a cultural armour for Schwitters that was steeped in a symbolic rhetoric of Millenarian mysticism, humour, play, and the ritual use of abject materials. Schwitters himself was plagued by three distinctly apocalyptic moments in his life: the First World War, flight to Norway in 1936, and an escape from Norway to England in 1943. Each time, Schwitters renewed his art and, in some sense, himself, following the traumas, until external pressures broke through and forced him anew to take evasive or defensive action that went beyond art's metaphorical protection.

The changes in Schwitters when he first began Merz were profound. For example, his friends spoke of Schwitters as having two personalities. The first personality led a respectable bourgeois lifestyle - he lived with his family, parents included, in a large home, married a second cousin, Helma, and often took jobs within walking distance from his own house, suggesting that he was something of a homebody.

\footnotetext{
${ }^{63}$ James Berger, After the End: Representations of Post-Apocalypse, (Minneapolis, MI: University of Minnesota Press, 1999), 30

${ }^{64}$ Herbert F Waldhorn M.D. and Bernard D. Fine M.D. eds. Trauma, Symbolism, (New York: International Universities Press, Inc. 1974) 65
} 
He developed a loud, boisterous, larger-than-life persona, however, for when he dealt with other artists or was performing. Furthermore, with Merz, he began to travel widely throughout Europe to meet other artists, introducing himself as the purveyor of Merz. His change in personality is noted by his wife, and it is something she acknowledges to have begun only after the end of the war when her husband had changed, artistically, from a mediocre expressionist (and a soft-spoken personality) to a member of the avantgarde. ${ }^{65}$ This change was one that both matched his view of the society as one of renewal, and also served as a camouflage for Schwitters himself - thus informing an overall function of Merz art as an art form that is primarily protective of the artist.

Schwitters' Merz deploys a slew of aspects that pertain to ritual and the occult in its efforts to become protective. Many cultures use play and games of reversal in their rites of renewal, as a way of safely crossing cultural barriers that are often considered dangerous. Schwitters' game of reversal in Merz is his use of trash in art. This process of turning trash into art also has a strong precedent in traditions of alchemy - particularly in the ideas of the great German alchemist, Paracelsus, who believed strongly in the alchemical step of putrefaction: that something must be degraded to its lowest possible form before healing can begin. Thus excrement can be considered an important element in the process of renewal. Such rituals exist in many cultures, not only western alchemy, and their purpose is to make the marginal and the abject acceptable and safe for contact with the people of the culture. Merz is a form of such ritual suitable for post World-WarOne modernity. Furthermore, his use of materials taken from everyday life, regardless of their content, or meanings divined from their arrangement, has its own affinities with

\footnotetext{
${ }^{65}$ Webster, 59
} 
occult traditions of protection. One of the earliest forms of magic utilized objects or materials either ejected or used by the individual. ${ }^{66}$

Even recent German rituals of protection paralleled Schwitters' work. During the First World War, German municipalities sponsored large communal rituals wherein a picture or statue was presented to the public. Members of the crowd would then buy nails from a solicitor and, one by one, they would step up to the sculpture or image and hammer a nail into the piece which was called nagelfiguren. The purpose of this ritual was to bring resolve and faith in the German war effort through a communal armoring of objects with the heads of nails. The images used in these rituals were always war-related (sculptures of the Kaiser or Hindenberg, images of German war machinery) and were a ritual and magical attempt at increasing a level of protection for the German military. ${ }^{67}$ The anecdote reported by Richard Huelsenbeck in which Schwitters introduced himself to Club Dada by saying, "I'm Kurt Schwitters and I nail my pictures together," may thus have a second meaning - one that emulates the German social ritual use of nailing as a form of protection.

The final strategy deployed by Schwitters in utilizing his art as a protective shield is one of humour and play. Humour has long been theorized as being a way of negotiating tense situations and periods of crisis. It has the capacity to alleviate stress and provide a calming effect upon the body of someone who is experiencing crisis. ${ }^{68}$ According to Freud, it is a tool in safely testing social boundaries, with laughter serving

\footnotetext{
${ }^{66}$ Kurt Seligmann, The History of Magic, (New York: Pantheon Books, Inc. 1948) 42

${ }^{67}$ Susanne Brandt, "Nagelfiguren: Nailing Patriotism in Germany 1914-18" Matters of Conflict, ed. Nicholas J. Saunders, (London: Routledge, 2004) 62-89

${ }^{68}$ Herbert M. Lefcourt, Humour: The Psychology of Living Buoyantly, (New York: Plenum Publishers, 2001) 144
} 
as the mechanism by which nervous energy is discharged. ${ }^{69}$ Similarly, play has had the effect of being used to negotiate obstacles through inventive use of symbols, and has already been mentioned as having a traditional role in rites of renewal and crossing boundaries, as seen in various cultures rites of passage, initiation of shamanic figures, and yearly renewal rituals. ${ }^{70}$ It is, in fact, Schwitters' playing with varying cultural roles (whereby he situates himself as someone who exists between categories), which bears a number of affinities with such cultural traditions. It is also such uses of play and humour that further strengthen Merz art as a protective artistic idiom.

In the 1923 Proletarian Art Manifesto, Schwitters wrote, "Art ... aims to liberate from the chaos (tragedy) of life". ${ }^{71}$ This statement suggests that Schwitters saw art as a medium through which he could transcend everyday life. The vast enterprise that was Merz, which eventually involved a transformation of his own domestic space into the Merzbau, as well as a large number of other artistic ventures (even a satiric political party, the Anna Blume Party of Germany), indicated that Schwitters wanted to create a wide avenue of escape or refuge from the everyday realities of Weimar Germany. The large number of Merz projects Schwitters created may seem to suggest that Schwitters had in mind a Merz reconstruction of the entire world. He even merzed, at least the name of, the city of Hanover - changing it to Revon, the name's last two syllables reversed. This is Schwitters' millennial gesture: to make a milieu constructed from the preapocalyptic world, an expanding cultural shell with Kurt Schwitters himself as its nucleus and chief architect. Safely ensconced in the center of a world of his own construction, he

\footnotetext{
${ }^{69}$ Sigmund Freud's theory of laughter and humour is expounded at length in his work, Jokes and Their Relation to the Unconscious, trans. James Strachey, (New York: W.W. Norton \& Company, Inc. 1963).

${ }^{70}$ Mircea Eliade, Shamanism: Archaic Techniques of Ecstasy, (New York: Pantheon Books, 1964)

${ }^{71}$ Webster, 134
} 
could force more and more of the bothersome aspects of external world away from its core, even as detritus from the external world was used to fabricate that very core.

All of these strategies come together in Merz art to form a protective shield and open a space in which Schwitters can hide from a hostile cultural environment. Merz initially emerges in 1919, shortly after the end of WWI and Schwitters' emergence from safely evading combat on the front lines where he, for the first time in his life, had to face the greater world at large rather than depending on his father for employment or hiding in art school. Merz thus immediately took on all the characteristics that give it its protective qualities - a one-man culture created only by Schwitters himself, with no other contributors. The patterns of Merz were themselves traumatically renewed every time Schwitters faced some kind crisis that could not be avoided. Merz began when Schwitters' real world was threatened - and it was his way of mastering the threat. Twice more Schwitters faced major crises in his life that could not be avoided through his art, crises that pressed through the mesh that Merz was supposed to be. The effects of these crises was that Schwitters' most essential Merz works, his canvases, changed in style and character as he found new strategies for taking control of the new problems.

The event in Schwitters' life that led to the formation of Merz was, of course the First World War - but the other two events were far more personally threatening to Schwitters and his existence as an artist. These were his flight from Germany to Norway in 1933 at the time of the Nazi crackdown on modern art; and a subsequent flight from Norway to England in 1940, again from the Nazis when they occupied Schwitters' Scandinavian refuge. The intrusion of the Nazis into the political-cultural landscape of Weimar Germany, and their uncompromisingly aggressive opposition to modern forms of 
art proved too overwhelming for Merz. Still, Schwitters would take flight and begin Merz anew elsewhere.

The strongest evidence that Merz is a protective art idiom is Schwitters' use of symbolic imagery. His iconography subtly draws on a number of esoteric traditions that are rooted in protective magic, including alchemy, astrology, and eschatology.

Schwitters has, in his writings, denied meaning in his works - but in spite of this, his works have been successfully interpreted as bearing iconographic meaning by a number of scholars, such as John Elderfield, Elizabeth Burns Gamard and Annegreth Nill. Furthermore, Schwitters' titles typically imply that he is constructing a meaningful image from his materials, not just an abstract equilibrium of forms. ${ }^{72}$ Many of his works follow in the vein of Kandinskyesque fields of suggestive colourful forms, rather than the fully abstract works of artists like Mondrian or Van Doesburg. Also, as a follower of Kandinsky's "Concerning the Spiritual in Art”, it is likely that Schwitters considered abstraction in art a modern strategy for conveying matters of spirit by visual means. Annegreth Nill has interpreted a selection of Schwitters' Merz collages, examining Schwitters' use of found materials by searching for meaning in the juxtapositions of words and images that appear on the printed matter used by the artist. ${ }^{73}$

Iconographically, his works can be read as carrying meaning that relates to his contemporary cultural environment. In the subsequent chapter, I will analyze the iconography of three works done subsequent to the three traumas in Kurt Schwitters' life. I will argue that Das Kreisen (fig. 1), an early Merz work, uses abstract geometric forms to convey a sense of apocalyptic renewal to follow the conclusion of the war and the

\footnotetext{
${ }^{72}$ This concept relates to ideas expressed by Kandinsky in Concerning the Spiritual in Art

${ }^{73}$ Annegreth Nill, "Rethinking Kurt Schwitters: An Interpretation of Grïnfleck" Arts Magazine, vol 55, Issue 5 (January 1981) 112-25
} 
establishment of a new era of peace. Das Kreisen, although not the first Merz-picture, is an image of the new world of Merz that Schwitters envisioned, the building of a new world from the fragments of the old. I will subsequently argue that after Schwitters fled Germany for the Norwegian coast, he began producing art such as the Merzpicture with Rainbow (fig. 2), evoking the story of Noah and the Ark, and Noah's promise of protection from God. Finally, Schwitters again fled the Third Reich from Norway to England, where, after a period of inactivity, he began producing fully abstract works such as Carefree (fig. 3), evoking a new sense of freedom that repeats the attitudes he expressed following the First World War.

Schwitters' art, like many other forms of abstract and early modern art, was full of symbolic meaning and iconography. ${ }^{74}$ As an acolyte of the German Expressionist movement and, as Richard Huelsenbeck called him, the "Caspar David Friedrich of the Dada revolution", Schwitters' work employed a number of Christian and mystic symbols. ${ }^{75}$ Schwitters acquired the Friedrich label for being too mystical for the members of Club Dada, who showed an aversion to most things mystically inclined. ${ }^{76}$ The result is that his visual works are the strongest evidence of his mystical and postapocalyptic concerns. Many of his images deal with spiritual themes of renewal, alchemy, divine and earthly separation and return - and often he uses explicitly Christian iconography, thereby continuing the pattern he began before WWI when he produced drawings and paintings which often prominently featured the cross. Schwitters' work, despite the appearance of chaos and Dadaist anarchy due to the use of trash as material,

\footnotetext{
${ }^{74}$ Maurice Tuchman, "Hidden Meaning in Abstract Art" The Spiritual in Art: Abstract Painting 1890-1985 ed. Maurice Tuchman (Los Angeles: Los Angeles County Museum of Art, 1986) 17-63

${ }^{75}$ Huelsenbeck, 145

${ }^{76}$ Perhaps an influence of Max Nordau whose work Degeneration decried the rise of mysticism in late $19^{\text {th }}$ century culture.
} 
actually demonstrates a fairly complex spirituality that is primarily concerned with issues of renewal, providence, and marginality.

Schwitters' Merz work thus emerged from a seemingly simple need for a man to indulge his compulsions. The compulsions to produce art, to collect objects off the street, and to play with words are all given an outlet in his work. Schwitters' art does resolve these needs in the artist, but his art is also functional in a mode similar to religious art of the world, in that its production is a kind of rite of protection. Images with very similar functions were produced in Medieval Europe during the time of the Black Death. Prayer scrolls, meant to provide protection from the disease to the holder were sold and they featured imagery and text from multiple religious traditions (blending Christian and pagan - often ancient Greek - symbols), in an effort to maximize their protective powers. Schwitters' work functions similarly, taking a number of traditions (a mix of Expressionism and Dadaism, the art movements most concerned with apocalypse and cultural renewal), pieces of material culled from real life, language, and symbols of renewal and apocalypse. Merz is a kind of protective magic appropriate for Schwitters' time, with central Europe in ruins, flooded by trash and detritus, and constantly threatened from every direction. Merz responds by using everything at its disposal to neutralize these threats. Throughout his career (one that included the abstract art of Merz and objective art, clear art of the academy, and intentionally attention-seeking advertising), Kurt Schwitters used Merz to cope with the damaged external world. Schwitters lived in a tumultuous period of European history - he seemingly lived a life of joyful exuberance through art, but he also had to negotiate his way through a great number of threats. The First World War followed by vicious domestic reaction to the 
treaty of Versailles and the rise of the Weimar Republic, inflation of the German mark, the rise of paramilitary groups such as the Freikorps and the Nazi Sturmabteilung, the rise of the Third Reich, and on a personal level, the threat of persecution by the Gestapo and the internment in England as part of a diaspora of German modern artists - all this drove Schwitters to respond with Merz art. Merz allowed Schwitters to absorb many of the bad things in his external environment and to restructure them into something good. It thus became the vehicle for what seemed to be a playful view of a world that actually was incredibly unstable and often cruelly violent - occasionally even directly violent to Schwitters himself.

Schwitters was one of a handful of artists who approached the post-war Weimar period with an optimistic worldview. This positive response to the end of the war may have taken its cues from the belief that the Weimar Government represented cultural renewal - although it may have also followed from sentiments expressed by numerous artists, before and during the conflict, that the war was an apocalypse. Schwitters extended this sentiment to a logical conclusion that the war's end signaled a dawning post-apocalyptic millennium, wherein "new things had to be made from the fragments." Making things from fragments is the essence of Merz art and eschatology; however, Schwitters also used apocalyptic iconography, and that is the subject of my next chapter. 


\section{Chapter Two}

\section{"New Things Had to Be Made Out of Fragments"}

Schwitters' iconography is a matter of some contention, primarily because the artist himself resisted the notion that his work held decodable meaning, whereas a number of scholars have provided plausible interpretations of his works. Schwitters insisted that his work was an abstract art that provided the viewer with an aesthetic experience achieved through the balancing of disparate materials and influences, rather than an intellectual experience of decoding. In Schwitters' unofficial manifesto of 1920 he wrote: "Today the striving for expression in a work of art also seems to me injurious to art. Art is a primordial concept, exalted as the godhead, inexplicable as life, indefinable and without purpose." Merz's primary function as an art, in Schwitters' terms, was to display a synthesis of everything that was available to the artist - both intellectually and materially - into an aesthetically pleasing form with an ineffable spiritual resonance.

Schwitters' works were not, however, haphazard constructions, despite their appearance as a riotous glut of forms and materials. Schwitters said: "Merz stands for freedom from all fetters, for the sake of artistic creation. Freedom is not lack of restraint, but the product of strict artistic discipline."2 His works were not randomly assembled, as the following anecdote from Raoul Hausmann suggests:

Beneath an apple-green evening sky in front of a high black railway embankment... A man, surrounded by shoes and clothes, was kneeling on the ground in front of a bag full of papers, like the entrails of a slaughtered animal. He was fiddling with a pair of scissors and a tube of glue on a piece of cardboard... As I approached I said, 'Kurt, what are you doing there?' Schwitters turned

\footnotetext{
' Kurt Schwitters, "Merz" The Dada Painters and Poets, ed. Robert Motherwell, (Cambridge MS: The Bellknap Press of Harvard University, 1951), 59

${ }^{2}$ Schwitters, "Merz", 59
} 
his head to look up and answered, 'It occurred to me that I've just got to fit a piece of blue paper into the lower left corner of my collage $30 \mathrm{~B} 1$, I'll be finished right away. ${ }^{3}$

Schwitters may have wanted a piece of blue for formal purposes or iconological significance; regardless, Hausmann's recollection of Schwitters at work demonstrates that the artist's compositional methods may have been flexible but did follow from premeditation.

Schwitters' own assessment of his art may be contested for two reasons. The first is that the meticulous method by which he constructed his works necessitated thought. We can infer from how he used materials in works such as Das Sternenbild (fig. 7) that his sense of balancing materials involved a balance of paint against found objects, and paper scraps bearing texts against indeterminate and therefore abstract objects - and through such juxtapositions meanings inevitably arise (even if unintended). Much of Schwitters' work, like that of many assemblage artists before him, involved a textual element - and the interplay of differing visual forms, including printed words, gives rise to meanings formed at their juncture, not to mention meanings intrinsic to the texts used. Schwitters may have deviated from the objective form, but unlike contemporaries such as Arp and Kandinsky, he rarely engaged in pure abstraction, which is elusive when language and actual objects are in use. ${ }^{4}$

Schwitters did, on occasion, produce Merz images with intended meaning and with very clear objective forms. He, for example, had produced in 1919 an image titled Merzpicture IA, The Alienist (fig 8), an image of a woman's face in profile. This image

\footnotetext{
${ }^{3}$ Raoul Hausmann, as cited in Webster, 95. It should be noted that Hausmann's comparison of Schwitters' bag of papers to the entrails of a slaughtered animal alludes to an archaic form of divination, augury, in which the will of the gods is read in the entrails left by animals after a sacrificial slaughter.

${ }^{4}$ William C. Seitz's book Art of Assemblage discusses the role of language in collage. He argued that experiments of sound and language in collage take their inspiration from earlier trends in developments in visual poetry. Also, Max Kozloff's book Cubism/Futurism, discusses the role of language and sound in Futurist art.
} 
is, perhaps, exceptional in Schwitters' oeuvre for it is, in fact, his most clearly objective Merz work as it shows a female face, rendered in a Fauvist style by a few brush strokes of oil paint, and surrounded by a few of Schwitters' collected objects. Although such paintings are rare in Schwitters' oeuvre, it does demonstrate a willingness to render objective forms, albeit in a highly stylized fashion. Merz was not necessarily as abstract as Schwitters stated it was in his texts; Merz did, occasionally, make clear references Schwitters' environment or to culture.

Although images that are so clearly objective are otherwise rare in Schwitters' body of work, there have been numerous cases made by other scholars as to the presence of representative objectivity in his works. Curt Germundson, for example, has written an essay in which he attempts to affirm both Schwitters' interest in producing objective Merz images as well as images with spiritual significance through an examination of the Schwitters' piece simply titled Merzbild 01 (fig 6). ${ }^{5}$ Germundson connects this image to a lineage of works in Schwitters' oeuvre that extends back to before the war, when Schwitters painted primarily in an Expressionist mode of style. Schwitters' 1919 Merz image, depicting a triangle formed out of found objects, set against an expressionistic, abstract background, was interpreted by Germundson as a highly abstracted church spire formed from Schwitters' found detritus. ${ }^{6}$ Well before Schwitters began Merz, the cross and church were common features of his drawings and paintings. These images reveal a spiritual side to Schwitters, reminiscent of the German romantics. ${ }^{7}$ In fact, Germundson uses Merzbild 01 as an affirmation of Richard Huelsenbeck's assessment of Schwitters as

\footnotetext{
${ }^{5}$ Curt Germundson, "Montage and Totality: Kurt Schwitters Relationship to "Tradition" and "avantgarde"" 156-183 Dada Culture: Critical Texts on the Avant-Garde, ed. Dafydd Jones (Amsterdam: Rodopi, 2006) 165

${ }^{6}$ Germundson 166

${ }^{7}$ Schmalenbach, 114
} 
“the Caspar David Friedrich of the Dada revolution", thereby reiterating Ramdohr's critique of the $19^{\text {th }}$-century landscapist as applicable to Schwitters. Friedrich von Ramdohr attacked Friedrich's 1808 altarpiece, Cross in the Mountains (fig. 9), by arguing that Friedrich was trying to express religiosity through landscape alone. Ramdohr's critique was that Friedrich was developing new uses for landscape when it was previously simply either a setting for figures or a genre on its own, and now it was being used for, in essence, spiritual purposes. ${ }^{8}$ Friedrich's work did, of course, include the traditional symbol of the crucifix; however the scene was dominated by nature: a craggy hillside, pine trees, clouds and sunrays - and at the time landscape was an inferior form of painting to the history scenes that depicted Christian narratives. Friedrich's work, then brought religion into a pictorial vision of landscape, elevating its status just as it appeared to corrode the status of the altarpiece. Over a hundred years later, Schwitters was experiencing his own version of the Ramdohr affair as the Berlin Club Dada artists ostracized him for uniting mysticism with Dadaist aesthetics and concepts. ${ }^{9}$ Germundson argues that Schwitters used garbage in the same way Friedrich used landscape, as a "lesser" artistic form, to express new spiritual impulses. Iconological similarities between Friedrich's and Schwitters' works include the central triangle in Das Merzbild, which is similar to the mountain peak in Friedrich's altarpiece; and the ladder-like form to the left of the triangle may serve as an axis mundi, similar to a mountain peak or a church spire. Schwitters used trash to express himself spiritually in an unorthodox and iconoclastic manner - thereby overriding the codes of the image by raising the status of his lowly materials into the realm of the spiritual through the meaning of his content.

\footnotetext{
${ }^{8}$ Werner Hofman's Caspar David Friedrich (New York: Thames \& Hudson, 2000) (P. 110), contains a complete translation of Ramdohr's review of Friedrich's Cross in the Mountains.

${ }^{9}$ Huelsenbeck, 146
} 
Germundson's interpretation of Merzbild 01 (fig. 6) posits the presence of iconography and spirituality in his work. His interpretation also provides an introduction to reading Merz as an art-idiom that uses found materials as a place of solace and spiritual sanctuary, much as Friedrich, a century earlier, had created an image of the land, rather than the space of the church, as a realm where such solace may be found.

Germundson's analysis of a single Schwitters' assemblage is convincing, as he demonstrates a progression from the Friedrich-influenced, conventionally Expressionistic oil paintings Schwitters produced before the war and the Merz works for which he became best known. This progression was established by Germundson as occurring through a use of iconography. There are, however, other indications that Schwitters was embedding specific messages in his work through imagery. Perhaps the strongest, and most obvious indicator used by Schwitters was his use of descriptive titles, which often provided some kind of anchor for reading the image. This can occasionally be quite vague, as in Kreisen of 1919, (fig. 1) which has been translated as "Circles" but also as "Revolving" and has thus led John Elderfield to interpret the assemblage as a machine in operation. ${ }^{10}$ Another image, Das Arbeiterbild, or "the Workerpicture" (fig. 10) is titled after the appearance of the word "Arbeiter" (worker) in the upper-right section of the image. From the presence of this word, a chain of connections is made by Elderfield, who argues that the work is expressing sympathies with the labour movement and the German Communist Party. Schwitters, according to Elderfield, expressed these uncharacteristically political views through the presence of the word (arbeiter) coloured

\footnotetext{
${ }^{10}$ Elderfield, 53
} 
red - the colour of Communists, or "Reds". ${ }^{11}$ Finally, the forms appearing within this assemblage's frame have been interpreted as being a highly stylized representation of a worker (produced with industrial materials like plywood plank fragments) or of industrial tools or machinery - thus representing the objects of labour and forming an overall meaning of political awareness and support for the labour movement. The work is, of course, highly abstract and the meanings are initiated by the appearance of the word, and its title, Arbeiter. $^{12}$

Another image that gives rise to interpretations is Das Sternenbild, or "The Stars Picture", (fig 7) an image that will be discussed in depth later in this chapter. Unlike The Workerpicture and a number of other collages, this image is not titled after a word that appears somewhere within the frame. Instead, it's a title that codes the two discs, one central, as stars. Such a title is different from Das Kreisen, another title taken from the objects, as "das kreisen" is more plainly descriptive of the forms Schwitters created - Das

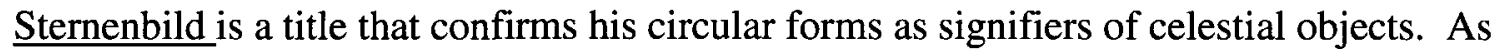
a frame of reference, the title also provides a key for how to read the image as a kind of space, or a natural setting - with the stars being set in a sky, and the lower segment of the work, particularly the base rectangle, representing the earth - while Schwitters fills the image with words pertaining to current events and objects that play with relationships of the celestial sphere to the earthbound. The central form of the image seems to be a star

\footnotetext{
${ }^{11}$ Schwitters had otherwise been very reluctant to use art to make political statements - and such resistance was a major reason for his exclusion from Club Dada. It should be noted, however, that as the rise of the Nazi party became more dire, in the late 20s, Schwitters had, in fact, joined the Social Democrat party, although otherwise Schwitters' chief political statement was to make a one-man parody political party called the German Party of Anna Blume.

${ }^{12}$ This image, like all Merz collages, is obscure in its meaning and may simply be a response by Schwitters to his external environment. Schwitters may be displaying an awareness of the labour movement, perhaps even sympathies with it but there is nothing to indicate that this work is displaying a political stance. It can thus be compared to Grosz's explicitly critique-laden drawing, Early at $5 O^{\prime}$ Clock (fig 11) in which the downtrodden workers are contrasted with the disturbingly hedonistic upper-class men in the lower register.
} 
connected to the ground by a string, perhaps suggesting a desire to transcend earth and access the celestial realm. Another such image for which Schwitters uses a variant mode of titling is his Picture with Light Centre (fig. 12) - a mostly tan or buff coloured, abstract collage with a centre of white. The title, though, transcends simple colour designations by suggesting that the centre is actually an emanation of light from some core, rather than simply a buff and white abstract painting. It is such titles that justify finding meanings, and specifically spiritual meanings, in Schwitters' work. His emphasis on the formal abstraction in his work was largely to affront the political demands of his Dada comrades, who - particularly Huelsenbeck and Grosz - were interested in direct political action and using art as a conduit for political agitation, and thus were hostile to Schwitters' apathetic attitude towards Germany's political atmosphere. ${ }^{13}$ Schwitters' consistent assertion that his works resisted meaning and interpretations was likely a reaction to those artists nearest to him, who were most vocal in challenging the merit of his work while simultaneously sharing affinities with Merz. ${ }^{14}$

In Schwitters' 1920 Merz manifesto, he wrote: "I play off sense against nonsense. I prefer nonsense but that is purely a personal matter. I feel sorry for nonsense, because up to now it has so seldom been artistically molded." ${ }^{\text {,15 }}$ Schwitters claimed to "play off sense against nonsense" rather than other, similar binaries, such as rational/irrational or logical/illogical. His statement may be interpreted as using a mixture of objective and non-objective (sensed and non-sensed), in that some parts of images 'appear' fully

\footnotetext{
${ }^{13}$ One famous anecdote regarding Schwitters and Grosz, was that Schwitters went to Grosz' home to speak with the famed caricaturist, and when Grosz answered he responded to Schwitters' introduction by stating that he is not the artist Schwitters sought, Schwitters then responded by saying "nor am I Kurt Schwitters". ${ }^{14}$ The book Escape Attempts: The Theory and Practice of Resistance in Everyday Life, by Stanley Cohen and Laurie Taylor discusses the common strategy of modern artists in declaring that their art has no meaning. Therefore attempts made by the viewer to appreciate the work through a culturally prescribed method of interpretation are evaded.

${ }^{15}$ Schwitters "Merz" 60
} 
formed (like the cherry in the Cherry Picture (fig. 13)) while other forms are abstract and therefore seemingly nonsensical. This reading of the quote can thus be extended to meanings - but it may also suggest that Schwitters employed a playful use of materials and language to obscure serious meanings. Both the nonsensical and the non-sensed can be "artistically molded" to express the sense - i.e., the underlying spiritual messages. His strategies are often similar to the methods used by occultists and alchemists, as well as those of the dissembling tricksters of myth. Such strategies will be explained more fully in the third chapter.

In addition to iconographic readings of Merz works by John Elderfield and Curt Germundson, Annagreth Nill has done extensive work on uncovering the purpose of the texts and various paper scraps in Schwitters' work. Recalling Hausmann's anecdote about Schwitters searching for the perfect blue scrap with which to complete an image suggests that Schwitters was concerned with compositional structure. And while the method described by Hausmann does not necessarily imply an acute attention to constructing a meaning in his work, it does suggest that Schwitters was heavily concerned with forming a particular vision of an image, and rather than throwing his Merz-pictures together, took the time to assemble them from whatever scraps were appropriate to forming his ideal reconstruction of the world. Hausmann, and subsequently scholars like Nill and Elderfield, portray Schwitters as a kind of diviner who calls meaning out of an assortment of trash - and overwrites his meanings with play and ironic juxtapositions of forms.

Nill interpreted Merz constructions that may have been construed as completely abstract, in that they were entirely assembled from colourful paper scraps - rather than a 
mix of scraps and objects as in the more objective of the Merz assemblages. Nill reads Schwitters' fully abstract works as a kind of colourful poem in which the artist formed his meaning through juxtapositions of different words, colours, symbols imprinted upon the scraps, and through reference to external cultural elements, whether they be manufacturing concerns, political organizations, the cultural climate, etc. ${ }^{16}$ It is in this way that Schwitters blurs the line between visual and written works, creating a synaesthetic effect in both his art and his poetry. ${ }^{17}$

Nill examined Schwitters' work Grünflek, (fig 14) an image that is composed of paper scraps and is not supplied with a meaning through vaguely objective forms. Ambiguity is prevalent in the image - although 'Grün' of the title means 'green' ('flek' means 'spot') and refers to the central circular-form encircled by a green line, it also means the spade suit of a deck of cards, potentially referring to play or chance. ${ }^{18}$ Nill made sense out of this riot of torn papers by interpreting the meanings of the words and how they're positioned on the canvas. Nill argued that this work contains a number of meanings, but that primarily it expresses anxieties, possibly over the unstable economic environment during the period of inflation in the Weimar era as, according to Gwendolyn Webster, Schwitters was never financially stable and often struggled to make enough money to keep his family afloat. ${ }^{19}$ Schwitters' anxieties are emphasized with the presence in the image of the words "geld bezhalt", German for "money paid". ${ }^{20}$ Nill

\footnotetext{
${ }^{16}$ Seitz' book The Art of Assemblage asserts the origins of assemblage art in avant-garde poetry. This is, in essence, how Nill reads Schwitters' works.

${ }^{17}$ Schwitters also produced Merz poetry ("An Anna Blume" being his most famous poem) which was composed of text he found on scraps as well as from fragments of overheard conversations.

${ }^{18}$ Annegreth Nill, "Rethinking Kurt Schwitters: An Interpretation of Grünfleck" 112-25 Arts Magazine, vol 55, Issue 5 (January 1981), 118

${ }^{19}$ Webster, 111

${ }^{20}$ Schwitters produced numerous other images using money. In one work, Das Grosse Ichbild,(fig 15) Nill suggests that Schwitters used money, again, to express anxieties over inflation, and arranged the money
} 
interpreted the green area in the lower left of the image as a garden, a pictorial sign that suggests a kind of refuge from these problems. Schwitters may have been using money in this work to mock Germany's economic crisis and simply as a source of colour. Nill hypothesizes that Schwitters was producing a highly abstracted garden out of his materials - and that the garden may be a metaphor for collage. The word anlage, which means "construction," appears in the image, which Nill interprets, in conjunction with the work's title, to mean that Schwitters was planning a green spot - or a garden - and that the garden, in its varieties of plant life, is analogous to the collage with its varieties of materials. Nill fortifies her interpretation by stating that anlage may refer to construction but also in the way the paper scraps are placed on top of one another, to the placement of cards in a popular German card game called "Skat". According to Nill, 'skat' is an Italian term used by cardplayers to refer to a place of safe-keeping - although Nill hypothesizes that Schwitters was using the term, in this collage, to refer to discarded things, and thus his own use of saved rubbish in art. ${ }^{21}$ Nill is portraying Schwitters' Grünflek as being a collage-text that may be read in terms of what each fragment brings to the whole.

Nill's interpretation of Grünflek comes close to implying an interpretation of the work as containing a meaning of protection. One may build upon her interpretation by considering it as a talismanic work of refuge and sanctuary. Schwitters is planning a "green spot," or a garden in his work, one which is symbolically a refuge from the surrounding chaos of Weimar life (represented by such presences as the money). Although Nill refrains from interpreting it as such, 'skat' may, in fact, refer to a place of gambling was occurring.

${ }^{21}$ Nill, 120 
safe-keeping, and by extension refer to the garden Schwitters is forming in this work.

Nill never mentions in her article the garden Schwitters tended to as a young boy.

Schwitters wrote of his youth, "my basic trait was melancholy.",22 Webster wrote:

The cause of this misery dates from 1901, when he was on the verge of puberty. He had been given a piece of garden at his parents' cottage in the idyllic village of Isernhagen and he devoted much time to it, creating a miniature landscape for himself: 'with roses and strawberries, I made a hill and dug out a pond.' Then, when he was fourteen, local boys destroyed the garden before his eyes. $^{23}$

The attack on his sanctuary had a profound effect on Schwitters - he reacted by going into his first recorded epileptic seizure. Epilepsy subsequently plagued him with debilitating seizures for the rest of his life. This image, therefore, may be a confrontation with the trauma of what may have been the initial "apocalyptic" moment in his life. The garden had been very important to him, and even Schwitters' 1920 Merz manifesto begins with a brief reference to his childhood garden. ${ }^{24}$ Schwitters reclaims the garden as his sanctuary by making the garden and collage-art synonymous - thus establishing Merz as the Grünflek, a symbolic garden, one produced through the means of collage, and therefore a Merzgarden. As a garden produced through the strategies of artmaking unique to Schwitters, it is therefore a garden completely under the control of the artist, and therefore not only does it provide sanctuary, in an intellectual sense, but it is also invulnerable to outside attacks, unlike the destroyed childhood one.

Grünflek demonstrates something that is made consistently manifest in Schwitters' iconography - the response to the traumatic or apocalyptic moment. In this work, Schwitters responds to an attack on his childhood sanctuary by drawing it into the realm of Merz, thus sanctifying the garden against attack and in turn, making the garden

\footnotetext{
${ }^{22}$ Schwitters, as cited in Webster, 7

${ }^{23}$ Webster, 7

${ }^{24}$ Schwitters, Merz, 59
} 
again into a place of 'safe-keeping'. The apocalyptic moment is of extreme importance to Schwitters' art, as three major events characterize shifts in Schwitters' adult life: the First World War, the flight from Hitler's Gestapo into Norway, and his internment in a British refugee camp. These are, of course, not religious apocalypses, predicted by scripture - but they may be read as apocalypses in a more general sense. This approach requires thinking of 'apocalypse' as a kind of archetypal event, rather than the divine events of mass destruction and renewal described at length in Revelation and other religious texts (including the Book of Daniel, the apocryphal fourth book of Ezras, the story of the flood in Genesis; and, beyond Christianity, the story of Ragnarok from the Norse Eddas, and the Mayan Popol Vuh). ${ }^{25}$ Revelation may rather be seen as one manifestation of the archetype of apocalypse, and as a narrative that provides observers with a model for responding to actual events of great cultural change.

Das Kreisen (fig. 1) is symbolic of a cosmic renewal; it is a representation of the moment of return into a world which is constituted under the sign of Merz. What is pictured is a series of circles bisected by two straight pieces of wood radiating outwards from a single point at the top of the canvas. ${ }^{26}$ The image, at a cursory glance, appears similar to renaissance astrological/astronomical charts of the solar system (fig. 16), which may in fact be Schwitters' intention. Of course, as Schwitters produces all of this under the Merz banner, the ultimate message is that of a new reality coming into being that adheres to Merz precepts. Schwitters refrained from using text in this image, but the

\footnotetext{
${ }^{25}$ Eugen Weber Apocalypses: Prophecies, Cults and Millennial Beliefs Through the Ages (Toronto: Random House of Canada, 1999) 31 - Weber broadly defines apocalypses as about destructive ends, and millennialism as about new beginnings.

${ }^{26}$ With Schwitters' assemblage pieces that mixed nailed-on objects with paint and collaged papers, Schwitters would construct a wooden support structure on the reverse side of the canvas to enable such a mix of materials.
} 
work's title can provide a clue in decrypting the message Schwitters encoded into this work: while some literary sources (e.g. Gamard) translate the work's title as "circle" or "circles", others (e.g. Sudhalter, Elderfield) give the title as "revolving". ${ }^{27}$ Circles may, in themselves, imply a revolution: "circles" would be a title referring to the shapes depicted, but "revolving" refers to a circular motion in which an object returns to its point of beginning. If this is an image of revolution, then it may, in fact, be evocative of both circular motion in the cosmos and of a new world coming into being. Revolving can suggest the circular movement of celestial bodies in orbit, as well as the cosmological regeneration of all existence. It can be both spatial and temporal. The 'myth of the eternal return' typically refers to some sort of revolution in time - a cyclical cosmic pattern consisting of a utopian period followed by a fall from it; then, following the lowest point, there is the return to the state of origin, with rebirth as utopia. ${ }^{28}$

With Schwitters' Das Kreisen, he is depicting celestial forms floating in the ether, moving through space, while using the angled strands to represent the creative force that produces the new world. Such imagery finds its strongest precedent in the work The Ancient of Days by William Blake (fig. 17) - in which the God the Father figure is depicted creating the new world, an act signified the symbol of the golden compass. For Blake, this is the image of divine creation (albeit, in Blake's cosmology, the God figure is producing a dark world suitable for evil to thrive in.) The image is derived from the Book of Daniel but served as the frontispiece to William Blake's illuminated poem, Urizen, a poem that is essentially a reversal of the opening parts of the Book of Genesis

\footnotetext{
${ }^{27}$ Elizabeth Burns Gamard translates the title to The Circle, while Adrian Sudhalter translates it to Revolving. Elderfield also says that Cosmic Circles was an alternative title for the work.

${ }^{28}$ Mircea Eliade, Myth of the Eternal Return, trans. William R. Trask, (Princeton: Princeton University Press, 1954) 54
} 
from the Bible. ${ }^{29}$ While Blake's God-as-Urizen produces the world with the Golden Compass in the light-enshrouded figure's hand, Schwitters' own compass emanates from the top of his image's frame - a zone often associated with "above" and hence the celestial or the divine. The downward thrust of creative power depicted in this work can be seen as a counterpart to the upward motion of the lasso-like string in Das Sternenbild (fig. 7) that forms an axis mundi with the celestial realm.

The use of the compass as a symbol of divine creation is seen elsewhere, particularly in the seal of the Freemason brotherhood (fig. 18), wherein the compass and the square form, according to Freemason historian John J. Robinson, an iteration of the Star of David - a symbol of great significance to many groups that deal with gnosis and mysticism both ancient and modern. ${ }^{30}$ The Star of David (aka The Seal of Solomon) was an upward-pointing triangle and a downward-pointing triangle merged into a single diagram to denote the bi-directional flow of spirit. Spirit descends from the divine realm above, then spiritually uplifts those who receive it. In the Freemason adaptation of this form, the compass and the square, the tools of geometric drafting, become the symbols of involution and evolution of spirit and expand the definition to imply a divinity through geometry and design. The compass thereby becomes the tool of divine creation when it is in the capable hands of a celestial creator. The compass also emphasizes the intellectual capacity of the creator, as it is a tool of design - much like the artist's pencil or paintbrush - rather than a crude tool of constructive labour. The compass suggests a link between the hand and mind of its user. Unlike the paintbrush, however, the compass is used in designing that which will be made real - it is used at the intellectual level in a

\footnotetext{
${ }^{29}$ David Bindman, William Blake: His Art and Times (Toronto: The Art Gallery of Ontario, 1983) 106

${ }^{30}$ John J. Robinson, Born in Blood: The Lost Secrets of the Freemasons, (Toronto: M. Evans, 1989) 241
} 
mastery over nature - to improve the world, either materially or spiritually, as a space for human habitation. The compass as a symbol of spiritual significance also suggests the concept of divine geometry - that geometry and certain patterns and geometric forms have their own spiritual power. ${ }^{31}$

The Freemasons used the compass to express this idea that the world and the self can be re-made under the spiritual concepts of divine geometry. ${ }^{32}$ This concept of divine geometry has been followed by numerous others, including friends of Schwitters, particularly Schwitters' German contemporary and friend, the modernist architect Bruno Taut. Taut was an architect with a quasi-mystical view of architecture and the post-war milieu. He formed a group, which he headed, of mystically inclined avant-garde artists, writers and architects called The Crystal Chain. According to Elizabeth Burns Gammard, Schwitters was a member of Taut's group. ${ }^{33}$ The Crystal Chain was not an artistic movement in the same sense as the Expressionists or the Dadaists, who developed a particular worldview and united it with a certain set of aesthetic sensibilities. Rather, the Crystal Chain was a group of artists who shared a goal of realizing the spiritual in art. In a series of chain letters in which the authors used code names (often of materials, thus giving their group dynamic an alchemical inflection - Taut was Glas [glass], for example), they would write about a series of preoccupations. Of particular concern to the

\footnotetext{
${ }^{31}$ Schwitters repeats this geometric motif in other images, particularly in some of his rubber stamp drawings. A 1919 rubber-stamp drawing published in the Sturm Bilderbuch (fig 19) shows two compassarm-like lines radiating outward from a sun, a semi-circle, and an $\mathrm{R}$ (the sun in particular is reminiscient of Blake's image). On one line is an upside-down church connected with a house and a man standing upon the structure. Repeated in the drawing are the words "Berlin = friedenau" or 'Berlin equals peace'. Another 1919 untitled rubber-stamp drawing (fig 20) featuring the names "Der Sturm" and "Herwarth Walden" stamped repeatedly on it shows another compass form, this time with arms that taper at the ends and originate from a dot point suggesting a joint. Furthermore, this drawing contains a form in the upperleft that suggests a partially rendered protractor - indicating that Schwitters may have been interested in geometry, or at least its tools.

${ }^{32}$ The ' $G$ ' in the centre of the Masonic seal is said to stand for geometry according to John J. Robinson

${ }^{33}$ Gamard, 24
} 
group, and probably the most recurrent theme in the Crystal Chain letters, was the concept of utopia. Taut himself especially emphasized this theme repeatedly in the letters he wrote to his associates, stating in a 1919 correspondence:

The danger will be overcome when astronomy becomes astrology - which must come... Spiritualization! Where clarity still (or already) exists: world-building, word-construction, interpreting the earth, astrology, the horoscope. The highest happiness: transfiguration. ${ }^{34}$

Taut was writing about a "new architecture", but these statements could easily describe elements important to Merz as well. Particularly in Schwitters' statement that 'I found that one could shout joy through refuse, and it was time for us to begin to rebuild civilization upon the rubble of the old", these visions of renewal are manifest. Both Taut's and Schwitters' statements express similar goals. Their response to the end of the war was to strive for utopia - the appropriate aftermath to an apocalyptic event.

Furthermore, Taut's call for astronomy to become astrology will have some resonance on Das Kriesen (fig. 1) as will be shown in a subsequent paragraph. Already, I have noted that some of Schwitters' circles are linked to astronomy.

Although both visions were largely imaginative, Taut's was relegated to fantastic architectural drawings of the kind of buildings he imagined as being appropriately utopian. Schwitters' Merz project, conversely, was realized in his works - with Das Kreisen being one of its earliest expressions. Taut's actual buildings were innovative but socially utilitarian modernist structures. Schwitters' version of the millennial utopia was actualized through Merz, but was mostly personal - even anti-social - without a single other person being admitted to his one-man art movement. Still, the affinities Schwitters had with Taut were manifold - they both intended to remake the world through art -

\footnotetext{
${ }^{34}$ Bruno Taut, "Letter: 26 December 1919" 25 The Crystal Chain Letters: Architectural Fantasies by Bruno Taut and His Circle, ed. Ian Boyd Whyte, (Cambridge MA: The MIT Press, 1985) 25
} 
although for Taut this process was collaborative, while for Schwitters, it was a solitary endeavour and, in all likelihood, only meant to serve as a utopia for one. Yet Schwitters' affiliation with Taut's Crystal Chain group inspired him to give his work an architectural inflection (i.e., the Merzbau) as a means of transmitting the idea of a millennial renewal for the post-war era.

With the symbolic uses of the compass to denote a connection between intellectual creation and divine cosmic force, there is an implicit hand that uses the compass in its designs. In Blake's work, most of the image is devoted to the figure of God-the-creator. ${ }^{35}$ In Das Kreisen, the implied hand that manages the compass is that of Schwitters himself. The compass arms emanate from the absolute edge of the image, forming a link with the microcosmic world beyond to address playfully the fact that this new world is one of Merz, and therefore of Schwitters' own creation. This image, which I read as a visual manifesto of Merz cosmology, is the locus classicus of Schwitters' binding Merz to his own identity as well as to his worldview. This is a trajectory that begins with his self-reference as Kurt "Merz" Schwitters and culminates in the project of the Merzbau - the ultimate Merz construction wherein Schwitters converted his home into Merz. With Das Kreisen, Schwitters becomes the absent referent to whom the compass refers, a 'God-the-creator' figure. This is doubly so, as it was his hand that produced the image (creation), but also by his hand that the ravaged world is renewed in Merz (post-apocalyptic renewal) - hence the alpha and omega.

With this interpretation of the compass in mind, it is therefore significant that the rest of the forms are assembled in a way that bears affinities to an astrological chart. The

\footnotetext{
${ }^{35}$ Blake has another image which prominently features the compass, a drawing of Galileo in which he is, himself folded like a compass, and engaged in astronomy and mapping the heavens with the compass set in the centre of the image
} 
different circles are all arranged upon a single larger arc of wood, and are thus representations of the orbiting celestial bodies that make up the cosmos. Jacques M. Chevalier describes at length in his book, A Postmodern Revelation: Signs of Astrology and the Apocalypse, how apocalyptic rhetoric is rife with references to astrology, and is probably a derivation of astrological traditions. ${ }^{36}$ Although Chevalier's work is a thorough deconstruction of the Biblical Revelation with regards to astrological markers, his overall theme of the apocalypse as an event that is the ultimate culmination of astrology holds implications for Schwitters' Das Kriesen. It is through astrological signs that the apocalypse is known to the astute observer. In Germany, astrology had become quite popular after World War One. In 1917, the German astrologer Elspeth Ebertin published her first astrological almanach, which sparked a vogue for the divinatory form. ${ }^{37}$ Astrology was a system that imparted knowledge of earthly matters through a correct reading of the positioning of bodies in the cosmos. By representing an apocalyptic moment of re-creation through the Merz idiom, Schwitters is thus suggesting that the new world (both of Merz, and the Weimar Republic) may be understood through its debris. In such a representation, not only is Schwitters, through highly abstract imagery, outlining his vision for a Merz post-apocalyptic, but he also achieves one of the many reversals in meaning that find importance in Schwitters' system. At the same time that he makes the distant, cosmic realm into the lowliest form of (culturally) material substance, he elevates trash to the level of the cosmos, giving it the same meaning the cosmos has in the astrological system; but made manageable by Schwitters by keeping it all within a system of his own devising. Through evoking astrological charts, he also evokes cosmological

\footnotetext{
${ }^{36}$ Jacques M. Chevalier, A Postmodern Revelation: Signs of Astrology and the Apocalypse, (Toronto: University of Toronto Press, 1999) 97

${ }^{37}$ Derek Parker and Julia Parker, A History of Astrology, (London: Andre Deutsch Limited, 1983) 98
} 
knowledge through Merz art while further emphasizing the notion of apocalypse, with both evocations being important to understanding Schwitters' artwork as being personally protective to the artist.

This may be a Merz image of cosmogenesis. The compass arms cut through the series of circles, all arranged along the ring of another circle, thus creating the notion of celestial bodies in orbit. These circles form with the compass arms a closed system that represents the new millenarian world. The circle that falls outside of this system, drifting off into the blue/yellow background, is the old world falling away. According to numerous intellectuals, including Mircea Eliade and Carl Jung, the meaning of the circle in ritual and symbolic imagery is one of totality and completeness - with its centre representing a point of divine origins from which all emerges. ${ }^{38}$ In Schwitters' Das Kreisen, the circle seen in the upper right of the frame, which is excluded from the orbit of the other forms which are connected by the two rays emanating from the top, is shown to have two lines of some material within it. These two lines reach towards the centre of the circle but do not meet; rather, they appear broken, since one is bent slightly towards its end. One might even read this as a broken compass. This internal breakage indicates the damage done to the old world, and also indicates a necessity to form a new one, as the old one is broken at its heart. The centre is damaged and is no longer productive as a point of spiritual origins.

On the reverse side of the canvas Schwitters wrote, "Dr. Johannes Molzahn", another Sturm artist who produced paintings and woodcuts of cosmic forms. His image Star Movements (fig. 21) is similar in content to Schwitters' Das Kreisen, except that it

\footnotetext{
${ }^{38}$ Eliade discusses the symbolism of the centre repeatedly in his work, describing the centre as the site of spiritual emanations - and not necessarily a geometric centre in a circle. Jung, in Man and His Symbols, discusses the centre as carrying similar meaning but speaks of it in terms of imagery bearing the circle.
} 
lacks the compass-like lines from the top of the frame. Schwitters also wrote a poem for Molzahn in which he wrote: "Thou turnest worlds... Worlds turn the new machine to thee... Thou, thing the new machine space. And axles break eternity." ${ }^{39}$ Curator Adrian Sudhalter says that Schwitters' poem and assemblage pay tribute to a number of cosmic ideals Molzahn held, but that they also offered Merz as an actualization of these ideals. ${ }^{40}$ If the poem is meant as a companion to the collage then it may be referring to issues of astrology (in its repetition of the phrase "worlds turning" - the movement of the planets is the paramount concern of astrology) and cosmic renewal (in the phrases "new machine space" and "axles break eternity").

This image is a response to the first apocalyptic moment of Schwitters' artistic career, and a ritual re-enactment of the cultural renewal on three fronts: international (the end of the war), national (the establishment of the Weimar Republic), and personal (the development of Merz). According to Mircea Eliade, cultures often develop rituals of renewal that re-enact, and thus actualize for the group, events of divine renewal. Das Kreisen is a manifestation of such ritualistic impulses in art. It is a diagrammatic visualization of the creation of the post-millennial milieu that, for Schwitters, was the desired epilogue to the war. The work is pure form and colour, and aside from the fact that (paint excepted) the materials used were found on the street, it lacks any cultural references (unlike most of the Merz pictures that bear text). This thus emphasizes that it is a depiction of the most divinely primordial moment, that of creation. By rendering the moment of creation in such a way, Schwitters reasserts the spiritual and abstract while many of his avant-garde contemporaries, both in Dada and Expressionism, turned to the

\footnotetext{
${ }^{39}$ Adrian Sudhalter, "Kurt Schwitters: Revolving (Das Kreisen) Dada: In the Collection of the Museum of Modern Art (New York: The Museum of Modern Art, 2008) 277

${ }^{40}$ Sudhalter, in Dada 277
} 
earthly realms of radical politics and social critique for their subject matter. Das Kreisen displays the Weimar Republic's new beginning as a blank slate, not as a chaotic social maelstrom. Here it may be worth repeating the quotation from Schwitters' 'Proletarian Art Manifesto' (also contributed to by Arp, Van Doesburg, and Tzara) which said “Art is a spiritual function of mankind which aims to liberate from the chaos (tragedy) of life. Art is free to use any material it likes..."41 When this quotation (which sounds like it may pertain directly to Merz) is cross-referenced with the Schwitters idea of rebuilding through refuse and the interpretation of Das Kreisen as a work of cosmic renewal, the case for Merz as a millennial art is strengthened. Schwitters was making a statement about Merz and the end of the war. For Schwitters, Merz was an art in which he could 'escape the chaos' - and with this image, he makes the allusion that Merz is a realm into which escape possible.

The painterly background is of importance to reading this work as having spiritual significance. The blue-yellow ether provides a space from which all forms emerge - it is the cosmic background upon which the divine forces of creation produce their matter. The background is a purely abstract plane, the expressionist component of the work, upon which the artist placed the Dada forms found in his meandering walks. The concept of yellow and blue representing spirit is derived from the colour theories of Renaissance mystic Jakob Böhme and was common artistic property by the time of Schwitters. ${ }^{42}$ Schwitters was an adherent of Kandinsky's theories, especially with regard to colour, but

\footnotetext{
${ }^{41}$ Webster, 134

${ }^{42}$ Melanie Öhlenbach, “The Influence of Jacob Böhme's Theosophical Ideas on the 'Farbentheorie' by Phillip Otto Runge" 57-67 Masonic and Esoteric Heritage ed. Den Jaag: OVN, 2005. 61 - It should be noted that Theosophical ideas regarding the spiritual use of colour were popular in Europe during the early twentieth century. These ideas, espoused by writers such as Annie Bessant and C.W. Leadbeater were, themselves, influenced by Böhme's colour theories. It is probable that Böhme's ideas reached modern artists like Kandinsky through the modern Theosophical writers.
} 
Schwitters convoluted Kandinsky's ideas by fusing them to Dadaist ideas. This strategy constituted a reversal of sorts, as the three-dimensional forms affirm the background not only as a space in which the celestial forms represented by the wooden circles float - but also as a firm surface upon which a cluster of wooden circles and bits are attached. Schwitters thus makes a material out of the ethereal in this highly spiritual work, simply through his means of production. He draws the spirituality out of Expressionism, into the Dadaistic in this work, in order to conflate the two into a new sphere of spirituallyinflected artistic play.

The Weimar period came to an abrupt end with the election of the Nazis in 1932. Schwitters was not only opposed to politics in art but was notoriously oblivious to current events, and thus ignored the serious danger the rising Third Reich posed to the German avant-garde. Schwitters had many strikes against him on the Nazi checklist of human negatives. He was an avant-garde artist, he was an epileptic and therefore mentally defective by Nazi standards, he was an avid traveler and openly internationalist in his views, and above all he had made a scene at two Nazi art events. At a ceremony to hang a number of portraits of Adolph Hitler, Schwitters attended and, according to his son, Ernst, when he saw the portraits being carried in by handlers he said loudly, "should we hang them or just stand them up against the wall?"43 The double meaning of Schwitters' question was clear to the Nazi party officials in attendance, and Schwitters was subsequently noted as a radical deviant by Third Reich authorities. On another occasion, Schwitters attended a banquet hosted by the German Press Association to honour Italian Futurist poet and leader, F.T. Marinetti. The dinner was an odd occasion as it was hosted

\footnotetext{
${ }^{43}$ This anecdote is related by Ernst Schwitters in the exhibition catalogue, Kurt Schwitters in Exile: The Late Work, 1937-1948 ed. Nicholas Wadley, (London: Marlborough Fine Art, 1981) 37
} 
by Nazis (and attended by the Reich's leadership, save for Hitler) in Germany for the benefit of the Italian avant-garde, many of whose members pledged support to Italy's Fascist leadership. This event was therefore attended by a strange mix of figures, including Fascists and Nazi officials along with members of Germany's dwindling 'degenerate' art scene, including Schwitters who went with Lazlo Moholy-Nagy. Schwitters, made uncomfortable by the Nazis present, began to drink which led to an emotional outburst wherein he demanded from the German Culture Minister that he be left alone to produce his Merz works without persecution. Later when Marinetti got up to return the honour of the banquet by reciting some poetry, Schwitters rose from his seat and, concurrent with Marinetti's impromptu recital, began to shout out lines from An Anna Blume. ${ }^{44}$ This brazen act was something of a personal victory for Schwitters who confronted those who wished him and his work harm, but it was not long after this occurrence that he was persuaded by family to take refuge in Norway. Only days after his flight to Norway, the Gestapo appeared at his home in Hanover for an 'interview' which, to other artists caught in the Nazi web, meant indefinite incarceration as a subversive.

Such outbursts of political action were exceptions for Schwitters, who mostly ignored the threats of the Third Reich. In fact, his action at the German Press Association banquet was Schwitters attempting to reassert his right to create art without considering politics. Gwendolyn Webster cites a couple pieces of evidence in her Schwitters biography to suggest that he was at least somewhat concerned by the threat that the Nazis posed to artists, but that overall he was blasé about the whole scene and seemed content to wait out the Third Reich. Webster says that, in the early 1930s, an anti-political

\footnotetext{
${ }^{44}$ Webster, 256
} 
Schwitters nevertheless quietly joined the Social Democratic party. ${ }^{45}$ This Schwitters did at the behest of his wife, who was very upset over the rapid rise of the National Socialists and felt it necessary to show opposition by joining the Nazis' chief opponents in the Weimar political scene. Overtly, Schwitters' disavowal of Weimar politics came in the form of mocking laughter, evidenced by his formation of the Anna Blume Party of Germany. ${ }^{46}$ This party was, of course, only Schwitters and could have just as easily have been the Merz party. The party was formed as a gesture satirical of Weimar parliamentary politics, and was an attempt to master or cope with the contemporary political situation through strategies of humourous reversal. Such strategies are central to Merz's system. However, ultimately the political situation became too dire and broke through the wall Schwitters built around him with his various Merz projects. With a breach through Merz as a talismanic system, Schwitters fled the Germany of the Third Reich for a safer region in which to practise his art.

Schwitters took up residence on the northern edge of Norway on the coastal outskirts of a small city called Lysaker, where, before the Third Reich, the Schwitters family would vacation in the summers. ${ }^{47}$ He rented a small cottage in the countryside, isolated from everything: the German art scene, his wife (who stayed in Hanover), and even Norwegian society. This period was marked by a reduction in the frequency of Schwitters' work and writing, due to the fact that he left everything in Hanover, and that he was disconnected from a community of artists.

Schwitters was now alone in the country, whereas Merz had previously drawn on the influence of others and on the materials provided to him by the city. Instead of

\footnotetext{
${ }^{45}$ Webster, 244

${ }^{46}$ Schmalenbach, 146

${ }^{47}$ Schmalenbach, 150
} 
wandering the city streets, Schwitters now took his long walks through the Northern countryside, and also spent much time rowing a boat along the coast. This separation from an urban setting is reflected in Schwitters' new works, which continued the Merz idiom but with a greater emphasis on forms and materials gathered from nature and rural life. During the Norwegian phase of his career, Schwitters scoured the countryside for pieces of old farm equipment, driftwood and stones, which he incorporated into the Merz idiom as a way of negotiating with his new setting.

In many of Schwitters' works from this period that do incorporate the materials of the countryside, Schwitters often used natural materials like stone and wood in a 'mediated' state. Just as he had used paper scraps that have been filtered through Weimar's urban print culture to come out with text or colours emblazoned on them, he, in Norway, used natural materials that had been filtered in some way. Often he used pieces of old fencing, wood formed by human hands into the desired shape with nails protruding. Also, drawing more directly from nature, he collected driftwood and flotsam and jetsam - wood shaped by water erosion and bleached under the sun - and he collected stones from streams, smoothed and rounded by tumbling along water currents. This suggests that even when the kind of materials Schwitters sought were abundant, he continued to select forms that possessed visible signs of life - of being subjected to processes of memory and history. This is significant in esoteric terms as processed forms are charged with a kind of magical presence through their processing. Werner Schmalenbach wrote: “Schwitters' supposedly pure, abstract constructions are bursting with the vitality of things that have known human contact. Whether he knew it or not, it 
was this vitality that he was possessed by." ${ }^{48}$ Schmalenbach suggests that Schwitters held a fetishistic view of his materials. This sense of vitality in the used materials is a form of pantheistic traditions that see the spirit in nature, espoused by the Blaue Reiter painters, but extended to the materials found by Schwitters on the street. The idea that every object is a vessel for the spirit is also a notion espoused by German mystic Jacob Böhme (1575-1624), whose writings on spiritual matters were influential upon Der Blaue Reiter, and it is thus likely that his influence made its way to Schwitters as well. ${ }^{49}$

This Norwegian-period work is, like his earlier Merz work, a deployment of symbols to evoke a magical function, and a use of materials that, through their connection to the environment, serve as a form of geomancy. Many of his pictures composed during this period used stones, which implied a direct connection with the earth, and particularly rounded stones - which serve as a referent to the collaboration of stone and water. It is thus the processes of nature that produce aesthetically pleasing materials suitable for Schwitters' art. Schwitters, in using such materials, is acknowledging that nature, too is an artist (or, at least a form-giver) but he is also engaging very old systems of occult magic. By using natural materials, Schwitters is, in fact, evoking a more traditional form of magic than that of his Hanover Merz works, whereby the incorporation of materials from the surrounding environment performs protective functions. The smooth stones, in their invocation of nature's processes, call upon the forces of nature to protect, just as Schwitters, in earlier times, predominantly used print culture to construct a protective force in art.

\footnotetext{
${ }^{48}$ Schmalenbach, 89-90

${ }^{49}$ Böhme's work The Signature of All Things, in particular, explains the idea that all things, living and nonliving matter alike, possess vitality.
} 
Perhaps the strongest example from his Lysaker period of a protective environment is Merzpicture With Rainbow (fig. 2), from 1939. This image is another of Schwitters' many Merz skyscapes which explicitly include a natural or celestial form (cf. Das Sternenbild). In this case it's the immaterial light phenomenon, the rainbow, represented by a small rectangle painted to appear as the colour spectrum. The rainbow likely appears in this image as a traditional symbol with post-apocalyptic implications. It does not, however, refer to the iconography of the Book of Revelation, but rather to that of the flood, as recounted in the Book of Genesis. After Noah had successfully navigated the period of the flood in his ark, God said to him:

I have set my rainbow in the clouds, and it will be the sign of the covenant between me and the earth. Whenever I bring clouds over the earth and the rainbow appears in the clouds, I will remember my covenant between me and you and all living creatures of every kind. Never again will the waters become a flood to destroy all life. ${ }^{50}$

The Biblical flood in Genesis is the first 'apocalypse' of the canonical Bible. ${ }^{51}$ To the Bible's adherents, a part of the flood's significance stems from its location in a historical past. It was an apocalyptic event that occurred, and was endured by Biblical heroes. The story of the deluge and the survival of Noah and his family bears much of the same rhetoric as stories considered explicitly apocalyptic. It involves a paternal, angry god, unhappy with the sinful and decadent behaviour of his creation, man. God chooses a punishment that involves a near-total destruction of the planet and all life upon it, with the exception of his prophet, Noah, his family, and the animals chosen by Noah as residents of the ark, the vessel destined to survive the flood. The rainbow thus appears in

\footnotetext{
${ }^{50}$ Bible, Genesis 9:13-15

51 Joseph Anton Koch Noah's Thanksoffering, 1803 (fig 22) is a more traditional rendering of God making the covenant with Noah via the rainbow.
} 
the sky, placed there by God as a message that the floods are over, and as a promise to his prophet that he'll never flood the world again.

This story bears the similarities to the apocalyptic stories found in Revelation, in Daniel, and in the Apocryphal 4 Ezra, wherein a heightened state of human corruption calls down upon it the punishing wrath of God, which is only to be survived by a chosen few. The differences between the Flood myth and the various Christian apocalypses are significant, however, to an understanding of this work in Schwitters' oeuvre. All the Biblical narratives interpreted as forms of apocalypse, aside from the Flood, were products of vision states incurred by prophets. These visions typically foresaw a divine entity intervening in earthly affairs to alleviate a faithful group from its earthly torment. According to historians and modern theologians, the visions were codes to refer by metaphor to contemporary events, and the overall thrust of the vision was to suggest that the enemies of a people will soon be vanquished by no less a power than God. ${ }^{52}$ The flood myth represents something similar, but different, for apocalyptic visions refer to a future that is unknown but ever imminent. ${ }^{53}$ The flood, by contrast, happened at an indeterminate point in the past. Its ending is the point from which the current era emanates, as all before it was destroyed. The flood is a mytho-historical event, and to a religious person, something that actually happened and contributed to the forming of the present world.

Merzpicture with Rainbow is dated to 1939, the dawn of the Second World War. By 1939, the situation in Europe had become quite tense with regard to the Third Reich,

\footnotetext{
${ }^{52}$ Collins, 156

${ }^{53}$ Weber (32-33) suggest that the symbols of apocalyptic visions would be apparent and easily read by the intended audience. But because the symbols are so vague to subsequent readers they are easily recoded and reinterpreted. Every period provides its prophets with signs of end and renewal, often in the form of decadence and bloodshed.
} 
which had become increasingly threatening to its neighboring countries. By early1939 Hitler's expansionist aims, his policy of lebensraum and his desire to redeem Germany from the Treaty of Versailles were well known and thus war seemed imminent. For an artist who had lived through the First World War and was persecuted by the policies of the opening phase of the Third Reich, Schwitters' use of the rainbow symbol may have multiple meanings. With war looming over the European continent, Schwitters may be evoking the symbol of the rainbow to protect against war. ${ }^{54}$ The First World War was the deluge that should never happen again; indeed participants such as Britain instituted Remembrance Day as a yearly day of ceremony to honour the dead of the Great War and encourage a peace. In Germany, although the seeds of the second great conflict were sewn in the Treaty of Versailles, the institution of the Weimar Republic was part of a national effort to privilege the artist in Germany and foster a less war-like culture among the German people. Thus, in very practical terms these countries tried to reconfigure their cultures to discourage war in their futures. Certainly, any country that has been hit hard by a large-scale conflict would try to prevent such devastation from repeating, so the flood would not happen again. But with the rise of Hitler's Third Reich, it seemed as though a matter of honour for Germany to avenge its loss.

\footnotetext{
${ }^{54}$ It should be mentioned that one of Schwitters' major influences, Wassili Kandinsky, depicted rainbows in many of his paintings (for example his 1909 painting Murnau with Rainbow (fig 24) or Cossacks (fig 25) from 1911). In his text, Concerning the Spiritual In Art, Kandinsky discusses the harmonic use of colour in painting. He suggests that the soul responds to light, and colour and light used effectively can produce vibrations in the soul that lead to a spiritual elevation. Kandinsky assigns meaning and feelings to each colour in the spectrum (violet, for example, is "sad and ailing") but suggests that in harmony these feelings are modulated by their relation to one-another. Kandinsky does not write of rainbows in his text, but from his writing on the stirrings of the soul caused by colour combinations it may be extrapolated that the rainbow held a special place in his system of colour-soul correspondences. Because the rainbow is a form made from light, and is a strip made of all colours, it is conceivable that it is a way of producing complex responses of the soul. If Schwitters is following Kandinsky's lead in depicting the rainbow as much as he is referencing the rainbow of the Biblical Flood, then the symbol may, in this image, be a symbol of the descent of divine power and protection, and an elevation of the soul of Schwitters who had need to rise above earthly troubles.
} 
If Merzpicture with Rainbow is a response to the Nazi threat, then the Nazis were a 'flood' on two scales: the impending menace of international warfare, and the personal threat of persecution posed to Schwitters. Hitler attributed the moral decline of PostWWI Germany to modernist artists (he was a mediocre Realist artist, and had an axe to grind) ${ }^{55}$ Merz art was featured in the Nazi's Degenerate Art exhibition of 1937 alongside works by other Dadaists. The purpose of this exhibition was to undermine the avant-garde by repeating the pseudoscientific belief that the radical innovations of avantgarde art were the products of mental illness. ${ }^{56}$ The "insanity" of the works was further emphasized by the exhibition organizers through the crooked hanging of some works, including Schwitters' ${ }^{57}$ Schwitters was, of course, only sought as a degenerate artist due to his Merz works and to the two outbursts noted earlier - his academic works likely would have met the Third Reich cultural standards for content and style, if not for quality - and therefore it is appropriate that Schwitters uses Merz as a totem for calling for protection from his pursuers. He invoked the symbol of the rainbow as a form of personal protection, not just against a repeat of war, but to symbolize hope that the Nazis will not find him and again try to force him to give up his Merz work.

Aside from paint, wood is the primary material appearing on this assemblage. A cross, made from twigs and a rubber stopper, appears floating above the rainbow and almost hovers above the surface of the canvas. Following in the tradition of Friedrich, Schwitters' Romantic predecessor, the cross is used to represent the presence of the divine in the image (cf. Friedrich's Cross by the Baltic Sea (fig 23)). While all of the

\footnotetext{
${ }^{55}$ The introduction to the 2006 anthology The Arts in Nazi Germany: Continuity, Comformity, Change, by Jonathan Huener and Francis R. Nicosia explains in depth the Nazi attitudes towards art and culture.

${ }^{56}$ Stephanie Barron, Degenerate Art: The Fate of the Avant-Garde in Nazi Germany, ed. Stephanie Barron, (Los Angeles: Los Angeles County Museum of Art, 1991) 12

${ }^{57}$ Barron, 54
} 
other bits of wood are finished in some form, the artist used rough, broken sticks to make his cross. Thus God is made from the most natural materials on the canvas. Also important is the presence of the upward-pointing triangle (appearing with rounded edges) situated directly above the rainbow, almost to appear as though it is resting upon it. In esoteric iconography, an upward-pointing triangle means evolution, the ascent of the spirit. Also, there is a strip running the full height of the canvas, and a piece on the right clearly taken from a broken-down crate. Both of these pieces of wood serve similar protective purposes, as it appears that Schwitters was boarding up his image, fortifying it with scraps of wood. The board taken from a crate is particularly evocative of this meaning, as a crate's purpose is to protect cargo from damage during shipping. This use of wood from crating can thus be read as a symbolic evocation of the ark - the seafaring vessel God instructed Noah to create as a means of weathering the deluge and delivering survivors to its end, from which the post-diluvian world is constructed. In the flood narrative, the ark is a means of human, earthly protection that Noah provides to himself, by which he is delivered ultimately into God's divine protection signified by the rainbow. The ark is signified by strips of wood, thus forming a dichotomy within the image between painted nature, and the human constructions evidenced by the processed wood with a divine power hovering over everything. Schwitters used the Merz idiom to construct a mythic image in a synthetic cubist landscape. The wood is, through this strategy, given double meanings. The crate wood most clearly signifies 'ark', but simply being from a crate anchors it in the Merz idiom and has its own protective capacities which are found in the everyday. The strip of wood on the left, also signifying the ark, gives the impression that the painted image is being boarded up, fortified against bad 
weather, and it also forms an axis mundi by which the divine is accessed. Furthermore, the wheel at the crux of the cross may signify the steering apparatus of the ark and suggest Schwitters as Noah, navigating the flood successfully.

Although he did not write of a particular interest in the myth of the flood and the ark, Schwitters' home in Hanover was known as being something of an animal sanctuary where he kept a variety of small creatures. ${ }^{58}$ Also, in the Merz collages that do contain animal imagery, they often appear in pairs. For example The Cherry Picture (fig. 13) displays two kittens in the lower-right portion of the canvas. Picture with Spatial Growth/Picture with 2 Little Dogs (fig. 26) is an image first made in 1920, but in 1939 two dogs were added and the work was retitled, according to Karin Orchard. ${ }^{59}$ Picture with 2 Little Dogs is perhaps of peripheral significance to understanding Merz-Picture With Rainbow as evoking the story of Noah. The two dogs in the work are actually threedimensional china figurines set in a box affixed to the surface of the collage. The fact that Schwitters made this addition in 1939 may indicate that he was thinking about this particular narrative in protective terms at this time. He fled for England in April, 1940, and in keeping with an interest in the narrative of Noah and the ark, he kept two white mice in his pockets as companions through the journey. ${ }^{60}$

Ultimately, reality had pierced Schwitters' defenses and he was again threatened by the Nazi menace. The German military invaded Norway on April 9, 1940 and Schwitters had to flee a second time. Schwitters found himself in England in 1942 and was interned with other German refugees in an English prison-camp for eighteen months.

\footnotetext{
${ }^{58}$ Webster, 105

${ }^{59}$ Karin Orchard, "Kurt Schwitters' Spatial Growths", 32-65 Kurt Schwitters: Merz - a Total Vision of the World, eds. Annja Müller and Heinz Stahlhut (Bern: Benteli Publishers, 2004) 34

${ }^{60}$ Webster, 303 . Webster cites two anecdotes recalled by Schwitters in which trouble with Norweigan authorities were averted by the presence of his mice.
} 
During the war and his internment, Schwitters unknowingly suffered a set of tragedies. The greatest was the bombing of his Hanover home, which meant the death of his wife, Helma, and the loss of his life's work, the Merzbau. While living at the camp, he had done little work, mostly academic painting, and made contact with a number of other German refugee artists and writers also interned at the camp. This period was something of a lull in Schwitters' career, and he was largely unhappy in England, having been even further isolated from the exuberant milieu he had known in Weimar Germany.

When Schwitters was released from internment, he continued his Merz practices. While in Germany Schwitters was able to make a living from his art activities (selling collages, and producing advertising), but unfortunately in England he could not find much of an audience for his works. ${ }^{61}$ An appreciation for avant-garde art was limited in England, and Schwitters was unlikely, as a German man in his sixties, to build a list of advertising clients. Instead, Schwitters felt forced to resort to doing academic portrait painting as a means of bringing in an income. Schwitters often lamented to his friends, particularly in his letters to Raoul Hausmann with whom Schwitters planned a post-war Dada publication titled Pin. To Hausmann, Schwitters complained that, "I live from painting portraits, but in England you must not even see any brushmarks on the surface of the picture. My pictures have brushmarks and therefore I have difficulties." ${ }^{22}$ To Schwitters, for whom art since 1918 had become a kind of play even if it made money, this was a near-intolerable situation.

Schwitters followed his release from internment with a return to much of his rhetoric and imagery he had used following the First World War. Schwitters produced

\footnotetext{
${ }^{61}$ Schwitters worked on a number of lucrative advertising contracts in pre-Nazi Germany.

${ }^{62}$ Jasia Reichardt, "Introduction", The Story of Pin. (London: Gaberbochus Press, 1962), 5.
} 
intensely abstract works of art unlike any he had made since the early Weimar period, and he pursued this line of production until the end of his life in 1948. The reason for this may be twofold: he was reacting to a forced sense of servitude in his career as a portraitist by making, on his own time, art that was completely unacceptable to a clientele he did not truly respect: and also, with the end of the Second World War, he was charged again with many of the same feelings that drove him during the period immediately following the First World War. This sense of renewal and newfound exuberance, and a return to a post-apocalyptic utopian outlook may be discerned in a 1947 work, Carefree (fig. 3). This image is a highly abstract efflorescence of texts and papers of various colours and textures that expresses and asserts Schwitters' freedom. After the war, Schwitters had experienced bad health, but there were also signs that his career as an avant-gardist was picking up again. He had found patronage from Harry Peirce, and interest in his work was growing in the United States thanks to Katherine Dreier.

Werner Schmalenbach, in his opus on Schwitters, never wrote about Carefree but he did set its image next to another work done by Schwitters five years earlier, shortly after his arrival at the internment camp, titled Aerated VII (fig. 27), a work that expresses the unhappiness the artist felt after arriving in England. Schmalenbach sets up these two images as a 'before and after' set, with WWII and Schwitters' time spent in England functioning as absent referents. The earlier collage contains phrases such as "Not Fantastic", references to North America (where Schwitters had hoped to go rather than England) as well as travel stubs pertaining to his flight to London. These scraps suggest a state of mind, with 'not fantastic' appearing in the lower-right-hand corner, diagonally opposite to his 'delivered luggage' stub, bearing his signature, right next to a train ticket 
stub - the luggage was Schwitters', but he did not arrive where he had hoped.

Furthermore his ticket overlaps a photograph of a coastal landscape - likely the fjords of Norway Schwitters had recently left behind. To Schwitters, his home in Norway was more than just a safe haven from persecution, it was also a place he visited frequently in the years preceding his exile - often going there for summer vacations with his wife and son. In 1942 London, Schwitters was in a place purely as a safe haven, an unhappy refugee camp where he was held under suspicion. Aerated VIII has a black spot at its centre, recalling the abstract but spiritually suggestive work of his earlier career, Merzpicture with Light Centre (fig. 12). This image becomes a miserable counterpart to that work, with the black centre suggesting a dark abyss into which the artist can project his sadness and sense of longing over a second exile to a hostile new land.

His 1947 work, Carefree, may thus be read as a newfound exuberance for art. Schmalenbach was likely implying by juxtaposition Carefree as an expression of relief from the malignant longing encoded into the earlier Aerated VIII. Carefree is a post-war return to Dadaism at a time when all of the original Dadaists had moved on to other interests, whether they be Surrealism, Marxism, etc. Schwitters' response to the end of the War and his internment was a rejuvenation of his post-apocalyptic sentiments and utopian ebullience. The title, Carefree, of course suggests a lifting of pressures and a sense of freedom largely attributed to the child. Although this work is not loaded with esoteric iconology, a reading of a rhetorical, secular millennium is possible from this simple work produced by the end of his life. Schwitters experienced a repetition of the feelings he held after WWI, and the issue of repetition is explored here through a play with language. The title of the work, Carefree, exists here on a scrap of a piece of paper 
placed near the centre of the canvas. The only discernible elements in this work are its words - thus making this image into a kind of visual or decorated poem. And, as a poem pertaining to rebirth it echoes the themes of many of Schwitters' more traditional, written poems that explore the alchemical theme of renewal and rebirth to a higher plane of existence.

Schwitters cut the word 'carefree' down to 'refree', referring to the original, full word 'carefree' through the title, but here altering it to expand the meaning of the work. Here, the word can be understood to mean 'free again' at the same time that it means 'carefree' - thus referencing both the new sense of artistic freedom, the freedom from internment, and a new post-war era of utopian bliss. This return to 'carefree' days is further emphasized by the gesture of the production of the word 'refree' - cut from a scrap of paper bearing the word 'carefree', it recalls how, in 1918, Schwitters first produced the word 'merz' from 'kommerz' to begin his own artistic idiom.

The meaning of 'refree' is repeated (and expanded) with the phrase 'back alive' - another term that implies repetition. 'Back alive' suggests, more than being free again, the phenomenon of returning to life from death. This sentiment may be loosely linked with traditional apocalyptic rhetoric, although it also recalls the statement made by Max Ernst in his autobiography: "Max Ernst died the 1st of August 1914. He resuscitated the 11 th of November 1918 as a young man aspiring to become a magician and to find the myth of his time." ${ }^{\prime 63}$ In the tradition of the Christian Apocalypse, the return to life is an aspect of the Day of Judgment. This was when all souls are raised from the dead by the archangel Gabriel and weighed on the scales for their sins and virtues, as a determinant in

\footnotetext{
${ }^{63}$ Max Ernst, "Some Data on the Youth of M.E." View: Parade of the Avant-Garde, ed. Charles Henry Ford (New York: Thunder's Mouth Press, 1991), 42-46
} 
finding if they should pass into paradise. This is referring to a resurrection, a miraculous event that takes place in key points in Biblical scripture. Furthermore, the Resurrection of Christ is a key moment in the New Testament that revealed His divinity. In Carefree, Schwitters expressed a similar sense of rising from the dead to reassert Merz and its meanings, and reveal himself as still a force of avant-garde art. Such sentiments may have found their basis in 1946, when he was given the resources to begin a new Merzbau by Harry Pierce. ${ }^{64}$ This image thus reasserts the idea of Merz as a post-apocalyptic art form that laments the repressive past and anticipates a present and future in which Schwitters may live again.

This reading of the work is further emphasized by the fact that the words are all placed upside down. If it weren't for the initials KS written upright in the lower left, a viewer could easily perceive this picture as placed the wrong way around. Such a display of the image's textual elements further entrenches this as an image of reversal, that the world had been turned upside-down. This concept is of great importance to Merz in general, and will be discussed further in the third chapter; however in this image the concept is directly integrated into the work as a visual device. The "world turned upside down' is a common theme in millenarian rhetoric, including that of the Christian Revelation. Coming back to life and turning the world upside down may refer to Merz and Schwitters himself being renewed in some sense - especially when contrasted against the earlier Aerated VII that centered around a black void. Carefree is a ritualistic rebirth that gets back to Schwitters' roots and returns to Schwitters' original notions of Dada art as being something of a spiritual-artistic salve for a damaged civilization as well as a traumatized individual.

${ }^{64}$ Webster, 388 
Schwitters' work is rife with symbolic meanings, often pertaining to issues of apocalypse or protection. Although his Merz images veer towards abstraction, they do convey meaning through very simple means. Das Kreisen conveys meaning through an arrangement of geometric forms, whilst Merzpicture with Rainbow evokes Biblical narrative through a simple arrangement of colour and a thoughtful use of real-world objects as materials. Finally, Carefree, a collage Schwitters made as he neared the end of his life, asserted a newfound sense of freedom through the arrangement of words that appear within this collage. In this chapter, therefore, I have chiefly engaged in iconographical and textual evidence of Schwitters' desire for renewal and protection. These are not his only strategies for achieving protection through artmaking, however. Chapter three will address additional inflections of this preoccupation. 


\section{Chapter Three}

\section{“A Game we Play with Serious Matters. That is Art"}

In the previous chapter, evidence that Schwitters' work was full of iconographic meanings pertaining to issues of protection vis-à-vis millenarian themes was provided. Schwitters deployed symbols to imply something programmatic in his images - the issue of using art to form a protective force against the external world. Given Schwitters' socio-historical context, the artist faced many threats from which protection was needed. Such threats included political repression, war, bad reviews (that often included attacks on his character and assumptions about his mental state), and the trauma of painful memories (like the attack on his childhood garden) or epileptic seizure. Schwitters used Merz as a way of producing an artistic environment in which he was safe. Merz did not, however, develop as a protective art form through iconography alone. Merz is a manifestation of a number of different strategies aimed at providing Schwitters with a kind of artistic, one-man utopia. The materials he used and the methods he took to procure them, the kinds of art he produced in Merz, the arrangement of his materials on a canvas, his use of humour, his positioning of Merz in the German art world - all of these things contributed to what Merz ultimately was: Schwitters creating a world for himself out of the materials of the other. Many of these protective strategies relate to occult or esoteric traditions, while others are simply a matter of psychology or physiology, but they all share in the effect of Merz as a protective art. Regardless, strategies of self-protection seem to exist at every level of the Merz project. 
The methods through which Schwitters acquired his materials provided him with his first line of defense. Schwitters' long walks or bicycle rides around Hanover to collect materials also mitigated against his epileptic seizures. Schwitters' epilepsy was first triggered when the artist was a child. He spent a summer tending to a garden on his family's property and one afternoon local boys came and violently destroyed all the work he had done. This event was so emotionally upsetting to the young Schwitters that it triggered his first violent epileptic seizure which subsequently plagued him well into adulthood. ${ }^{1}$ While this traumatic event may be the impetus for Schwitters, in later life, to seek protective forms in his art, it also produced in him an immediate necessity to overcome certain physiological afflictions. His seizures were described as being quite debilitating and lasting for hours. ${ }^{2}$ A seizure could be a day-long affair for the artist. He was described by friends as losing his ability to speak coherently, then seizing up for up to four hours. He afterwards succumbed to exhaustion, and often slept for a number of hours. Before WWI, Schwitters attended the academy in Dresden where he often took long walks to look for landscape vistas to sketch. Although these walks were useful to his art training, Schwitters found that he never experienced seizures (or their preliminary symptoms) during these walks, and began going for walks just to prevent them. ${ }^{3}$ The Dresden art academy was nearby to a vast countryside, unlike Schwitters' Hanover home. With the development of Merz, Schwitters required large amounts of diverse materials, and thus took to walking or riding his bicycle around Hanover on long meandering journeys. Many artists, poets and philosophers (Yeats, Henry David Thoreau, Kant) have discussed their need to walk - considering it a way of combining intellectual activity with

\footnotetext{
${ }^{1}$ Webster, 7

${ }^{2}$ Webster, 7

${ }^{3}$ Webster, 21
} 
physical activity. ${ }^{4}$ For Schwitters, walking not only engaged the whole man in a mind/body unity, but it also directly involved a creative/protective unity as well.

Schwitters' choice of materials is of great importance to his work as a protective artform. The most basic and obvious way in which Schwitters' works evoked protective meaning was simply by using everyday materials that served quotidian protective functions. Many of his works include lids, mesh wire from animal caging (which may be seen in Das Sternenbild (fig. 12)), bottle caps, as well as wood taken from crating, found in the already discussed Merzpicture with Rainbow (fig. 2). Such materials, commonly found in Merz art, all deal with protection by enclosure, and may thus refer to the artist producing the kind of sanctuary he had as a child with his garden, albeit one that is not so easy to strike at physically. Other materials reference protection in other ways. The appearance of a luggage claim stub in Aerated VII (fig 27), for example, - references the safe passage of Schwitters belongings.

Schwitters used Merz to express concerns about protection on a number of levels - one level was iconographic, but the protective properties of Merz art run more deeply than talismanic iconography. Using materials from everyday life has affinities with traditions of protective magic. Surrealist painter, and occult historian Kurt Seligmann has found that the parings of the body (hair and nails) and objects that have been used by an individual were of central importance to the earliest forms of magic ritual in western civilization. ${ }^{5}$ Throughout occult history, the prima materia of ritual, both protective and malignant, has been the base matter of everyday life - the ejecta of the body, and objects that have been used but discarded.

\footnotetext{
${ }^{4}$ Rebecca Solnit, Wanderlust: A History of Walking, (New York: Viking, 2000) 14

${ }^{5}$ Seligmann, 43-44
} 
Magic ritual has, historically, largely functioned through the use of metonomy and synecdoche. The material of the body can stand for the body that produced it (metonomy). Objects of use, when discarded, lose their use value but can take on symbolic values, and most importantly they can stand for their user (synecdoche). In a magical sense, such materials are charged with the essence of their source - they are made alive through use or by virtue of coming from life. Schwitters adopted this use of magic, using objects of personal significance or objects pilfered from visiting friends. The Merzbau, Schwitters' merzed home, contained within it a number of 'grottoes' dedicated to his friends. To complete his grottoes, which were essentially little shrines reminiscent of the shrines or reliquaries dedicated to saints, Schwitters inserted some indexical form from each friend. This included nail clippings from Theo Van Doesberg, a pencil from Mies Van der Rohe and a bra taken from Hannah Hoch's luggage during a stay with the Schwitterses. ${ }^{6}$ The concept that non-living materials have some kind of spiritual life is a pervasive one through the pre-modern world, as outlined by Mircea Eliade in his examination of the spiritual use of materials in his work The Forge and the Crucible. ${ }^{7}$ Although Eliade explores the materials and minerals of the earth being perceived as bearing spiritual properties to those who make use of them by virtue of the fact that they are products of nature, Eliade's basic premise may be relevant to Schwitters' Merz work. Schwitters too used materials which were 'alive' in some sense. Given his view that the new world was to be built on the ruins of the old, the found material, rubbish and scraps are the fertile, organic soil from which a new world of art is produced. It is alive and magically charged because it is a product of human culture, just

\footnotetext{
${ }^{6}$ Gamard, 103

${ }^{7}$ Mircea Eliade, The Forge and the Crucible: The Origins and Structures of Alchemy, trans. Stephen Corrin, (Chicago: The University of Chicago Press, 1962)
} 
as in a more archaic epoch a material was alive because it came from nature. Schwitters conceived of Merz as something of a new primordialism - a very extreme return to beginnings, but beginnings founded on the collapse of an advanced, industrial society. Schwitters viewed his works as existing in a state of becoming, and this is emphasized by the materials he uses. ${ }^{8}$ Rubbish and waste exist in a state of being that is thought of as being at the end of a process. Rubbish is simply everyday materials coded as waste, materials that have been altered by a process they have been put through - thus implying that there is a kind of life cycle to the objects Schwitters used. Such an idea thus serves as the basis for his post-apocalyptic view - each scrap of each work by Schwitters is a microcosm of his view of Merz as the vanguard of an emergent world.

Schwitters not only produced Merz works in as many different art forms as his abilities would allow, he also 'merzed' household objects. Of particular significance to the notion of Merz as a protective art were, in addition to the Merzbau, merz-boxes (fig. 28) and a merz-mirror (fig. 29). The merz-boxes become real, functioning crates of merz artwork - encasing other objects in Merz. The mirror (fig. 29) has a different function from the box. Its reflective surface is merzed over, and therefore it no longer returns the gaze of its user. The mirror becomes another merz-collage surface. Yet it is still a handmirror, meant to reflect the image of its holder. It may thus have been meant to reflect Merz to Schwitters, who ultimately incorporated Merz into his own identity. The merzmirror offers a tangible 'reflection' of Schwitters. Or it may be read as reflecting the world around it, a creation made with mirrors, a reflection of the world with its own actual waste materials serving as its reflection. The arrangement Schwitters gives the materials demonstrates his mastery over this reflection. Thus to be reflected in Merz was

\footnotetext{
${ }^{8}$ Schmalenbach, 94
} 
to be renewed through the products of cultural waste. The mirror refers to Schwitters' gaze, the vision of Merz and how it merzed what fell before it. Akin to this, Schwitters thus renewed even his city, Hanover by removing the first syllable 'han' and reversing what remains to 'Revon'. Revon was Hanover, but Hanover as seized by the mind and gaze that renews what it holds into Merz. The Merz-box protects through enclosure, while the Merz-mirror "reflects" the world back as Merz (were there such a word, one might say that the Merz-mirror 'flects' rather than 'reflects'; it presents, rather than represents). Merz-mirrors subvert the function of a real mirror and give new meaning to the tradition of "art as the mirror of nature." In a real way, they are closer to the tradition of the magic mirror - the mirror that shows a future state rather than simply repeating the present.

Traditions of alchemy are also important to understanding Merz. Alchemy is often associated with the more ignoble end of scientific research, but to modern artists its role in the roots of modern chemistry is secondary to alchemy as a form of philosophical mysticism. Traditional alchemy involved a number of primary pursuits: first, foremost, and best known is the transmutation of metals. Its main idea was that a base material (often lead, but many prominent alchemists, including Paracelsus, cited excrement as the ultimate base material) could be transformed into precious materials, like gold. The other two pursuits were the creation of the philosopher's stone and the search for a material called aqua vitae. The philosopher's stone was a quasi-legendary substance (its actual form is unknown and a matter of speculation to alchemists) that, when applied to a base material, would greatly facilitate the transmutation of gold. Aqua Vitae was the water of life, another mythical substance said to provide extended vitality to living things. 
The true importance of alchemy, however, was not to discover a source of easy gold and wealth; it was for the alchemist to transform the self. The quintessential alchemical pursuit was termed 'the great work'. This was the process of discovering the philosopher's stone through a series of steps that are supposed to take the utmost in patience and observation (a single step in the process may take the alchemist a year or more to complete). The alchemist, engaged in the great work, is, at the same time, involved in the process of purifying his soul and achieving transcendence. This was the essence of alchemy: that the transition of a base material to a material of considerable value required the alchemist to put his soul to the same tests. The long process of working alone on a project with scientific pretensions takes on a mystical essence of the search for spiritual transcendence and greater universal awareness. The process, despite its basic search for material excellence, involves a movement of the individual away from the material plane, and a rising above earthly concerns.

Merz bore significant affinities to alchemical traditions. Schwitters considered his art, above all, to be about the balance of materials, and to some extent, concepts ("I play sense against nonsense"). This balancing of disparate materials is grounded in the alchemical process, which often finds transcendence in the uniting of opposites - a unity that should be matched by a balance within the soul of the alchemist (or, in this case, artist). The most common factor to all Merz art is its elevation of detritus to art status. Elizabeth Burns Gamard, in her book on the Merzbau, suggested that for Schwitters, an artist interested in wordplay, one of the most appealing aspects of the word 'Merz' for Schwitters was that it sounded similar to the French expletive, "merde" (shit), or its variant "merdre" - a word known to all Dadaists as the first word spoken in the seminal 
play Ubu Roi by Alfred Jarry. Such a play on language would be alchemical in two ways. First would be its reference to a base material; and second, it echoes the obscure use of language prized by alchemists, who often preferred to use symbolic imagery and esoteric poetry to convey ideas rather than scientifically recording their findings. By so doing, alchemists protected their occult wisdom from the unworthy.

Schwitters' transmutation of Hanover into Revon is an alchemical move - perhaps the step of purification, wherein the base matter is purified into its essence. Elizabeth Burns Gamard, in her book on the Merzbau, shows a particular concern for alchemy in Schwitters' work - she notes that his story, "Der Zweibel" (The Onion), for example, is about an individual named Alvis Basentiel, who is broken into pieces (its opening line is: "The day I was to be slaughtered was a very busy day") and then reassembled - with the king, his executioner, falling dead upon the moment of his rebirth. ${ }^{9} \quad$ This short story has affinities with Shamanic initiation rites, and with both the steps of alchemy and the diction of alchemical writing, which was often simultaneously poetic and obscure. For Burns Gamard, this story is a metaphor for Schwitters' view of Merz as an art of 'unforming and forming' - the components of the past assembled into the new. ${ }^{10}$ She writes:

In 'Der Zweibel', a parallel tale of spiritual journeying expressed in the terms of alchemical mechanics (dissolution, purification, trituration, union, cooking), and solution (re-assemblage), lurks just behind the story's expression. In addition, there are references to alchemical materials and symbols such as sulfur, salt, the colour green (the intermediate colour in the chromatic scale and hence the colour of romance), flames ("Hollow burns stomach flame sulfur blood"), earthworms, fat and silver. To both conceal and abet the message of the story, Schwitters intersperses the text with parenthetical remarks that initially appear nonsensical, but in further analysis may act as deliberate marks or traces of the alchemical process... 11

\footnotetext{
${ }^{9}$ Gamard, 67

${ }^{10}$ Gamard, 68

${ }^{11}$ Gamard, 68
} 
The story is, according to Gamard, directly alchemical, and in its reference to alchemy, it is referring to Merz' ability to do what alchemy did - make something spiritually precious out of base materials - and re-assemble that which has been broken down into spiritually superior forms.

Merz was fundamentally art made through an alchemical process in the sense that it transformed base materials, refuse from Hanover streets, into objects of value and works of spiritual expression. Moreover, Schwitters' Merzbilden are also full of explicit alchemical references. Most notable are the appearances of the word 'gold' on paper scraps in a number of images. ${ }^{12}$ Such works explicate the alchemical in Merz by humorously producing a form of the precious material sought by alchemists through the insertion of papers bearing the proper word.

Roger Cardinal theorized that Merz works comprise sets of a collection for Schwitters. ${ }^{13}$ The forms that find their way into his assemblages are often printed with text and graphics - the objects he uses can be visually connected with once having a useful function. These forms thus are charged with memory, both cultural and, often, personal. The diary is a way of preserving the memories of the writer. Unlike the personal diary, however, Schwitters' collages do not bear a linear narrative of personal experiences. Instead they are far more ambiguous. They refer to their own origins, the process by which Schwitters had come to acquire them, and also the meaning with which Schwitters himself charges them. The materials Schwitters used simultaneously serve as

\footnotetext{
${ }^{12}$ An example of this use of the word 'gold' in his work is Untitled (Collage in Interior of a Trunk Lid) (fig. 30)

${ }^{13}$ Roger Cardinal, "Collecting and Collage-Making: The Case of Kurt Schwitters", 68-97 The Cultures of Collecting ed. John Elsner and Roger Cardinal. (London: Reaktion Books, 1994) 77
} 
metaphors for memory and as actual markers for memory. ${ }^{14}$ This is because the materials he uses are in a decayed state, affirming the deforming power memory has with regards to preserving the past.

In addition to the role Schwitters' materials play in memory and its preservation, the alchemical factor in Merz may be related to anthropologist Mary Douglas' ideas about marginal materials and purification. In her book Purity and Danger, Douglas suggests that many groups conduct rituals that convert things and people that are coded as impure, things that pose a threat to the group's purity, into things that are pure - thus allowing the group to recoup them. Douglas demonstrates how ritual becomes a way by which a tribal group manages its environment and organizes its boundaries. The group will find ways by which dangerous substances are made acceptable and safe through a kind of filtration of ritual. Many systems of folk belief posit that contact with that which is impure or dangerous actually will bring protection to the individual who makes contact, or to the associated group. ${ }^{15}$ This overlaps with the ideas of the German Renaissance alchemist Paracelsus, who wrote: "Putrefaction is the chiefe degree and first step to generation. There are many bad, unwholesome...things which after their putrefaction become good... and become wonderfully medicinal." ${ }^{16}$ Schwitters' Merz artwork is a form of such ritual, as it elevates the status of trash and refuse to that of art. Donald Kuspit wrote that collage has the "purifying" effect on materials in art that certain

\footnotetext{
${ }^{14}$ Leah Dickerman, "Merz and Memory: On Kurt Schwitters", The Dada Seminars, ed. Leah Dickerman and Matthew S. Witkousky, (Washington D.C.: The National Gallery of Art, 2005) 113-125

${ }^{15}$ Mary Douglas. Purity and Danger: An Analysis of Concept of Pollution and Taboo, (London: Routledge, 1966). The chapter "The System Shattered and Renewed" in particular discusses the system of purification stemming from contact with the impure. Furthermore, as the chapter title suggests, Douglas discusses these encounters with the impure and dangerous as components in rituals of cultural renewal.

${ }^{16}$ Paracelsus, "From The Nature of Things and Paracelsus His Aurora" 151-170, The Alchemy Reader: From Hermes Trismegistus to Isaac Newton, ed. Stanton J. Linden. (Cambridge: Cambridge University Press, 2003) 153
} 
rituals have on the self in various cultures. ${ }^{17}$ By collecting refuse and setting it into a frame, Schwitters purifies trash, elevating it to art material. Merz goes beyond an elaboration of Duchamp's ready-made concept, however, to give refuse a role in spiritual expression. This process of elevating detritus' status was done through using trash to produce works in established modes of art: i.e., through Schwitters' consistent production of framed, canvas Merz-paintings, and through heavy reference to the avant-garde styles of painting. Schwitters' Merz works are easily read as art, rather than as the anti-art shock strategies of many of the "official" Dadaists. It was by bringing his found materials into these artistic traditions that Schwitters sanitized them and made them pieces of a new spiritual vision.

This intersection of ritual use of materials and the potential for protection may cross with Schwitters' domestic life. Schwitters, despite his affiliation with Germany's avant-garde art scene, was mired in middle-class respectability and domesticity. He lived and worked at home, in a house owned by his parents. He wrote of spending the period during which he was serving with the military as a time when he had had luncheons with elderly women in the park. ${ }^{18}$ He spent his Sundays every week eating lunch with his wife and mother-in-law. The Berlin Dadaists mocked him for this. Huelsenbeck and George Grosz thought him to be living in a bourgeois nightmare and considered it, along with his mystical pretensions, grounds for excluding the Merz artist from their social circle.

Schwitters himself felt somewhat stifled by his domestic life, particularly the constant contact with parents and in-laws, and it may be that Merz was a strategy for escaping

\footnotetext{
${ }^{17}$ Donald Kuspit, "Collage: The Organizing Principle of Art in the Age of the Relativity of Art" Relativism in the Arts, ed. Betty Craig (Athens GA: The University of Georgia Press, 1983) 130

${ }^{18}$ Webster, 103
} 
without leaving this environment. ${ }^{19}$ It is Merz artwork that brought Schwitters into contact with the avant-garde scene, and many of his artist-friends described him as behaving differently (with much more joie-de-vivre) at avant-garde art events than he did when they saw him at home. ${ }^{20}$ But Schwitters produced Merz using the waste of everyday life, including, quite often, his own domestic life. This demonstrates Merz as having some sort of ritualistic effect in renewing Schwitters and bringing him out of a domestic environment while maintaining some connection to it. Douglas' argument that contact with the lower materials can bring renewal and protection is evidenced in Schwitters' Merz work and the behaviour that it sanctioned.

Humour and play are two of the most important protective aspects of Schwitters' work. Both forms of levity pertain to ritual, to mythmaking, and to cultural renewal. Humour and play can be ways of breaking down the world and reorganizing it, through language and symbols, thus bringing it under the control of the player. Schwitters' sense of humour was well known and many of his friends credited him with constantly making jokes and playing with words. ${ }^{21}$ Furthermore, his works are full of games and humour that permeate every level of their being. Dorothea Deitrich, in her book on Schwitters, stated that the disparate elements in Merz were fused by play, and the balancing of these materials was a game. ${ }^{22}$ Schwitters' play begins with his name and its appearance in his work. He signed many of his works with 'Kuwitters', a childish mangling of his name, or as "Kurt 'Merz' Schwitters" - intermingling his own identity with the art he

\footnotetext{
${ }^{19}$ Webster. 102

${ }^{20}$ Webster, 105

${ }^{21}$ Webster, 99

22 Dorothea Deitrich The Collages of Kurt Schwitters: Tradition and Innovation, (New York: Cambridge University Press, 1993) 69
} 
produces. ${ }^{23}$ Schwitters' 1921 work, The Cherry Picture (fig. 13), has been interpreted by Adrian Sudhalter to be an odd self-portrait. ${ }^{24}$ The central feature of the work is a card bearing an illustration of cherries under which, in decorative script, the word 'kirchen' (cherries) is printed. Suldhalter says that "Kurtchen" ("little Kurt") was a pet name for Schwitters, and it is likely that 'kirchen' was meant to evoke this name. The interpretation of this image as a playful self-portrait is further bolstered by the fact that it contains other self-references, particularly lines from his poem "An Anna Blume" and the letters "Sch" upside-down in the lower right corner. "Sch" appears in more than one of Schwitters' collages, and is the first phoneme of the artist's name. This is a repetition of the artist's initial cut-up of the word "kommerz", itself an act of play, but with his own moniker used as Merz material (almost as if, as "Kuwitters", he had an 'Sch' scrap leftover for future use). The humour and self-referentiality is akin to how Picasso and Mondrian included 'KUB' in Cubist paintings.

Donald Kuspit, in an essay titled "Tart Wit, Wise Humor", considered Merz to be fundamentally humourous in its exploration of trash, a cultural byproduct that is essentially excremental, as its primary artistic material. ${ }^{26}$ Kuspit's assessment thus intertwines Schwitters' use of humour and play directly with the materiality of Schwitters' works - and hence binds them to the overlapping issues of apocalypse, alchemy and mysticism, and memory. Schwitters, unlike many of his Expressionist peers, (and more like his fellow Dadaists) has chosen to make levity a major component

\footnotetext{
${ }^{23}$ Webster, 59

${ }^{24}$ Sudhalter, 277

${ }^{25}$ Elizabeth Burns Gamard suggests that Anna Blume was an alter-ego for Schwitters. One of Schwitters' collages is the label of the Anna Blume book glued over Schwitters' head and face in a photograph.

${ }^{26}$ Donald Kuspit, "Tart Wit, Wise Humor", 93-101 Artforum International, Vol 13, Issue 1 (January 1991) 95
} 
of his artistic overview and an integral part of his self-construction as a post-WWI artist. However, unlike many of Schwitters' Dada contemporaries, who relied on shock humour as a tactic - which often had the effect of assaulting their audience rather than supplying mirth - Schwitters relies on softer forms of humour, like wit and incongruous imagery.

Humour is profoundly related to issues of protection as it pertains to Schwitters' Merz artwork. Foremost, humour has the effect of being directly protective. Psychologically, and even physically, humour can ease tensions and reduce stress. ${ }^{27} \mathrm{~A}$ fair amount of research now exists on humour, with the most foundational writing on humour's effects likely by Freud. Psychologists Lawrence La Fave, Jay Haddad and William A. Maesen have produced scholarship on laughter's ability to enhance selfesteem. ${ }^{28}$ Freud provides a view of laughter from a morally neutral perspective. He determined that humour is a strategy for an individual to approach tense subject matter without investing too much of the self. If a tense situation persists, then the individual may attempt to negate his or her investment in the situation by explaining that he or she was not serious. If tense subject matter is successfully broached by humour, then, according to Freud, nervous energy is discharged in the form of laughter. ${ }^{29}$ Although later psychologists and other theorists have expanded Freud's views on the effects of humour and laughter, his work is useful for linking laughter and humour as a strategy of protection for the individual.

\footnotetext{
${ }^{27}$ Herbert M. Lefcourt, Humour: The Psychology of Living Buoyantly, (New York: Plenum Publishers, 2001) 143

${ }^{28}$ Lawrence La Fave, Jay Haddad and William A. Maesen. "Superiority, Enhanced Self-Esteem and Perceived Incongruity Humour Theory" Humour and Laughter: Theory, Research and Application, eds. Antony J Chapman and Hugh C. Foot. (Toronto: John Wiley \& Sons, 1976) 63-92

${ }^{29}$ Freud, 101
} 
Henry Lefcourt, a psychologist specializing in humour research at the University of Waterloo, has written extensively about the effects of humour on the human mind and body. Lefcourt had done numerous studies on how tensions are eased by the introduction of levity into a situation. ${ }^{30}$ Lefcourt's studies determine that when humour is used successfully, the effect upon the laughing body is profound: blood pressure is reduced, muscles loosen, and an all around state of relaxation is entered. ${ }^{31}$ Therefore, the potential that humour has to affect the body positively, when effective, makes it an appropriate vehicle for mediating between an ideal and a real world that is heavily divergent from the ideal. Unlike an outright attack, humour has a tendency to put people at ease, literally, and thus makes people receptive to ideas without prompting a counter-attack.

Humour does have the counter-effect, however, of softening the blow of criticism or making criticism appear palatable. Humour is often used as a kind of shrouding for critique - when used effectively it can give levity to the reception of criticism. ${ }^{32}$ William Willeford noted in his book on the history of clowning, The Fool and the Sceptre, that the fool at court, who was effective at the use of humour, was given a certain unwritten license to speak of things that were taboo to others. The 'fool' was actually a joking philosopher, or social critic who could give offense as long as they were amusing. An effective use of humour to obscure the truth he speaks was at the heart of this critique leading to a double wrapping of protection: the positive effects humour can have on the

\footnotetext{
${ }^{30}$ Lefcourt also uses extensive anecdotal evidence, citing stories in which jokes have been used to ease tensions between people who are otherwise in discord with one another.

${ }^{31}$ Lefcourt, 142

${ }^{32}$ Studies however, have also been conducted on the effect of bad humour - done with the intention to offend. This often causes anger and rage in the recipient, who is often inflamed both at the criticism and further enraged by being made the object of fun. This was the tactic of many of the Dadaists and Futurists whose use of humour was often to insult the audience directly - hence causing rioting at many of their performances.
} 
listener, even if he is the object of criticism lying in the joke, and the obscuring effect of the ambiguous use of language inherent to humour. ${ }^{33}$

Schwitters had good reason to employ humour in his Merz work. The Weimar Republic was a privileged time and place at which to work as an artist, and Schwitters found a place in the new artistic climate. The new republic had many, many problems however, stemming from the First World War and its aftermath. The post-war years were characterized by heavy discord: labour unrest, food shortages, government corruption, and currency inflation plagued the populace and, as a byproduct, nurtured extreme political factions. Anarchists, Communists and Nazis thrived in this climate, and violence was common between these movements, some of which had paramilitary wings specifically to engage in street fighting with rivals. ${ }^{34}$ References to many of these issues appear in Schwitters' work, but he used humour to comment upon them in subversive ways. The most prominent example of this was his use of money in his images. During the period of inflation, Schwitters often used banknotes as a colouring agent in his work. This was a humorous response to the inflation, and implied the notion that the colourful bills were 'not worth the paper they're printed on.' Schwitters assigned a new kind of value to the bills that were incongruous with their original purpose but logical under the socio-economic circumstances. Schwitters had already suggested that Merz, in a general sense, is an art to respond to post-war scarcity of resources - thus intertwining Kuspit's assertion of Merz as basically humourous because it uses trash, to the post-war economic realities of Weimar Germany. Also his 1919 work Das Sternenbild places words, clipped from a newspaper article about a case of corrupt government officials and Freikorp

\footnotetext{
${ }^{33}$ William Willieford, The Fool and His Scepter: A Study in Clowns and Jesters and Their Audience, (Northwestern University Press, 1969) 133
} 
bloodshed, upside-down above the central 'star' in the sky. Schwitters is using his ability to maneuver words in his images to distance those events from the ground, creating an incongruity between the corrupt current events of the time and the celestial imagery.

The extremist movements that found support in the wake of Germany's loss did so by claiming that Germany had lost its moral direction. Such claims were supported by calling into question the value of the arts. In particular, the art of the avant-garde was particularly questionable for its moral deviancy and - due to the influence of texts like Nordau's 'Degeneration' - for the alleged genetic degeneracy of its creators. As such, artists of the avant-garde represented moral and genetic decay before World War One, and could thus be easily scapegoated as a source of the internal weakness faulted for Germany's loss. Then, after the loss, artists like Dix and Grosz mocked the veterans and the Germany military system, seemingly finding joy in defeat and contributing further to the nation's decline.

Laughter can be a way to resist social order or subvert it. Despite the pretense that Weimar Germany was privileging artistic freedom over warrior fervour, the dominant artistic mode was of seriousness. Even among the Dadaists prone to mocking the political system, like the members of Huelsenbeck's Club Dada, seriousness was prevalent, as the movement was primarily concerned with advancing a Marxist ideology. While works like Das Sternenbild make reference to political turmoil, works such as The Alienist (fig 8) subvert the serious in art. Schwitters painted the image of his wife, in profile, surrounding her visage with Merz objects. Much of Schwitters' income throughout his life came from painting portraits, often by commission, and by merz-ing a rendering of his spouse he could subvert a serious tradition without consequence. 
Adding a bit of detritus to the canvas subverted the portrait, bringing levity to a rendering of a serious personality. Additionally, Schwitters pursued this avenue by using reproductions of famous paintings and Merzing them.

An analysis of Merz as humourously protective may be assisted by exploring some of the ideas expressed by Russian philosopher Mikhail Bakhtin in his 1965 book, Rabelais and his World. Bakhtin, working in the USSR, thought of humour, laughter, play and the grotesque as having the ability to disturb established orders and bestow power upon the joker. Drawing on the absurd stories of Pantagruel and Gargantua by medieval French writer, Francois Rabelais, Bakhtin examined a number of subtle modes of cultural subversion he categorized as the 'carnivalesque'. The carnival is the 'world turned upside down' - the temporary reversal of social order that brings about cultural renewal through a collective expression of joy - all are equal, but the poor would pretend-play as the aristocracy, and vice versa. Under the "carnival spirit", a system of joyous reversal, images of destruction actually refer to rebirth, and death refers to regeneration. ${ }^{35}$ Laughter in this spirit is not meant to be mocking, as with the work of many Dadaists, but rather has a "relatively whole character, and is related to the entire living process, to both its poles. The triumphal tones of birth and renewal can still be heard." ${ }^{36}$ Bakhtin notes that festivals of renewal, such as the Saturnalia festivals of ancient Rome (or modern New Years' events), are joyous occasions that directly link laughter with cultural renewal. ${ }^{37}$ The carnival presented a temporary space where a group would return to its origins. Schwitters' work carried the themes expressed by

\footnotetext{
${ }^{35}$ Mikhail Bakhtin. Rabelais and his World, trans. Helene Iswolsky, (Bloomington IN: Indiana University Press, 1965), 217

${ }^{36}$ Bakhtin, 64

${ }^{37}$ Bakhtin, 70
} 
Bakhtin as carnivalesque: collectivity, play and laughter, equilibrium, emphasis on the 'lower-strata' and the potential for reversal. ${ }^{38}$ Under Merz the world is turned upsidedown and is thus renewed. The Rabelaisean carnival upon which Bakhtin bases his theories were characterized by the rich posing as poor, 'king-for-a-day' events, an emphasis on bawdy behaviour and decadent abundance. ${ }^{39}$ Schwitters' work contained all of these elements.

It is important, in a discussion of Schwitters and the carnivalesque, to acknowledge Schwitters' two lives - the boisterous provincial avant-garde artist, and the quiet, middle-class family-man who respectfully ate lunch with his wife and mother-inlaw by the garden on Sundays. The Club Dada members found Schwitters objectionable, in part, because they witnessed both sides of the artist and found the latter to be detestable. ${ }^{40}$ But Webster notes that Schwitters behaved differently around his fellow artists than he did when he was with his family - often wisecracking, telling corny jokes, being loud and flamboyant, and speaking in a strange manner mixing Hanoverian vernacular dialect with off-the-cuff wordplay and childish prattle. This is important to the idea of the carnivalesque, because the carnival was a setting in which one's normal social role was subverted. Merz was the carnival of the self, into which Schwitters escaped from his daily domestic life.

The carnival as a form of polyvocal subversion of the established order is also of fundamental importance to Schwitters' work. For Bakhtin, the carnival was a place

\footnotetext{
${ }^{38}$ Schwitters produced in 1947 a collage he titled Carnival (fig 31) that adheres precisely to Bakhtin's definition of the term. The most prominent feature in the work is a young woman smiling (expressing the 'carnal' element) with a scrap covering her eyes (masquerade). Furthermore, Schwitters cut up the word 'carnival' in the lower-left part of the collage, to display only "an...al", thus referring to the lower strata of the body that Bakhtin emphasizes so thoroughly in his theory.

${ }^{39}$ Bakhtin, 81

${ }^{40}$ Huelsenbeck, 146
} 
where many people could collectively express themselves in a manner that is opposed to the dominant order without explicitly speaking against the dominant order. This occurred through role-play (role reversal), travesties (wearing of clothing beyond one's own station) and humour referring to the body's lower strata. ${ }^{41}$ Although Schwitters worked alone as an artist, he, like Bakhtin's Rabelais, infused his work with a full sense of the carnival. His work can be thought to give rise to many voices by its found materials; the printed material of an entire culture may be found in his work - as anything could conceivably be merzed. Furthermore, the materials have all been used. They speak of being handled by hands other than the artist's and they speak of being discarded and found. Schwitters makes unknowing participants, then, of those who contributed to his art by handling and throwing away his materials before they are set into art. It is therefore difficult to know, if his collages made from torn papers were torn by him or if they were found in such a state. ${ }^{42}$ But Schwitters subverts them through his playful editing and placement on his work, so that they speak not only of the dominant culture but also in the ways Schwitters determines, which are often in opposition to the original context. Hence, Schwitters' art has affinities with the Carnivalesque. Also Schwitters attempted to blend every conceivable art style - so just as the low culture can be found in his work, so can the culture of high art - from Expressionism to Dada to Constructivism. Schwitters' millenarian view of the post-war world divided it into spheres of art and non-art. For example, Schwitters declared, in opposition to the Club Dada point of view, that art should not be political, for one could not serve two masters. Politics falls within the boundaries of the real, while art, especially the newly emergent trend of

\footnotetext{
${ }^{41}$ Bakhtin, 64

${ }^{42}$ Schwitters did have a predilection for tearing his paper matter, but he also clearly showed a penchant for using materials that bear signs of wear and decay.
} 
abstraction pursued by Schwitters, transcends the real. Merz reconciles the 'real-world' with Schwitters' millenarian vision through using materials from the every-day. The matter of play then comes into the equation of Merz. Play is easily connected with humour, as the two forms often overlap and humour may even be categorized as a subset of play. But play in the Merz context has a place beyond humour. Play can be thought of as virtually any joyful activity done voluntarily. ${ }^{43}$ There is reason to believe that Schwitters saw Merz primarily as a form of play. Although he sold some Merz works, largely through his relationship with Herwath Walden, as the 1920s continued he had difficulty selling the collages. He relied on his other businesses, such as advertising and typesetting, to provide for himself and his family. ${ }^{44}$ For Merz to be protective it was necessary that it existed as a field of play for the artist, not a luxury item for the rich. In 1946 Schwitters wrote to Raoul Hausmann: "A game we play with serious matters. That is art. ${ }^{, 45}$ Play, as an activity, often has a ritual element to it rooted in the concept of re-enactment. ${ }^{46}$ Consistent with other forms of ritual, it may often be a form of re-enactment of an event or it may be a form of event preparation. Many of the games played by the First Nations peoples of North and South America, for example, are rituals that revolve around themes of death and renewal. ${ }^{47}$ Similarly, children often pretend to be grownups and play grown-up activities as a form of preparation. Many children's games are ritualistic re-enactments of events that have occurred. Children pretend-play war, acting out battles based on historical models. Such forms of play may bridge

\footnotetext{
${ }^{43}$ Roger Caillois, Man, Play and Games, trans. Meyer Barash, (New York: The Free Press, 1961) 6

${ }^{44}$ Before the Nazis, Schwitters was handling some fairly lucrative advertising clients via his business.

${ }^{45}$ Schwitters, as cited in Schmalenbach, 103

${ }^{46}$ Steven J. Fox, "Theoretical Implications for the Study of Interrelationships Between Ritual and Play" Play and Culture, ed. Helen B. Schwartzman (West Point, NY: Leisure Press, 1980) 54

${ }^{47}$ The essay "Play as Life: Suggestions for a Cognitive Study of the Mesoamerican Ball Game" by Robert L. Humphrey, examines how a dangerous ballgame, called Tlachitli, played by the Mayans, was a ritual of life, death, rebirth and the movements of celestial bodies.
} 
between preparation and repetition. Merz, a form of play with cultural materials, lies in between the two dominant forms of ritual-as-play. J. Huizinga, in his book Homo Ludens, considers creativity and mimesis forms of play, but struggles with the notion that painting and sculpture are play. ${ }^{48}$ Huizinga said that painting had no visible action, was fixed in matter, and was the product of labour - all factors that prevent art-making from being considered play. But Huizinga also states that if art is made as ritual, then it is play, because ritual and play are closely linked. ${ }^{49}$ And Huizinga asserted that one of the purposes of play was to go "outside the reasonableness of practical life." 50 Schwitters meets the criteria of ritual and escape with his work, as he declared Merz a form of prayer in 1920, peppered his work with religious signifiers, and espoused the merits of nonsense. Also, Huizinga considers the impulse to decorate with art a form of play; an impulse that Schwitters indulged often when decorating household objects, and the house itself with the Merzbau.

According to the two most important theorists of play, J. Huizinga and Roger Callois, play temporarily opens up new spaces in which it occurs. They determine that the rules of play allow it to create a second reality in which the players operate. ${ }^{51}$ Huizinga cites an example wherein this alternative is protected from disruption. When he watched his son play with toy trains, the son said "don't touch the engine or the passengers will know its not real", ${ }^{52}$ Huizinga notes that this statement establishes that an alternative reality exists in his son's play, but also that there is an acknowledgement that this alternative is not real. Schwitters has an analogous experience. With the rise of

\footnotetext{
${ }^{48}$ J. Huizinga, Homo Ludens: A Study of The Play-Element in Culture, (Boston: Beacon Press, 1950) 166

${ }^{49}$ Huizinga, 167

${ }^{50}$ Huizinga, 158

${ }^{51}$ Callois, 7

${ }^{52}$ Huizinga, 8
} 
the Nazi party, Schwitters largely ignored the political climate of Germany, and this was achieved by making Merz an apolitical art. In his Merz magazine, he wrote of the ANKP, the Anna Blume Party of Germany - an obvious farce on German politics by citing his own Anna Blume (a perpetual metaphor for Merz and on occasion, for himself) as the namesake of a political party. This playful satire was another way of expanding the sphere of Merz Schwitters had created around himself, as even though Anna Blume was famous, the name held no relation to politics and meant little to others. Ultimately however, Schwitters, at the behest of his wife, Helma, acknowledged that Merz was the realm of play, and as a prelude to ultimately leaving for Norway, Schwitters begrudgingly joined the Social Democratic Party of Germany. Schwitters joined because Helma was concerned for Germany and for her husband (vulnerable as a life-long epileptic and as an avant-garde artist) and felt it was important to join the opposition. So Schwitters had to be prodded into acknowledging the real-world crisis that threatened his Merz realm, before temporarily giving up his protective Merz-play.

Play was strongly manifest in one particular tendency of Merz that ran through Schwitters' career. Schwitters merged styles but he also played with art history's canon, merzing popular, official or famous images. Some images were merzed prints of Renaissance or Baroque masterpieces, including Raphael's Madonna and Child (fig 32) and Correggio's Holy Night (fig 33). With these works, Schwitters is playing with images of significance to the history of art - and with explicitly religious imagery. $\mathrm{He}$ blended representations of some of the most important moments of Catholic orthodox belief, and the most revered works of art history, with bits of ribbon and travel documents. The play-ritual-art matrix Schwitters creates here evokes a new kind of 
transcendence and spirituality, as the Magi and animals are replaced with detritus from everyday life. Sociologist Peter L. Berger discusses humour, play and the spirit in his analysis of religion and modernity, A Rumour of Angels. Berger suggests that humour, as an incongruity, can bridge distances between disparate and distant realms, and also that the comic "reflects the imprisonment of the human spirit in the world."53 But for Berger, humour can be a way of transcending this imprisonment by laughing at it. Schwitters left the central religious features intact while playing with the periphery to subject the original image and meaning to his own vision of the Merz world as a modern transcendental art rooted in forms of play. It should be noted that while Huizinga and Callois state that the rules of play open up a space that is outside of normal reality, this colludes with Eliade's concept of religious ritual opening up a spiritual space that exists in the same state as that of play.

Finally, Schwitters' work is significant for reconciling divisions in art of his time, and bridging stylistic categories. This helps to establish Merz as a space that is unique to Schwitters by evading artistic spaces that have already been heavily colonized by the ideas of other artists - which was a common theme in the manifesto-laden avant-garde of the period. It also establishes Schwitters as something of both a shaman and a trickster figure, two archetypal figures that possess the ability to navigate between realms and show mastery over them. Although the shaman and trickster can often be read as

\footnotetext{
${ }^{53}$ Peter L. Berger, A Rumour of Angels: Modern Society and the Rediscovery of the Supernatural, (Baltimore, MD: Penguin Books, Inc. 1971) 90
} 
opposites, they are conflated in the work and actions of Kurt 'Merz' Schwitters, who can be thought of as the 'wise fool'. ${ }^{54}$

Bakhtin's theory of the grotesque may be drawn upon to provide a foundation for examining Schwitters as a trickster. The grotesque, to Bakhtin, was more than the ugliness, deformity, and exaggeration of the body to which the term is often applied. Bakhtin defined the grotesque as the "topographical element of the bodily hierarchy turned upside-down." 55 The grotesque uses the "logic of opposites, the contact of the upper and the lower level," although the emphasis is placed on this lower level. ${ }^{56}$ But the lower level can be spiritually powerful in this system:

The grotesque body is cosmic and universal. It stresses elements common to the entire cosmos: earth, water, fire, air; it is directly related to the sun, to the stars. It contains the signs of the zodiac. It reflects the cosmic hierarchy. This body can merge with various natural phenomena, with mountains, rivers, seas, islands, and continents. It can fill the entire universe. ${ }^{57}$

This ability for the grotesque body to accommodate everything is similar to Schwitters' concept of Merz, which may also absorb everything into it. For Schwitters, the grotesque also overlaps with his sense of humour, play and with his alchemical tendencies, in that it is the bringing in of trash to the realm of high art and avant-garde painting. The "logic of opposites" means that the upper strata of the body are made impure by the lower strata, and thus there is an emphasis on the body's ejecta as it emanates from this high-low blending. The ejecta of the body that emanate from the orifices of the body's lower half connect the body to the external world. Conventionally the body appears to the viewer as a self-contained unit, and a pristine vessel, especially given many quasi-spiritual notions

\footnotetext{
${ }^{54}$ The 'wise fool' is a trope that appears in folklore, esoterica, and literature throughout history. The 'wise fool' is a figure whose laughter and joking reveal truths and whose clumsy actions yield beneficial results. Examples include the 'Fool' card of the Tarot, and the jester of Shakespeare's play, King Lear.

${ }^{55}$ Bakhtin, 309

${ }^{56}$ Bakhtin, 309

${ }^{57}$ Bakhtin, 318
} 
of the human body as a copy of God. With the grotesque, however, the body comes into contact with the world around it through the functions that can be thought of as disgusting or unseemly. Furthermore a human is a duality of spirit and body - often thought of as upper and lower strata - but the grotesque confounds this duality, uniting the two realms into the reality of a unified human that interacts with the world beyond itself. The result is thus that the status of the two strata is not reversed, but brought into some accord. The upper is reduced, but also the lower is raised so that it may have some kind of spiritual resonance. Schwitters' work was grotesque in the Bakhtinian sense.

The tendency to view works of art as self-contained units was even further entrenched once abstraction was introduced and paintings lost their referential component. Artists like Kupka, Kandinsky, Mondrian, and Arp, who pursued a path of total abstraction, aspired to ascend fully above earthly things. Their art represented the unseeable impressions of the spirit and the inner-world of imagination through art and colour. Their art could be read as an analogue for the pristine upper strata of the body (i.e., as spirit). Merz was an exploration in abstraction every bit as spiritually guided as that of Kandinsky or Mondrian, but pristine abstraction is subverted by Merz's grotesque element, the found materials used - the merz/merde. Already imprinted with this worldly significance, the scraps interconnected ideas of spirituality and abstraction with everyday life that extend beyond the frame of the images.

This strong sense of the grotesque connects Schwitters to the trickster archetype. The trickster is a figure in mythology whose significance lies in transgressing the boundaries thought to be firmly set in a culture. Often through following his or her own self-interest, the trickster demonstrates the possibilities of alternatives to the established 
categorical boundaries of a society or culture. Schwitters' use of the grotesque transgresses and hybridizes the categories of various artistic styles to open up realms of art that exist between them. It is this ability to move between realms of art (not just between Expressionism and Dada, but also between other binaries, such as objective and abstract) and therefore other realms of culture that gives Schwitters his resemblances to the trickster, but also to the shaman ${ }^{58}$ Both the figures, traditionally, are capable of moving between realms of spirit and matter - dichotomies that are encapsulated and bridged within Schwitters' art. Each figure serves a different purpose and Schwitters' work and actions reflect both of them.

In Lewis Hyde's analysis of the trickster figure in both myth and reality, Trickster Makes this World, he notes a number of important traits of the trickster that are important to Schwitters' career in Merz. They are the tendency to wander aimlessly, the lucky find, imitation, and the already-discussed emphasis on grotesque humour. These traits of the trickster suggest a willingness to accept chance and random events, as well as a strong concern for his own well-being. The traits establish the trickster as resourceful and bearing wisdom that pertains to not knowing (the "wise fool" again). These activities of walking and finding open up new opportunities for the trickster, endowing the figure with "the wit to work with happenstance." $" 59$ Dealing with chance is one of the main categories of play, 'alea', according to Roger Callois, and is an important factor to Schwitters' works, which were composed constructions made from materials often discovered by

\footnotetext{
${ }^{58}$ Schwitters never stated that he was influenced by primitive peoples the way many of his contemporaries were. This section of the thesis is intended only to suggest that Schwitters' life and work were similar in form to the forms of shamanistic and trickster figures in stories and scholarship on those figures.

${ }^{59}$ Lewis Hyde, Trickster Makes this World: How Disruptive Imagination Creates Culture, (New York: Canongate, 1998) 96
} 
chance. ${ }^{60}$ Despite Raoul Hausmann's anecdote, cited earlier, about Schwitters searching his materials for a scrap of blue paper; the consistency with which Schwitters actually 'composed' his collages is unknown. It has been suggested by art historian Christian Janecke that some works were far more given to chance and accidental juxtaposition of the materials than others; and Schwitters would not have carefully planned out every collage. $^{61}$

Ultimately, what is noted by Lewis Hyde and other scholars who have written about the trickster is that the trickster often transgresses through imitation of the rulemaker. Often this is an imitation of the shaman. ${ }^{62}$ Lewis Hyde, for example, suggests that the trickster can only imitate. ${ }^{63}$ It is through this imitation and mimicry (according to Callois, mimicry is one of the most basic forms of play) that the trickster actually, if temporarily, becomes that which is being imitated, only to open up the boundaries defined by the authority even further. Schwitters was an imitator and much of his work was rooted in mimicry. For example, he followed in the model of the various other contemporaneous radical art movements even though he worked as an individual. This included the taking of a movement name, publishing a journal, issuing communiqués and manifestoes, hosting performances, producing works of art in a variety of formats, and, occasionally, communicating with the media. This mode of operation had been taken up by the Italian Futurists, the De Stijl artists, the different Dada factions,

\footnotetext{
${ }^{60}$ Christian Janecke's article Schwitters and Chance examines at length the role chance played in the Merz collages. Janecke acknowledged chance as an elusive element in his work, suggesting that the distance in time between now and when the works were originally produced may obscure chance as a guiding method of artmaking because the fragments all appear to bear witness to a particular period.

${ }^{61}$ Janecke, 174

${ }^{62}$ Mac Linscott Rickets, "The Shaman and the Trickster", 85-105 Mythical Trickster Figure: Countours, Contexts and Criticisms, eds. William J Hines and William G. Doty, (Tuscaloosa AB: University of Alabama Press, 1993)

${ }^{63}$ Hyde, 43
} 
and the Expressionist groups. Schwitters had done all this in emulation of other groups, but did it as a single artist. Hence, unlike many of the artists of other movements who left their original milieu, (such as Tzara or Carrà), there are no differences between Kurt Schwitters the artist and the Merz movement. Schwitters eventually signed his name, Kurt "Merz" Schwitters, and an advertisement for a Merz show displays the formula 'Kurt Schwitters $=$ Merz', declaring the two to be the same. Merz is thus the earnest expression of a trickster imitating the avant-garde milieu as a strategy for self-expression and self-expansion. Schwitters, a single artist, found a space between two dominant artistic tendencies and occupied it, imitating all of the forms of the major art movements, incorporating into it the other major trickster traits, the lucky find and aimless wandering, but also shamanic traits of symbolic danger and connection between realms. Furthermore, interlocking with these forms are ideas of renewal and polyvocality, the grotesque and alchemy, humour and play, which all fall under the rubric of protection that is primarily of importance to Schwitters himself. The trickster, seeking selfpreservation, transgresses boundaries by evading authorities' efforts to preserve them.

Kurt 'Merz' Schwitters' work and methods had, in addition to the trickster affinities, parallels to its archetypal converse, the shaman. Broadly speaking, the shaman is a specialist in mediating between the spirit and material worlds; a mortal figure with extra-ordinary abilities. The shaman was responsible for leading the rituals of healing and cultural renewal, while the trickster is primarily responsible for his own well-being. Here there are the tensions that exist in Schwitters' work and are difficult to resolve without thinking of Merz as a conflation of the shaman and trickster archetypes. With the beginning of Merz, Schwitters was trying to rebuild the world from its fragments, 
following a destructive event. Thus he was attempting to actualize his post-apocalyptic vision for all, from the used, fragmented objects of the social collective. Schwitters was attempting a broadly healing act, but essentially he was using external objects to heal the self. ${ }^{64} \mathrm{He}$ had both shamanic and trickster motivations, as it were.

Mircea Eliade, in his study on worldwide shamanistic practices, Shamanism:

Archaic Techniques of Ecstasy, determined a few consistent elements to global

shamanism that are also present in Schwitters' work. Foremost among them is the ability to mediate between the spiritual and material planes of existence:

Healer and psychopomp, the shaman is these because he commands the techniques of ecstasy... Through his own ecstatic experiences he knows the roads of the extraterrestrial regions. He can go below and above because he has already been there. ${ }^{65}$

In Schwitters' art this is exemplified by his use of found materials to imagine spiritual meaning, and overlaps with a sense of the grotesque and alchemical in his work.

Second is the process of initiation in many shamanic cultures, wherein the novice passes from being a normal member of the tribe into becoming a shaman. The initiation rituals overlap with many of the consistent themes of apocalyptic rhetoric, and involve a ritual death and rebirth and a ritual encounter with the spirit world. ${ }^{66}$ One of the key features of shamanic initiation rites is for the initiate to be metaphorically/ritualistically broken down and then reconstituted from the past fragments of the self. The rituals of initiation renew the self, and renew the community by providing them with a new shaman. The purpose of such renewal is to repair the world and to return to the

\footnotetext{
${ }^{64}$ It has been widely speculated by scholars of shamanism such as Nevill Drury that the shaman was a mentally ill member of the tribal unit, therefore gifted with a sense of vision above that of other members. Schwitters' epilepsy would thus connect him to the shamanic tradition in this regard, as his seizures would send him into trance-like states for hours at a time

${ }^{65}$ Mircea Eliade, Shamanism: Archaic Techniques of Ecstasy, trans. Willard R. Trask. (New York: Pantheon Books, Inc. 1964) 182

${ }^{66}$ This kind of ritual death is also echoed by the writings of Dadaists Max Ernst and Hugo Ball.
} 
perfection of the beginning. ${ }^{67}$ Merz was, conceptually at least, a reconstitution of the fragments of a culture that had already been broken into parts. Furthermore, the short story, Der Zweibel, which Elizabeth Burns Gamard identified as being alchemical, is also, in its story of dismemberment and supernatural reassembly, a parable of shamanic initiation. ${ }^{68}$ The newly initiated shaman, fresh from a spiritual death and rebirth, is enabled to move between worlds and can assist in the guidance of his community within the boundaries of its spiritual parameters. It is significant, then, to consider that Dorothea Dietrich interpreted the story as being autobiographical. ${ }^{69}$

Schwitters' work with fragmented objects contains some parallels to the traditional shamanic ritual as described by Eliade. Schwitters nurtured a complex and knotted relationship among his artwork, himself, and the outside world that is clearly rooted in his use of fragmented objects. The objects he used were important to the external culture, and to his everyday life, and his merzing of them was a kind of shamanic ritual of himself and apocalyptic for the community. Merz was a rebuilding of the world after its fragmentation by the intense violence of the First World War - but the root of Schwitters' fragmentation was the fragmentation of the self. Merz was a reconstitution of fragments in juxtapositions that were absurd, setting objects into balance with one another where they would have no place in a previous construction of the world; or, in other words, in the non-Merz external world. The trickster could redraw cultural boundaries, but the shaman was the master of cultural renewal and a return to origins.

\footnotetext{
${ }^{67}$ Eliade, Myth and Reality, 51

${ }^{68}$ Kurt Schwitters "Der Zweibel", 121-127 PPPPPP: Poems Performance Pieces Proses Plays Poetics, eds $\&$ trans. Jerome Rothenberg \& Pierre Joris, (Cambridge, MA: Exact Change, 2002)

${ }^{69}$ Dietrich, 74
} 
According to Eliade, this was one of the shaman's chief roles in society. ${ }^{70}$ Schwitters was concerned with a return to origins, a theme that repeated through his writing, especially in his 1920 text, Merz, and his letters to Raoul Hausmann after WWII. As an elaboration of his view of renewing society with its fragments, it is a return to origins, but more specific works carry forth this theme as well, particularly his 1923 sound poem $U r$ Sonate, which blends Dada letter-poetry influenced by his friend, Hausmann, with the traditional structure of the sonata. ${ }^{71}$ The result is a patterned chanting of vocal sounds that, when performed in full, takes almost an hour to recite. The 'ur' component of the work's title is the German prefix meaning 'original' or 'primitive'. Rudolph Kuenzli wrote disparagingly of the Ursonate that Schwitters was regressing by blending the avant-garde sound poem with the traditional form, but although this act may have diverged from the Dadaist anti-art goals, it was consistent with Schwitters' views and methods. ${ }^{72}$ The sonata structure is the residue from the pre-war milieu from which Schwitters constructed his Merz poem. Furthermore, the sonata structure meant that the work would follow a rigid pattern, made from vocalized sounds, that bears similarity to the drum and chant sessions used by traditional shamans to achieve trance states. ${ }^{73}$

The initiation rite of shamans had a dual effect. The first was to renew the self as a being in touch with multiple realms of existence. The second is to renew the self as a being intricately woven into the fabric of the greater collective, so that the shaman

\footnotetext{
${ }^{70}$ This function of the shaman is articulated in Eliade's chapter, "Shamanism and Cosmology" in Shamanism: Archaic Techniques of Ecstasy, 259-287.

${ }^{71}$ Kurt Schwitters "Ur Sonate", PPPPPP: Poems Performance Pieces Proses Plays Poetics, eds \& trans. Jerome Rothenberg \& Pierre Joris, (Cambridge, MA: Exact Change, 2002) 52-79

${ }^{72}$ Rudolph E. Kuenzli, "The Semiotics of Dada Poetry" Dada Spectrum: The Dialectics of Revolt, ed. Stephen C. Foster and Rudolph E. Kuenzli, (Iowa City, IA: The University of Iowa, 1979) 51-70

${ }^{73}$ Ironically, the Dadaist with the strongest interest in shamanic tribal ritual was Richard Huelsenbeck, who, according to Annabelle Mezler, often did drum performances at the Dada Cabaret nights, and referred to himself as a 'Dada drummer' in the title of his memoir. It is probable that he was uninterested in the mystical aspect of tribal drumming, however, as he was Schwitters-the-mystic's most vocal critic.
} 
becomes the point at which all are connected. And this is done by the shaman being both matter and spirit, and the community being connected at a meta-level by the spirit world and the intermingling of everyone's ancestral spirits who communicate through the shaman. The skilled shaman then provides his people with a veil of spirit protection. Schwitters makes this connection between the self as renewed and as a part of the greater society through the materials he uses. Through the fact that they are fragmentary scraps and discarded objects, they are imbued with a certain life - and the fact that Schwitters has 'found' them implies a certain 'death' to the object after they are discarded following their intended use, and thus reborn, with traces of their cultural significance intact, as art materials. Schwitters is not in touch with a spirit-realm, per se, at least in a traditional sense. But rather this use of materials as a shamanic mastery over realms overlaps with Mary Douglas' theories about dangerously impure materials being made ritually pure, with alchemical readings of his work, and also with the mystic-pantheist understanding of Jacob Böhme who, in texts like The Signature of All Things, espouses a life force that exists in all objects and aspires towards transcendence. In the use of materials that pertain to his external environment, in an art form that is uniquely his, Schwitters weaves a spell that is both personally and broadly protective through art.

While the shaman puts himself at risk with the spiritworld in order to help others, the trickster is primarily concerned with his own satisfaction of needs. The trickster and shaman are often portrayed as contradictory archetypal figures, with the shaman providing spiritual boundaries to the group, and the trickster transgressing those boundaries and thus establishing that breaking the rules may have positive effects for the group. Schwitters bears aspects of both, and each can, perhaps, be correlated to the two 
prevailing tendencies in his art. The painterly mysticism of the expressionists (especially as Schwitters primarily draws inspiration from the modern mystic Blue Rider painters) is the shamanic aspect, while the play with words and found forms is drawn from Dada inspiration and serves to suggest the trickster element. These tendencies are balanced in his Merz works, so as not to suggest he is lampooning either art movement with pastiche. Rather he is honestly combining the play and mysticism into a single art form, whereas the Dadaists and Expressionists largely kept such forms separate. Schwitters is not out to use Merz as a vehicle for critiquing Dada or Expressionism, but is rather emphasizing what he finds useful and compelling in each movement. Whether he realized it or not, I believe he wanted to be a shamanic trickster.

Merz as an array of found objects and artistic styles took the appearance of being harshly avant-garde, and explicitly interested in shock. The Dadaists, whose stated aims were to shock their audience, rarely used rubbish to construct their works. Encoded into Schwitters' seemingly anarchic gesture of mixing detritus on a pictorial plane with contemporary styles of painting is a complex matrix of spiritual ideas and cultural undercurrents. Humour and play, the carnivalesque and the grotesque, apocalypse, alchemy and rituals of purification: these forms are all present in Schwitters assemblages. Furthermore, these undercurrents all interact to inform Merz as a protective art form, one that functions on a variety of levels. They exist at the level of activity - i.e., in the process of collecting materials and constructing the works - but also at the iconographic level and in Merz's most fundamental premise of art made from detritus. 


\section{Conclusion}

Over the course of this thesis, I have sought to argue that Merz served as a form of protective magic for Kurt Schwitters. It also had a potentially more social function, as it converted arguably ugly fragments of the old into a beautiful and harmonious aesthetic unity. With some frequency, this general principle of making gold from shit (to reiterate the alchemical analogy) was reinforced with iconography drawn from belief systems such as alchemy, magic, astrology, Theosophy and Christianity. What these systems have in common is the conviction that their adherents will attain a better world or higher state. Most also believe that the initiated will be protected by a higher force or wisdom than would be the case with the uninitiated. Like many of his contemporaries, Kurt Schwitters assigned a spiritual function to art and a spiritual role to the artist. Unlike most of these contemporaries, he also treated art as a personally protective talisman. His art had serious beauty and spirituality, but often it first looked like a witty or silly agglomeration of trash. Merz bridged high and low, spirit and matter, the sacred and the profane, seriousness and silliness. For this reason, I likened Kurt Schwitters to a conflation of shaman and trickster, and to the "wise fool."

I am deeply indebted to other scholars' biographies of Kurt Schwitters, to their studies on his art historical debts and contacts, and to their stimulating attempts to interpret individual pieces by Kurt Schwitters (I mention alchemy and the Merzbau only briefly in my thesis because of their centrality to Burns Gamard's Kurt Schwitters' Merzbau). I have isolated pertinent works of others to advance what I hope is an original and viable thesis as to the function of Kurt Schwitters' merzworks as a whole: namely, as a post-apocalyptic art that offers protection, like Noah's rainbow, from a recurrence of 
apocalypse (or, more prosaically, as a talisman against bad things). Hence my term, "merz magic." 


\section{Figures}

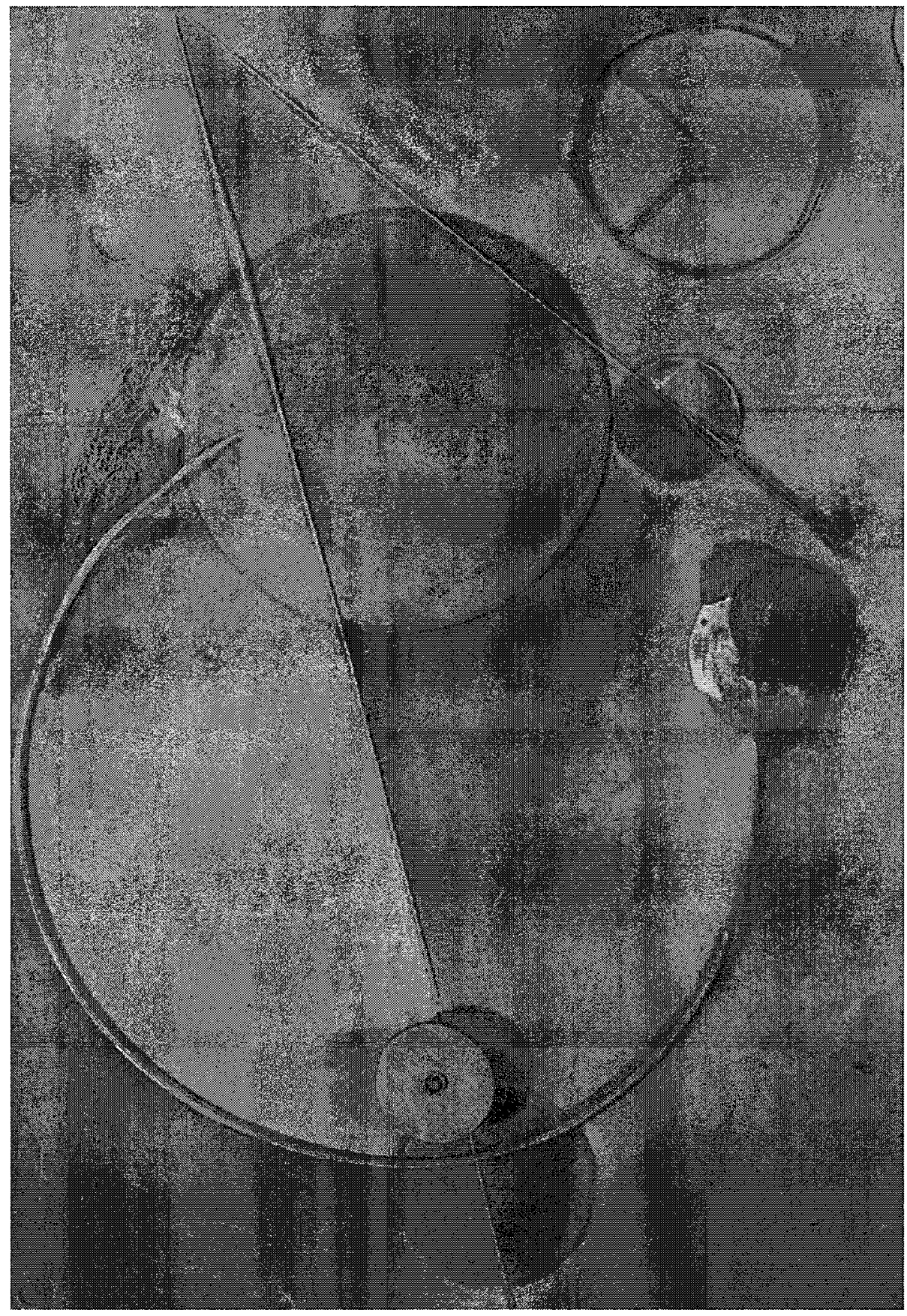

Fig. 1

Kurt Schwitters

Das Kreisen

assemblage

1919 


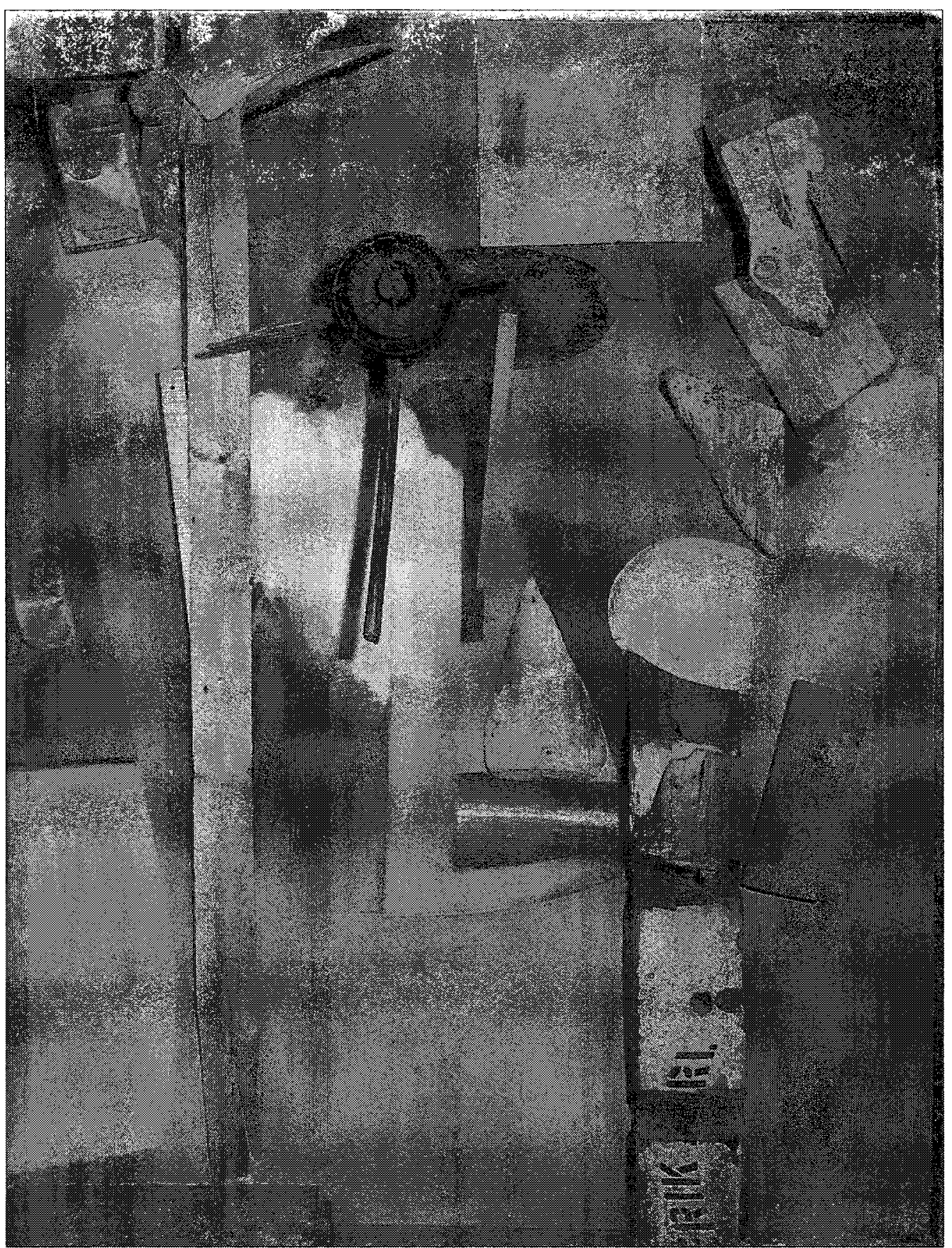

Fig. 2

Kurt Schwitters

Merzpicture With Rainbow

assemblage

1939 


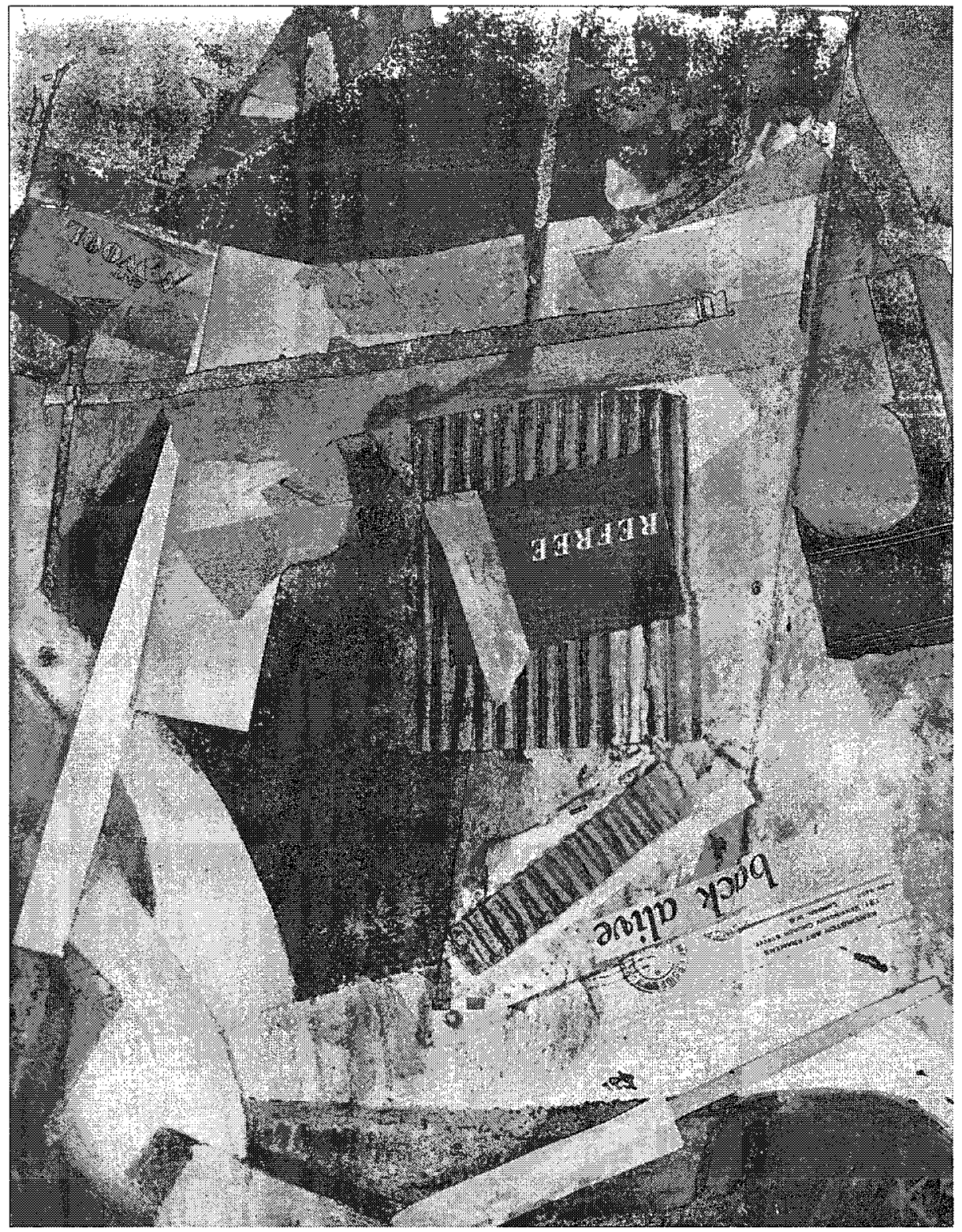

Fig. 3

Kurt Schwitters

Carefree

assemblage

1947 


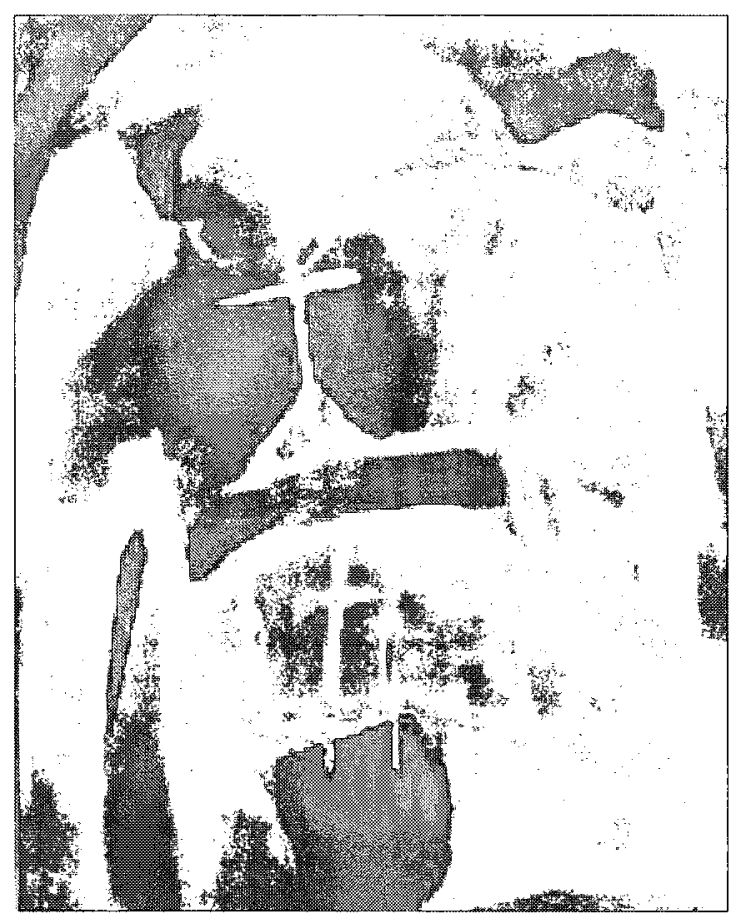

Fig. 4

Kurt Schwitters

Mountain Graveyard

Oil on canvas

1918

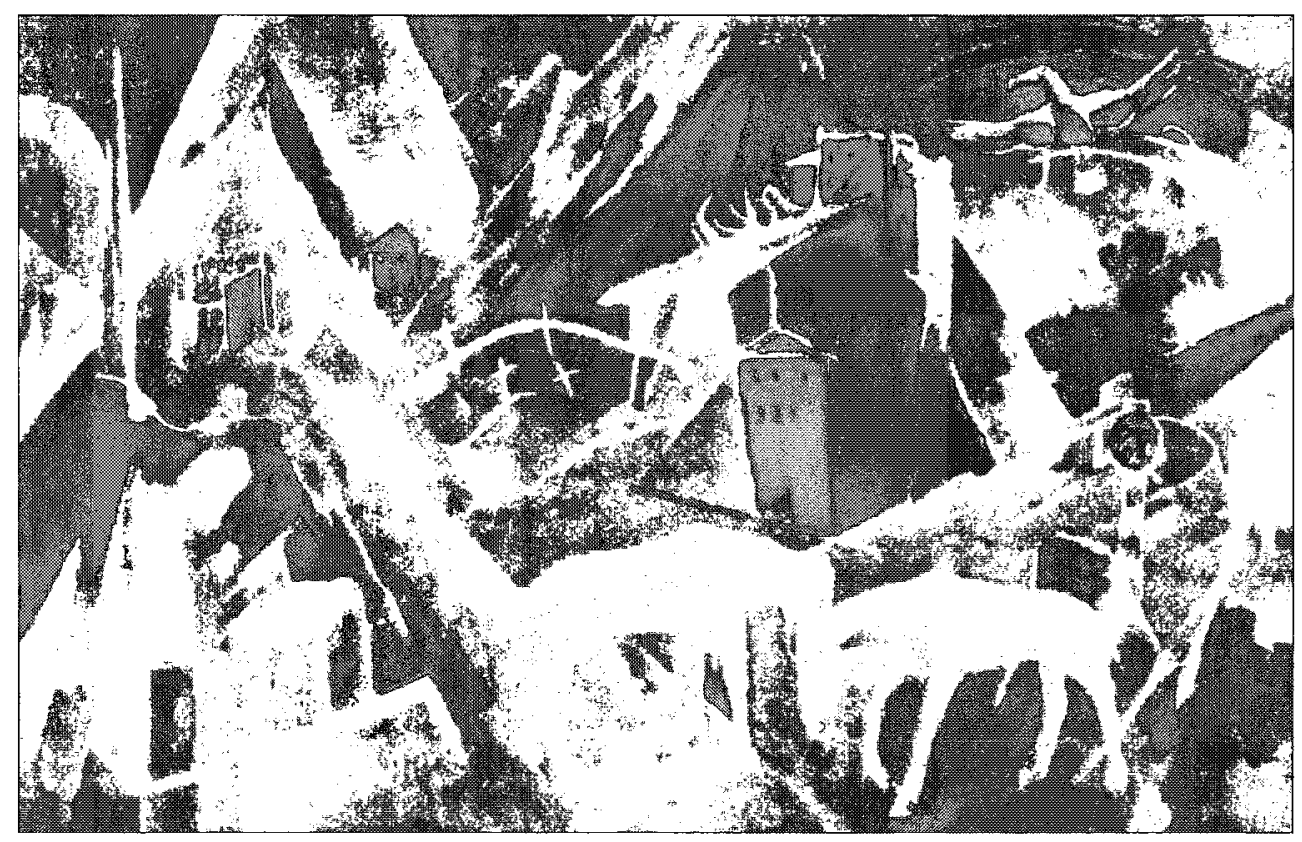

Fig. 5

Franz Marc

The Unfortunate Land of Tyrol

Oill on canvas

1913 


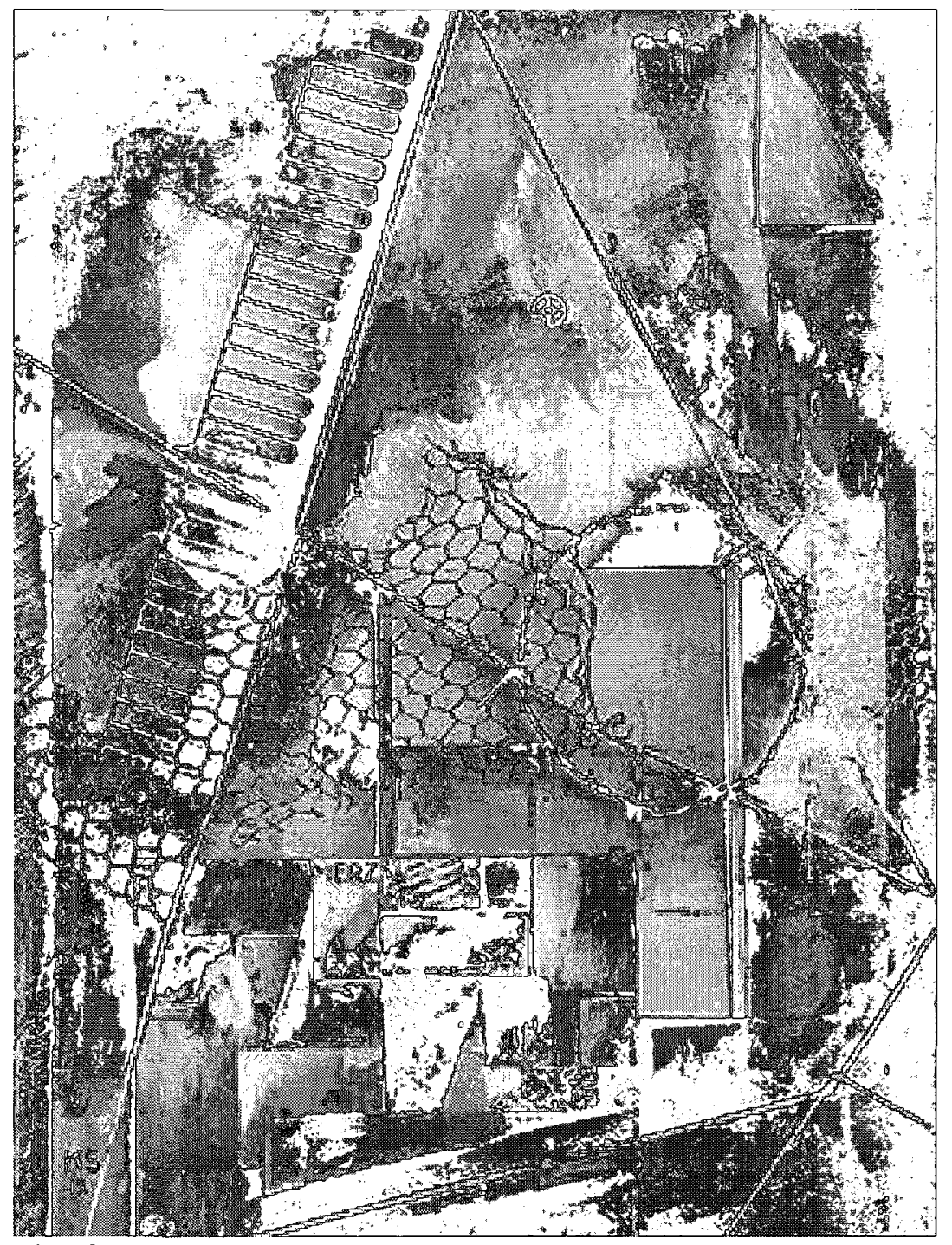

Fig. 6

Kurt Schwitters

Merzbild 01

assemblage

1919 


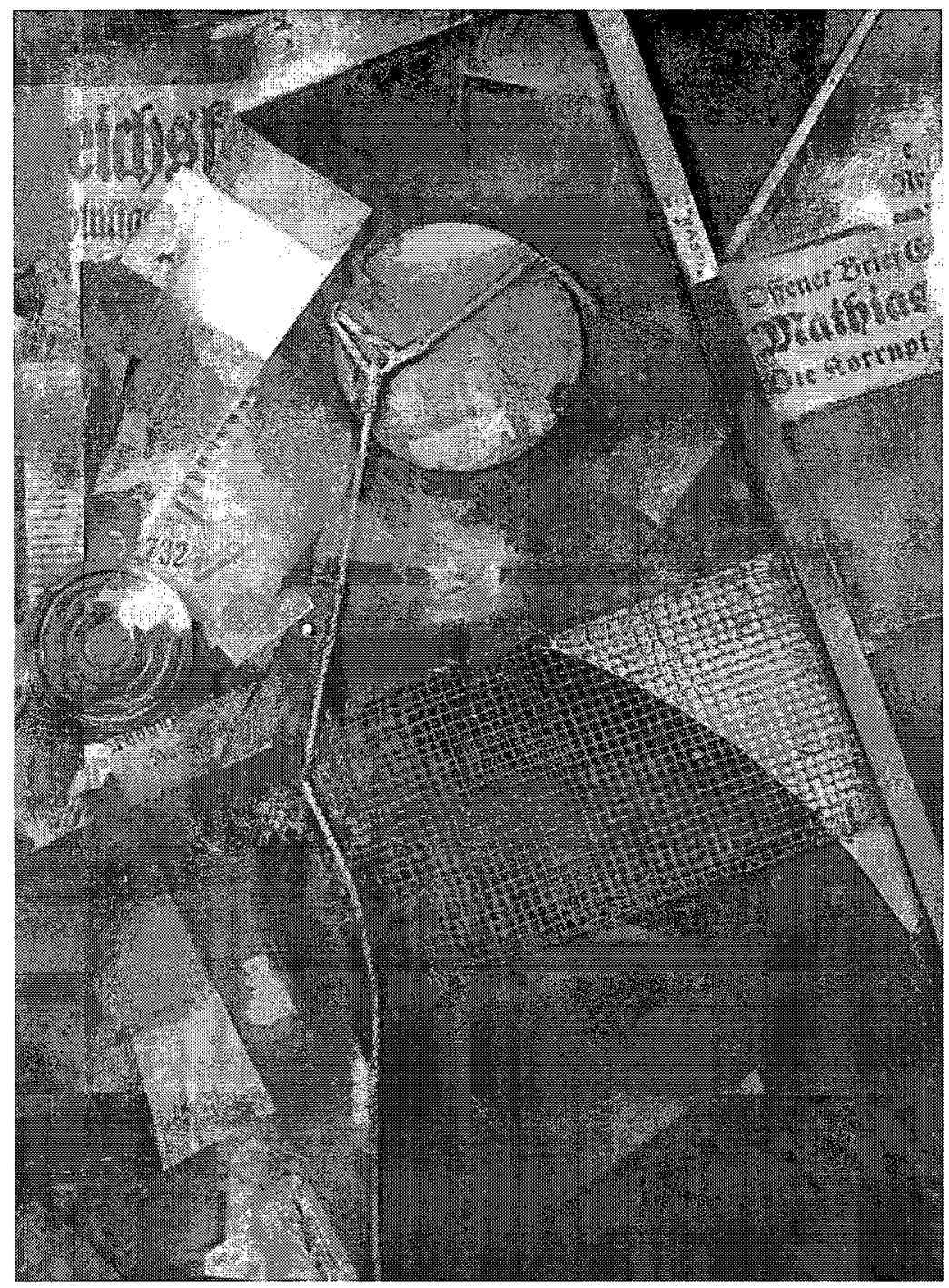

Fig. 7

Kurt Schwitters

Das Sternenbild

assemblage

1919 


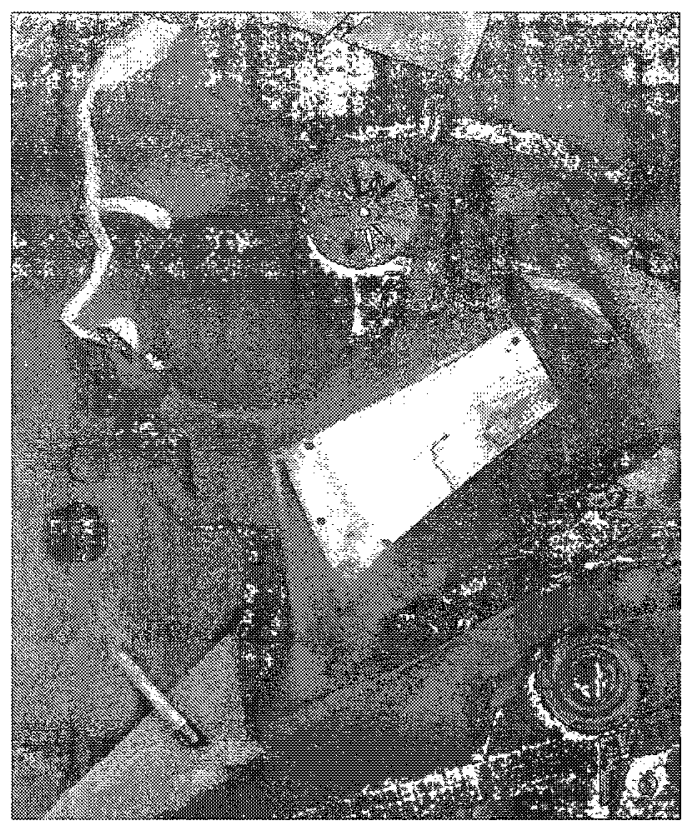

Fig. 8

Kurt Schwitters

Merzpicture IA, The Alienist

assemblage

1919

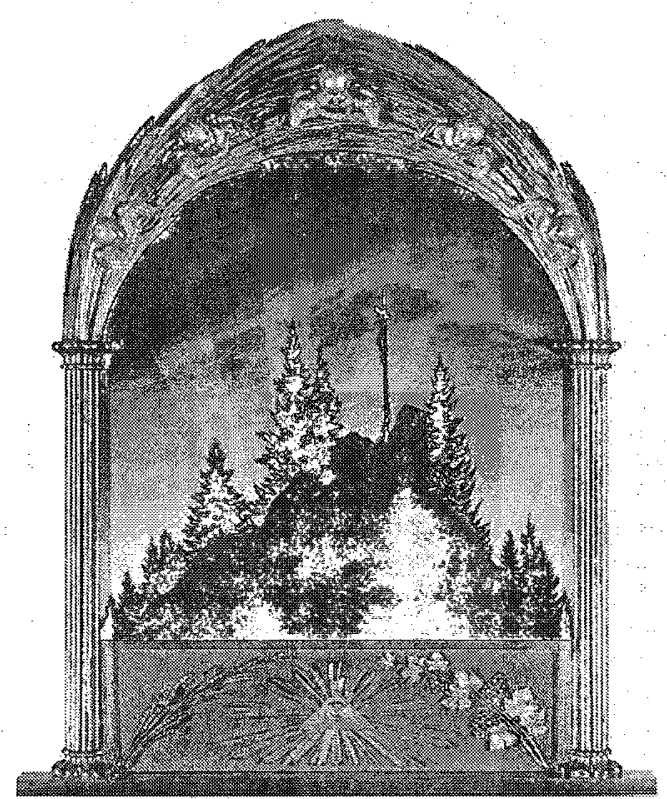

Fig. 9

Caspari David Friedrich

Cross in the Mountains

Oill on camvas

1808 


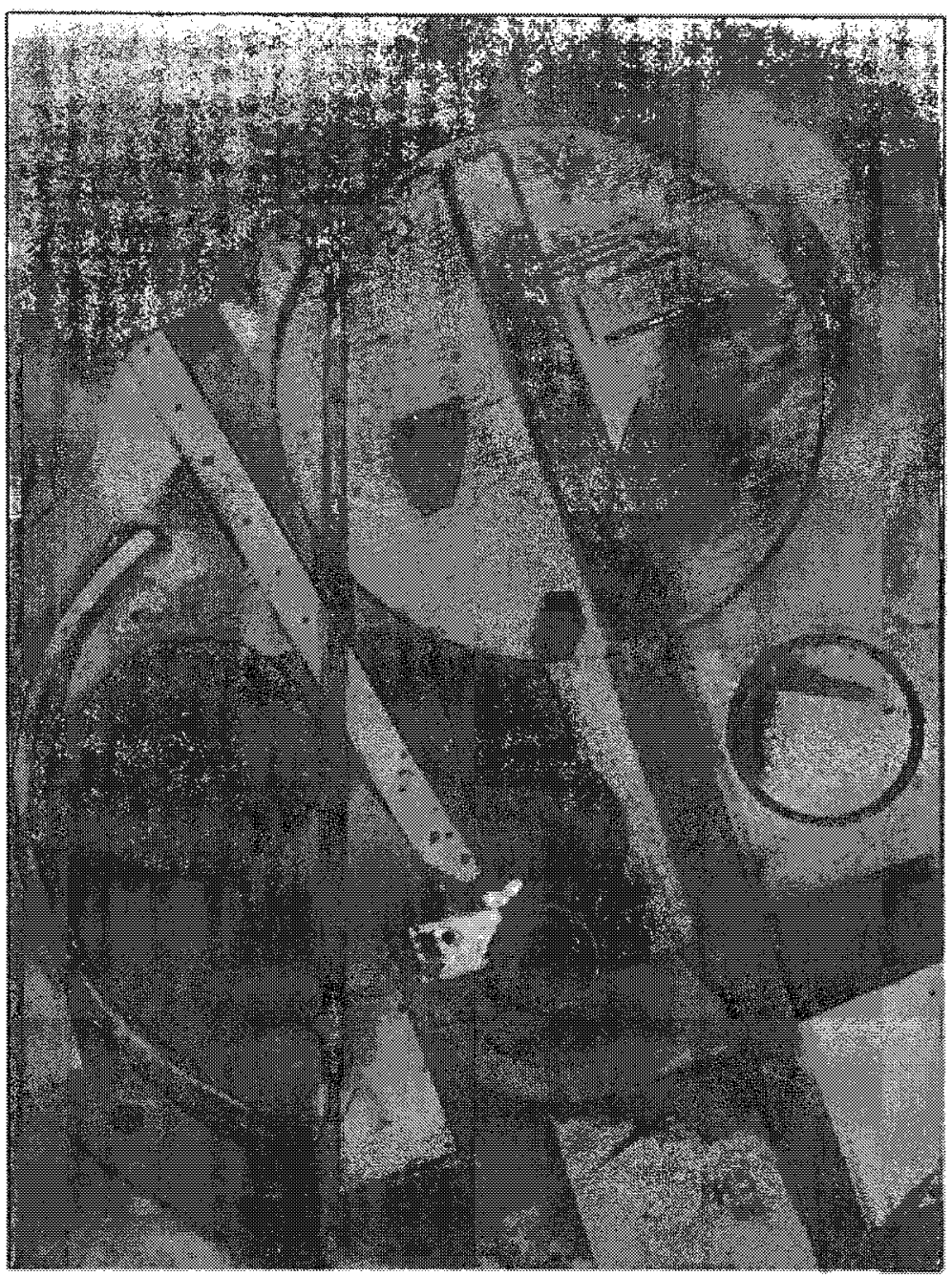

Fig. 10

Kurt Schwitters

Abeiterbild assemblage 1919 


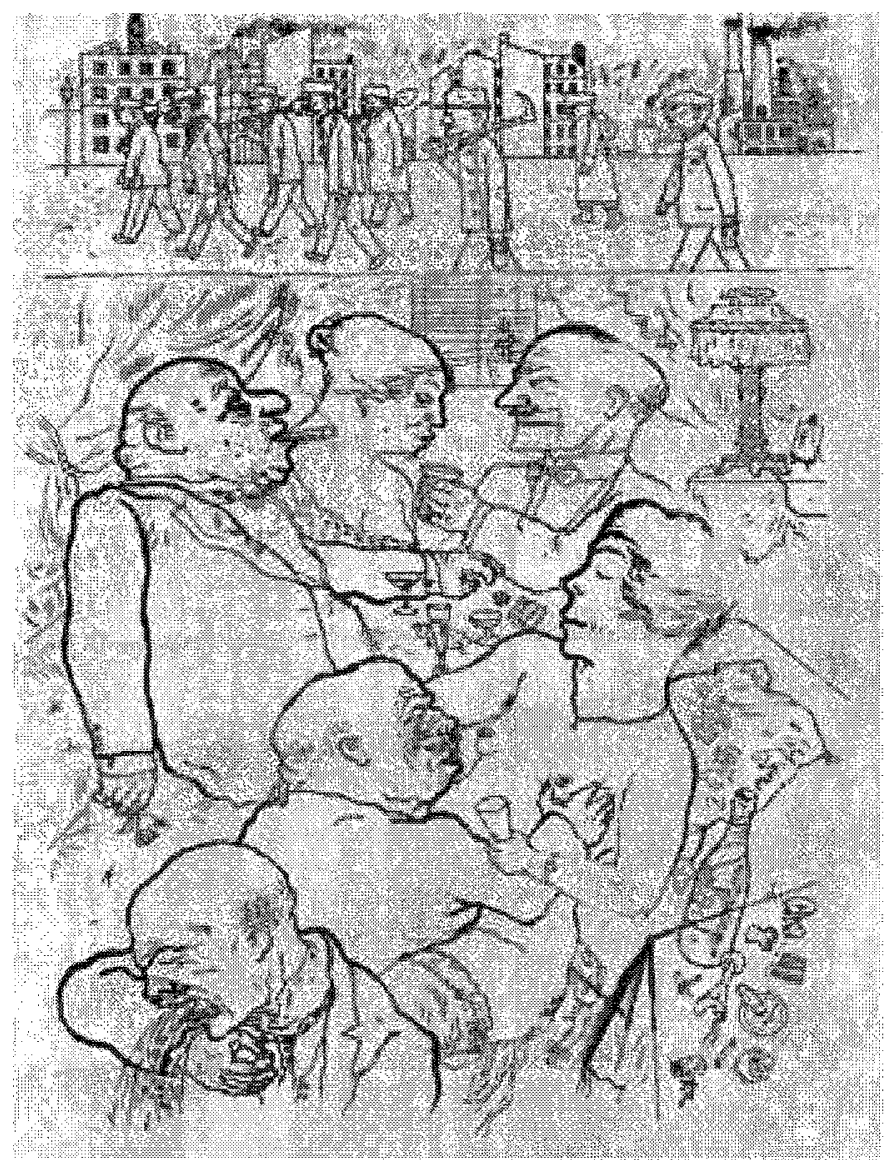

Fig. 11

George Grosz

Early at 5 O'Clock

1921

drawing 


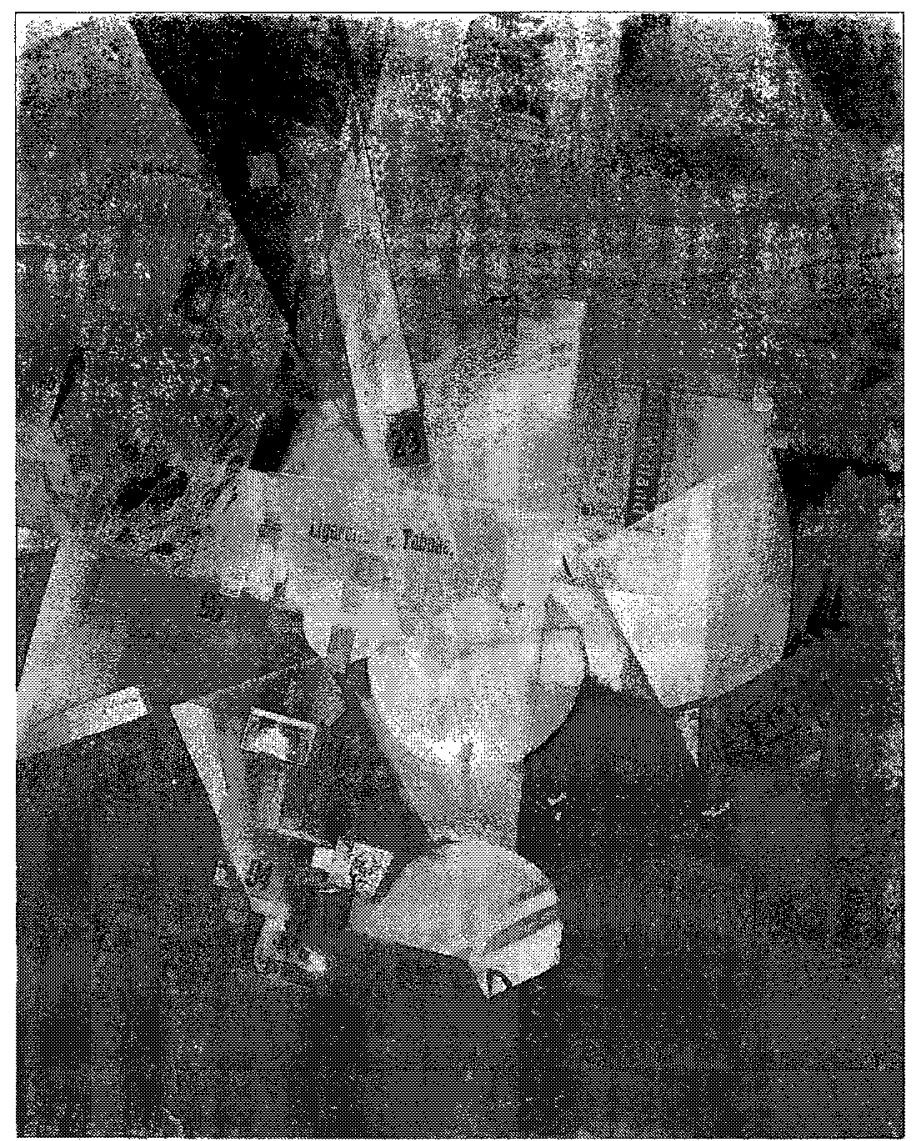

Fig. 12

Kurt Schwitters

Picture with Light Centre

assemblage

1919 


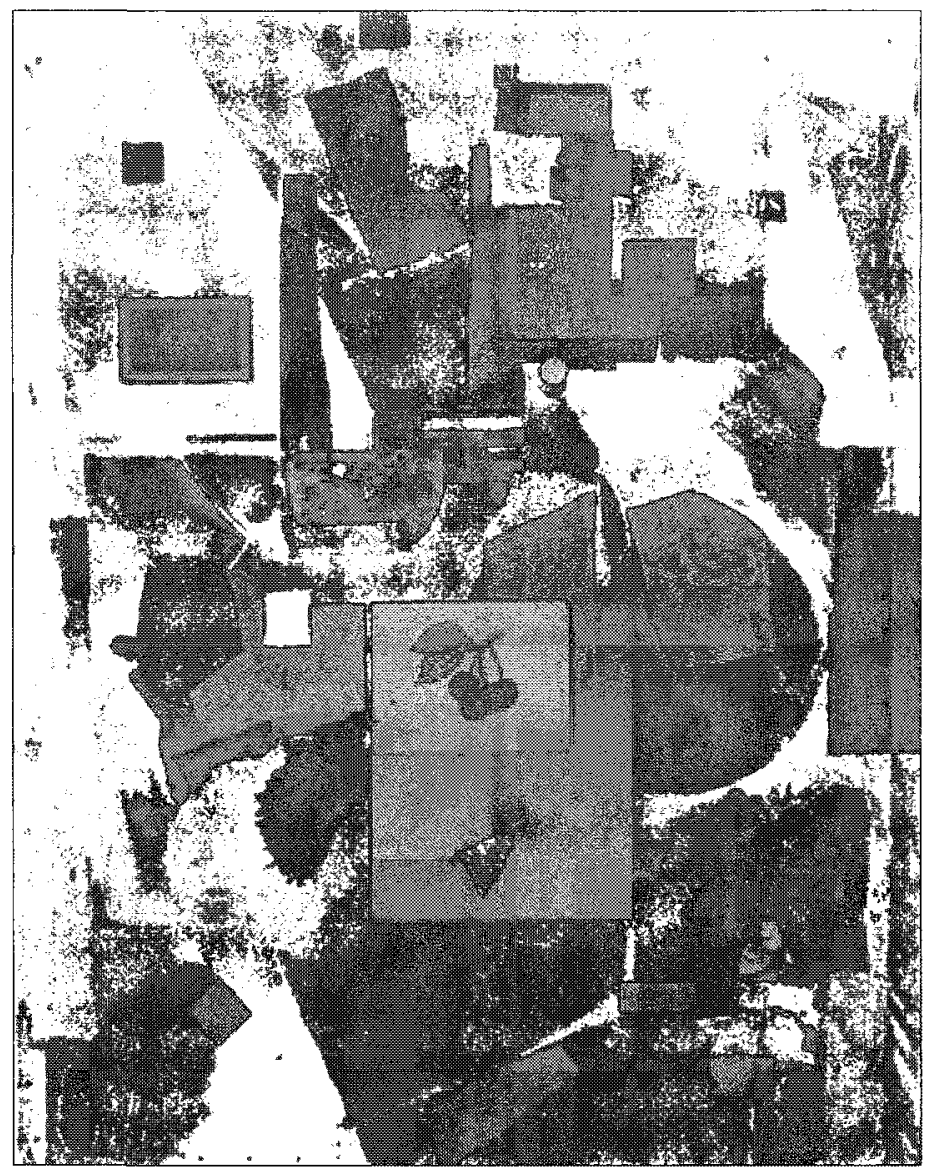

Fig. 13

Kurt Schwitters

The Cherry Picture

Assemblage

1920 


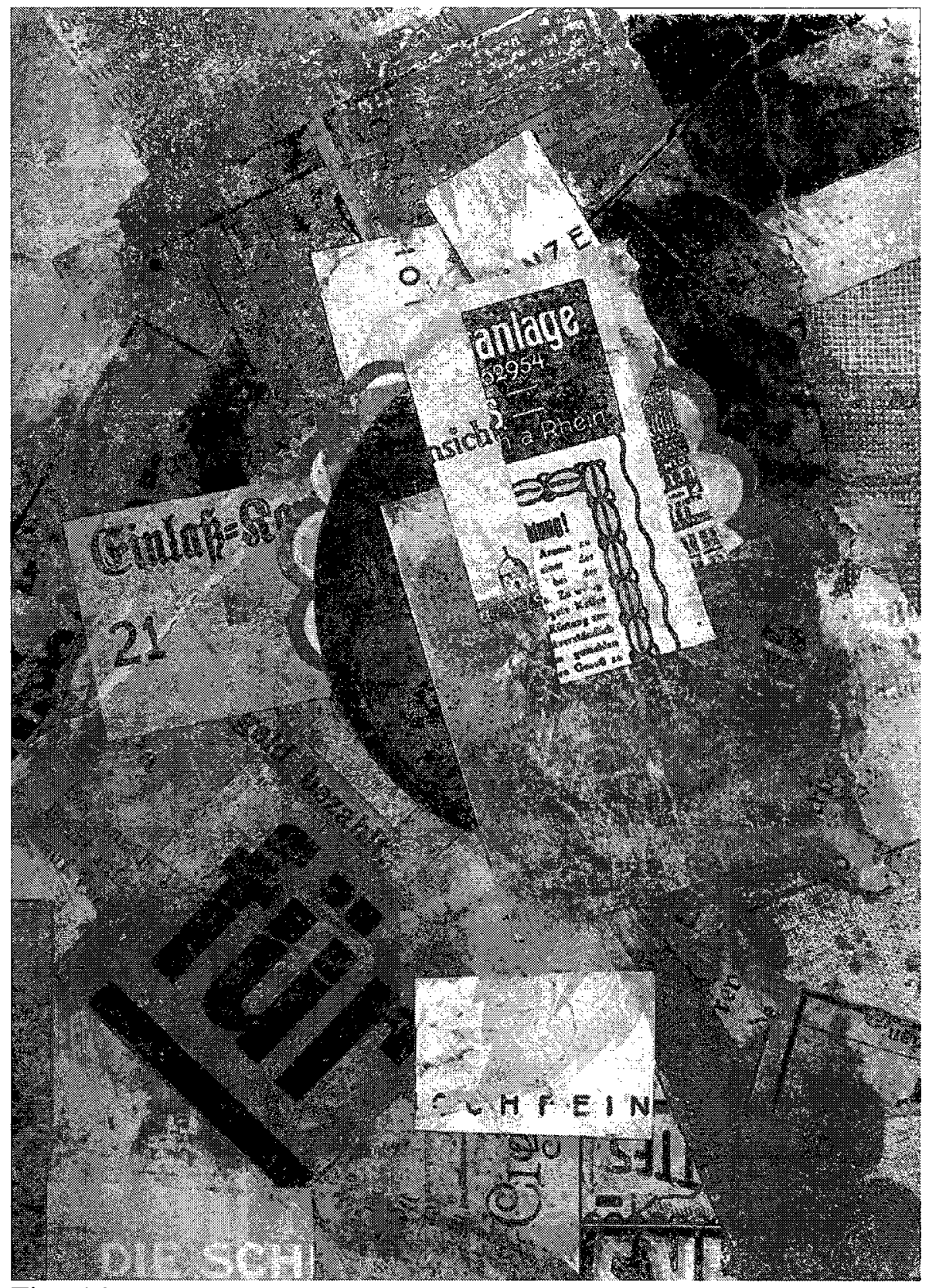

Fig. 14

Kurt Schwitters

Grüenflek

Assemblage

1920 


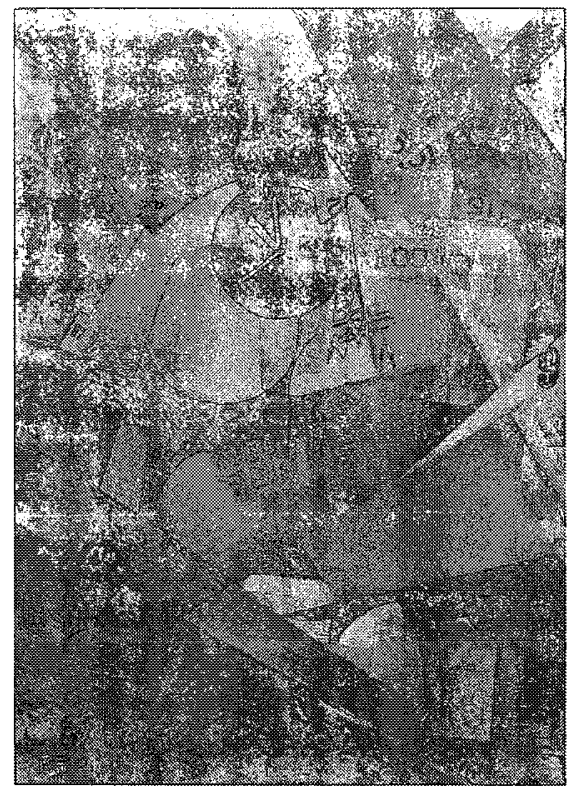

Fig. 15

Kurt Schwitters

The Great Ich Picture 1919 assemblage

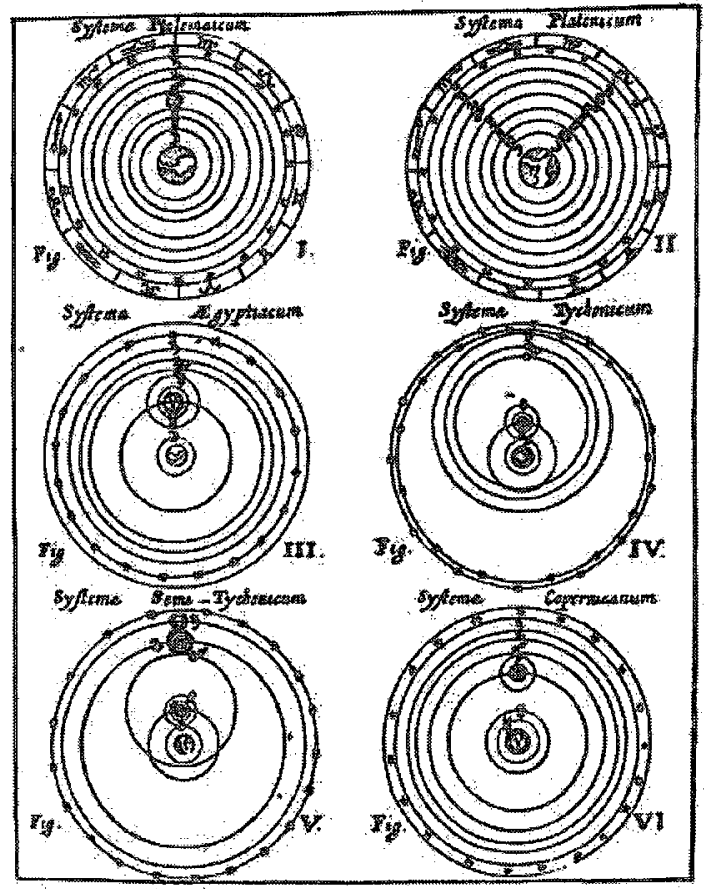

fig 16

Athanasius Kirchner

Astrological diagrams from Iter Extaticum 1671 


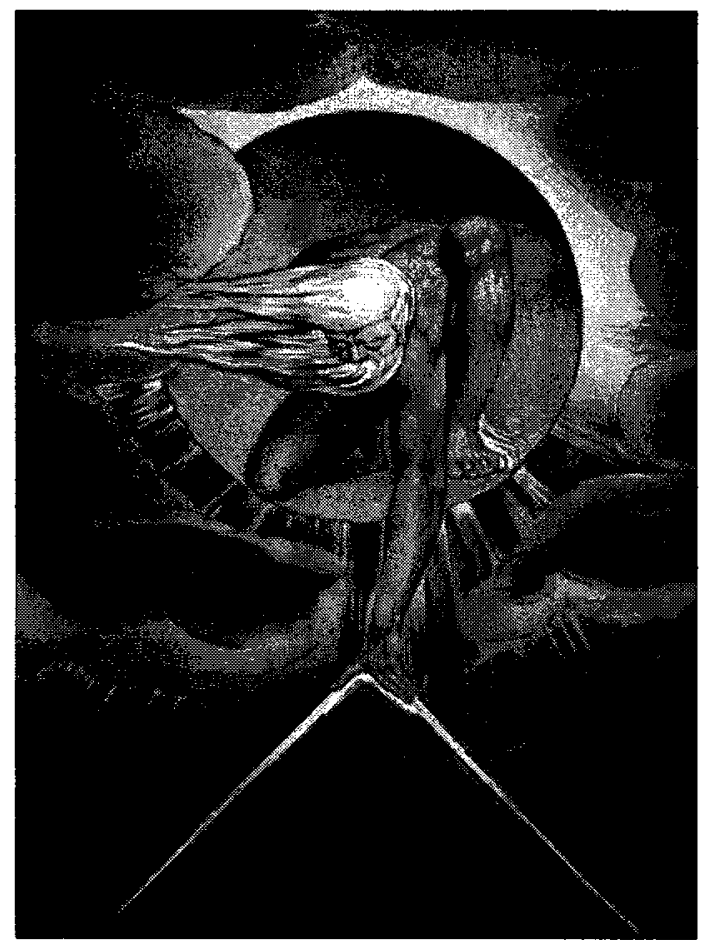

Fig. 17

William Blake

Ancient of Days

1794

watercolour etching

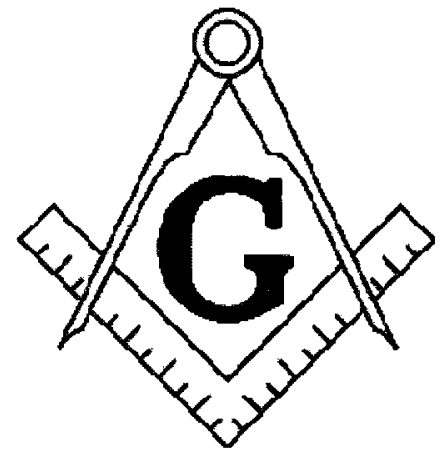

Fig. 18

Masonic seal 


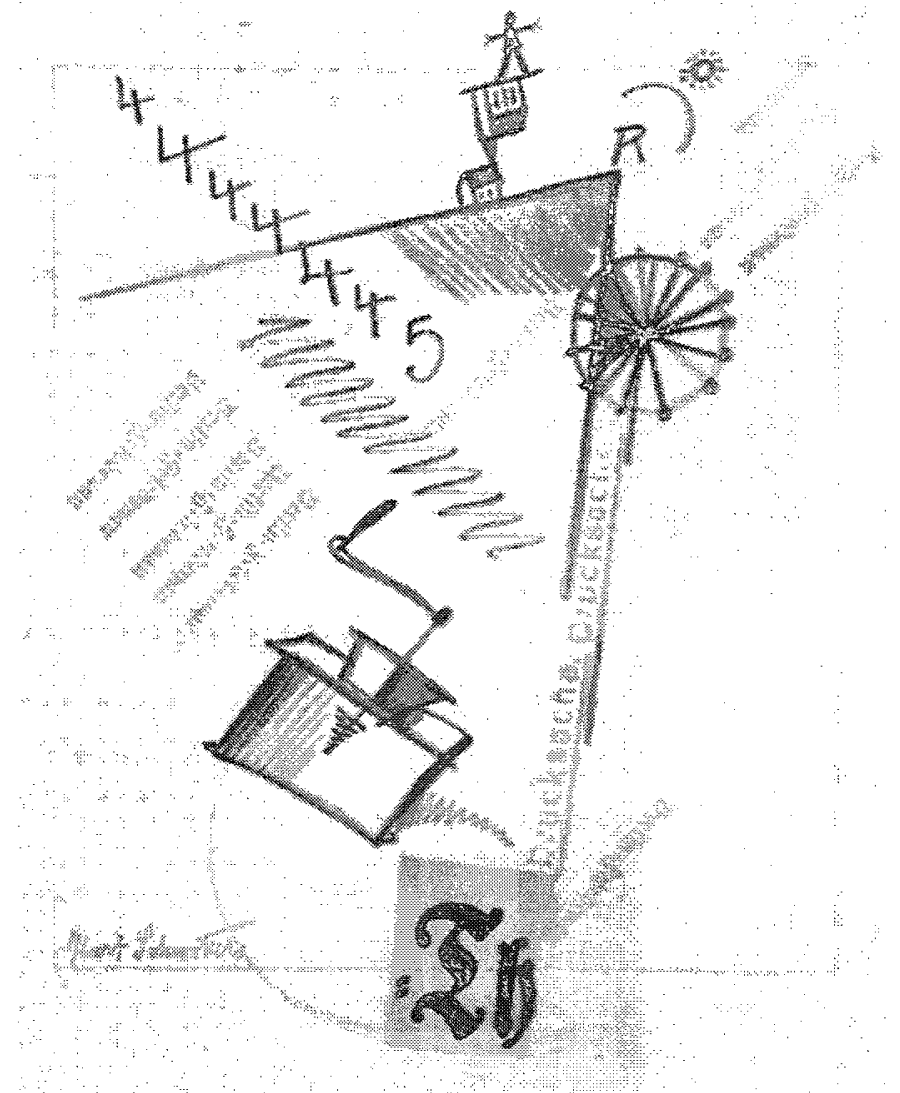

Fig. 19

Kurt Schwitters

Untitled drawing

1919 


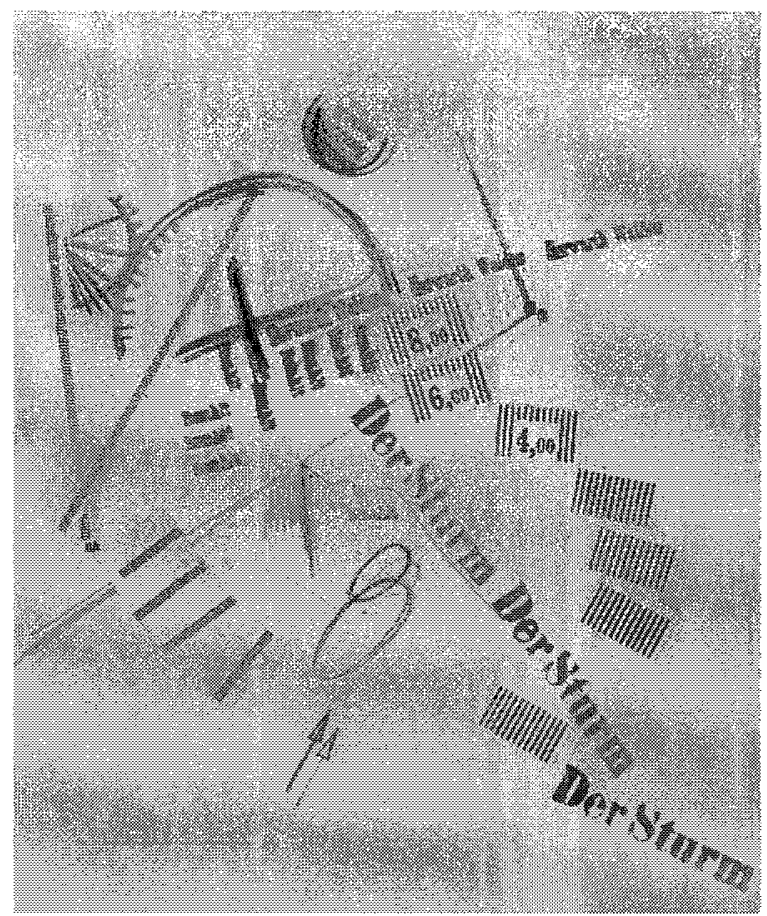

Fig. 20

Kurt Schwitters

Untitled Rubber-Stamp Drawing 1919

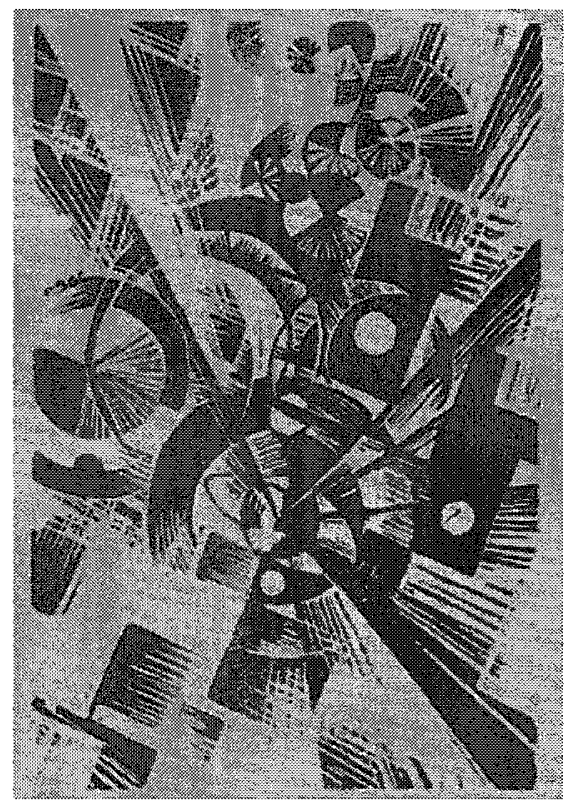

Fig. 21

Johannes Molzahn

Star Movements

1919

woodcut 


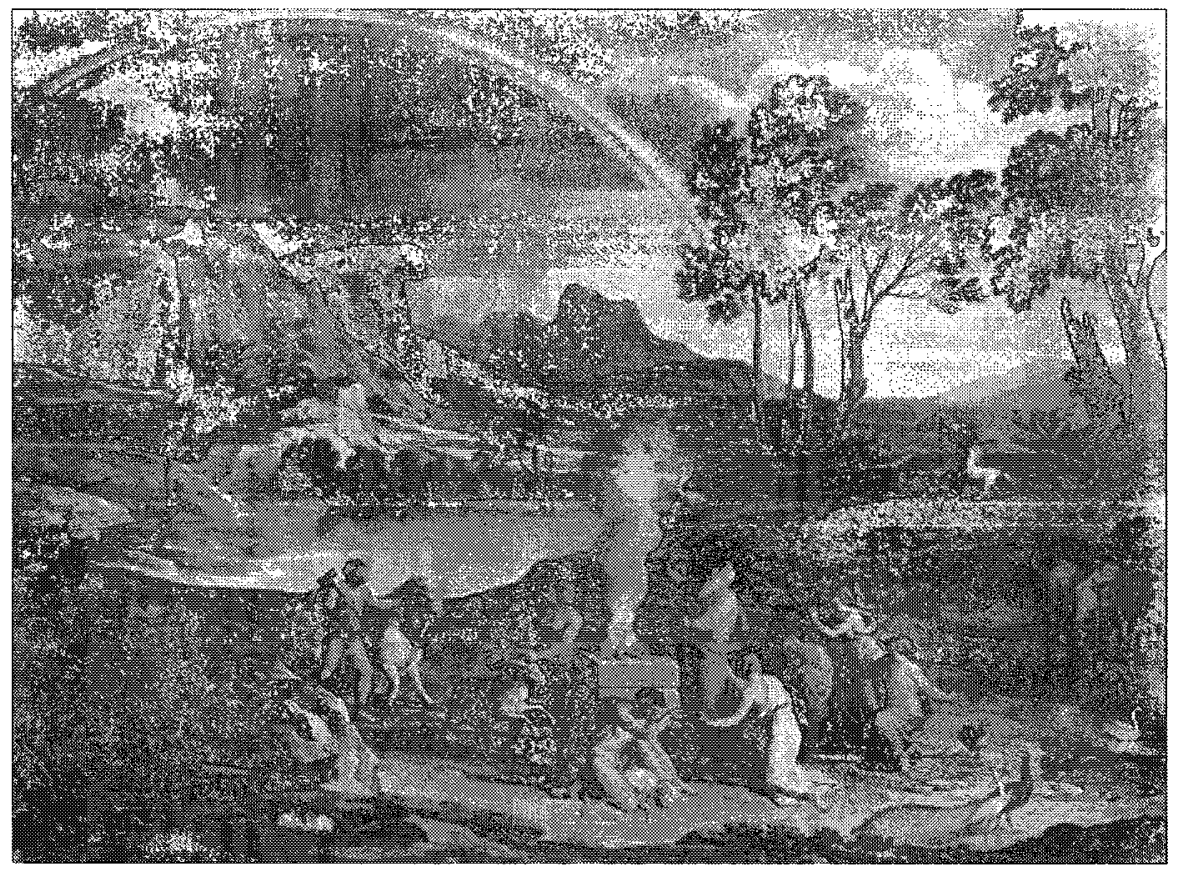

Fig. 22

Joseph Anton Koch

Noah's Thanksoffering

1803

oil on canvas

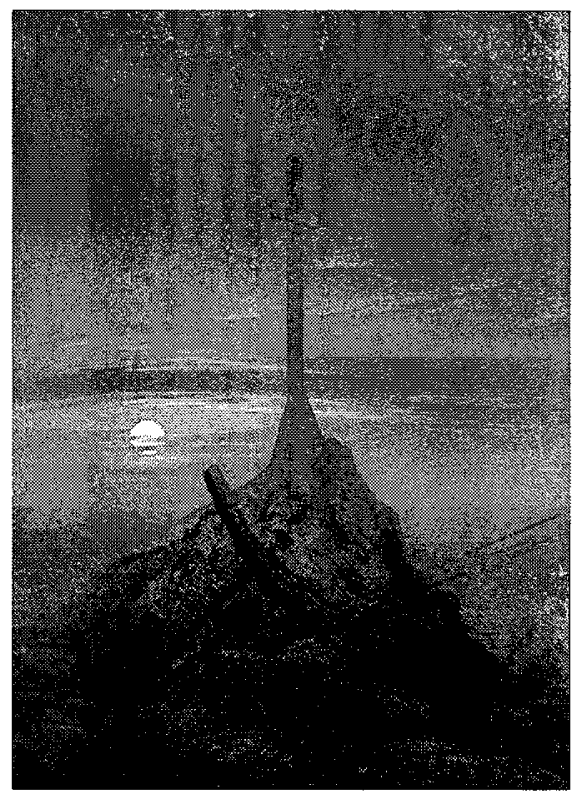

Fig. 23

Caspar David Friedrich

Cross by the Baltic

1815

oil on canvas 


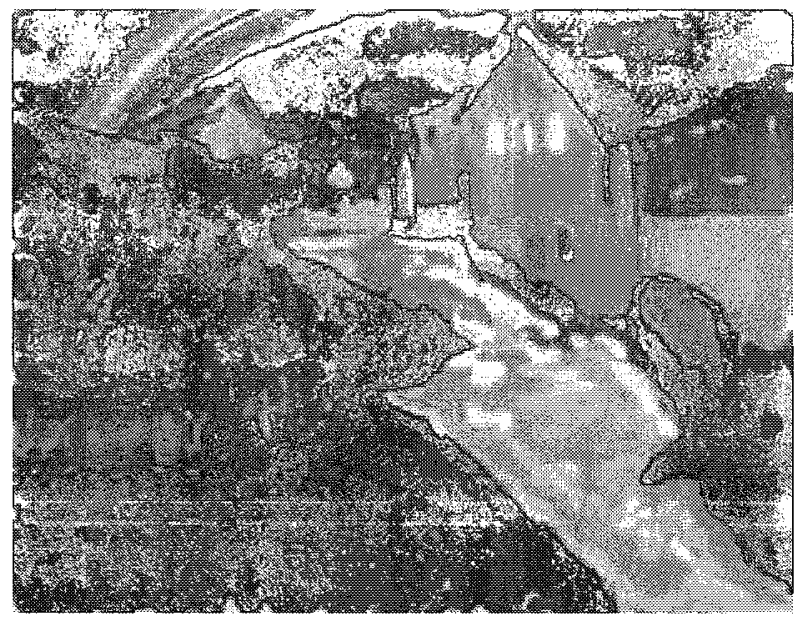

Fig. 24

Wassili Kandinsky

Murnau with Rainbow

1909

oil on canvas

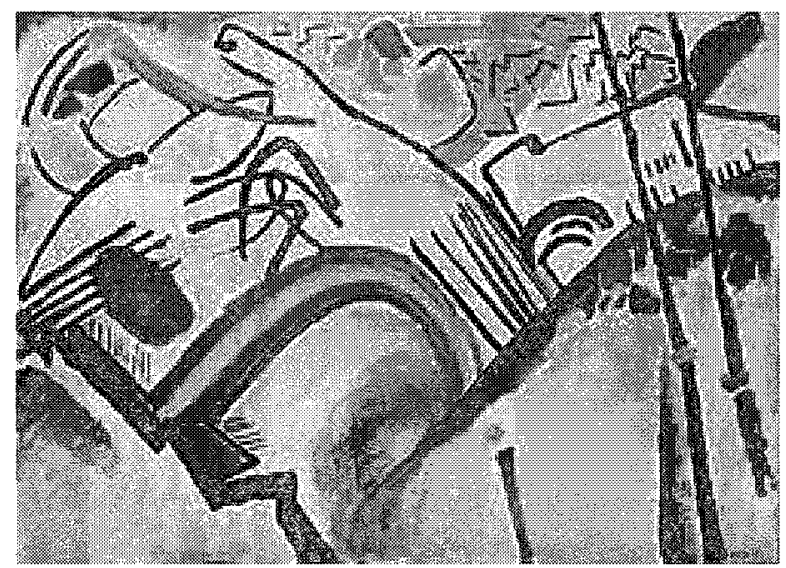

Fig. 25

Wassili Kandinsky

Cossacks

1911 


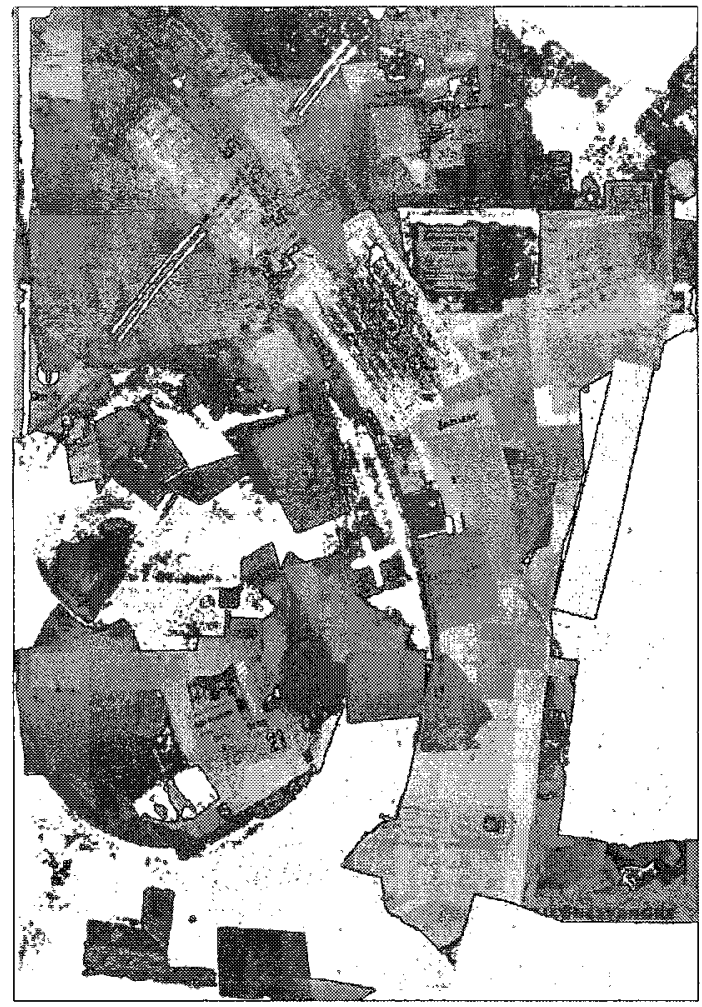

Fig. 26

Kurt Schwitters

Picture with Spatial Growth/Picture with 2 Little Dogs $1920 / 1939$

assemblage 


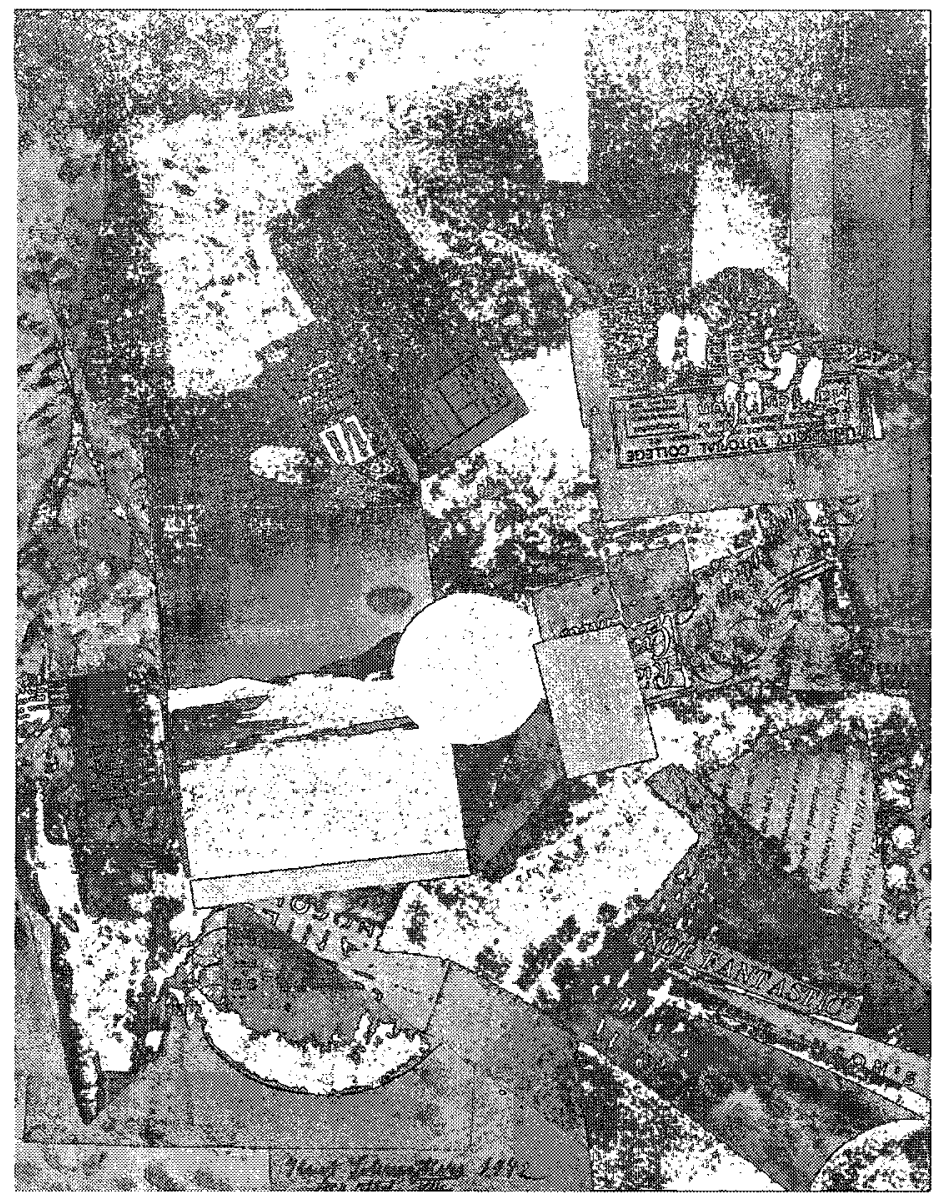

Fig. 27

Kurt Schwitters

Aerated VII

1942

assemblage

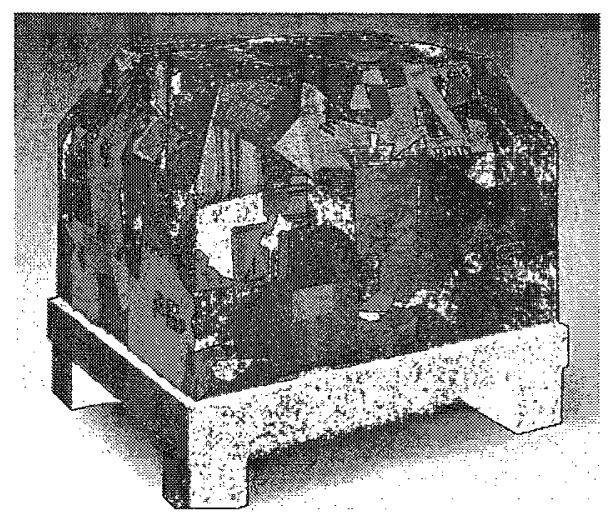

Fig. 28

Kurt Schwitters

Untitled (Merz Box)

1921

inlaid wooden box 


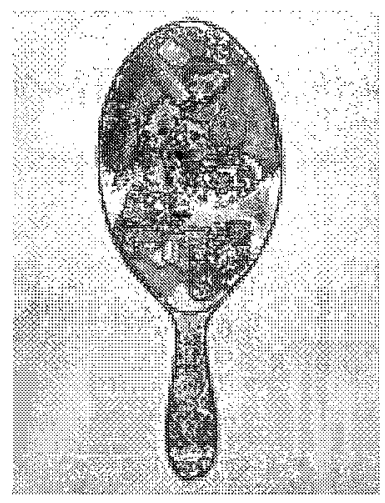

Fig. 29

Kurt Schwitters

Untitled (assemblage on hand mirror)

1920/1922

assemblage 


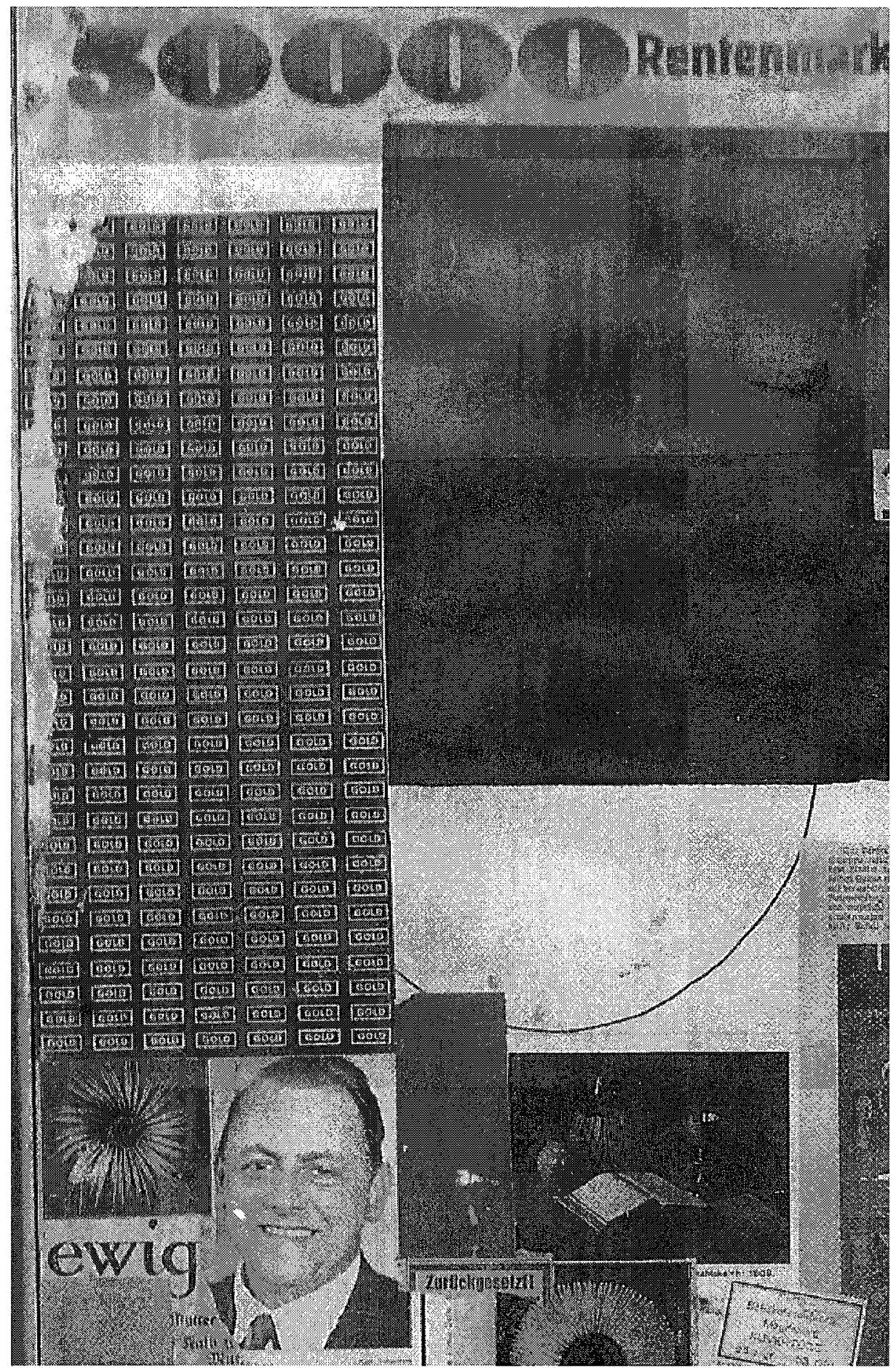

Fig. 30

Kurt Schwitters

Detail

Untitled (Collage in Interior of Box Lid)

1926 


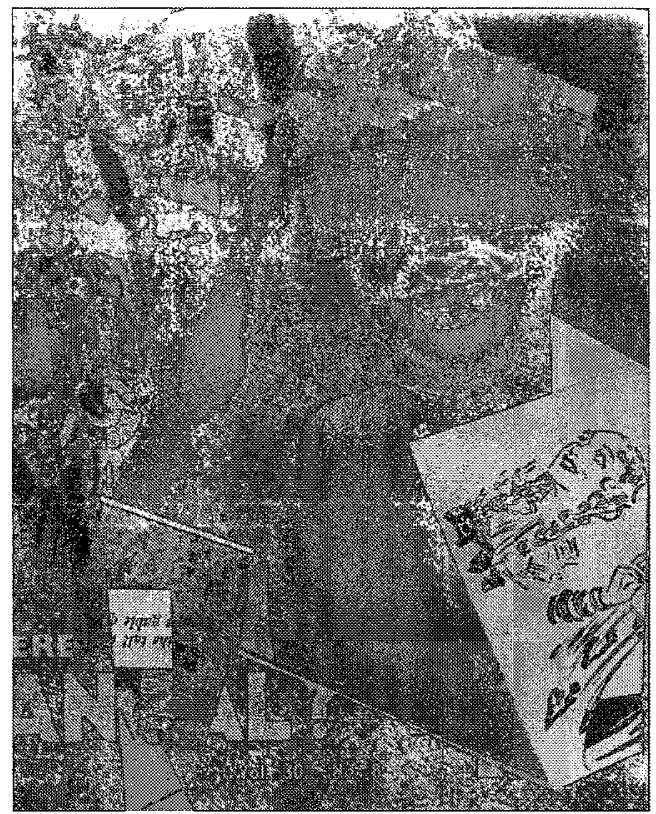

Fig. 31

Kurt Schwitters

Carnival

1947

assemblage

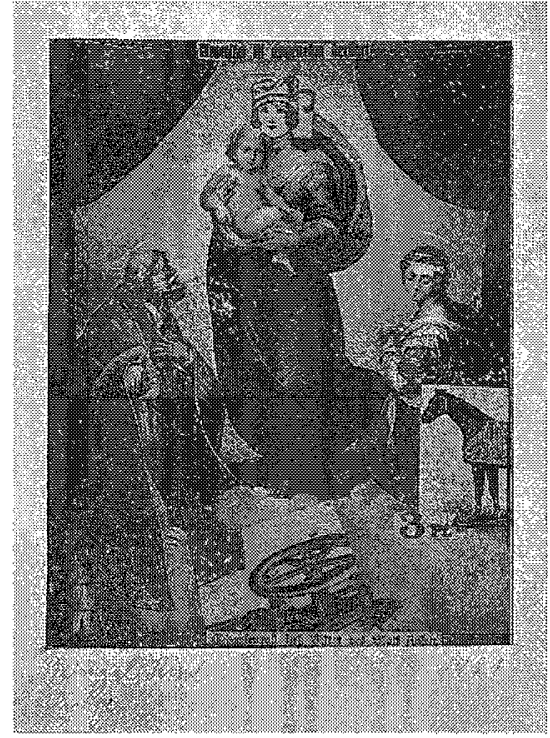

Fig. 32

Kurt Schwitters

Knave Child

1921

assemblage 


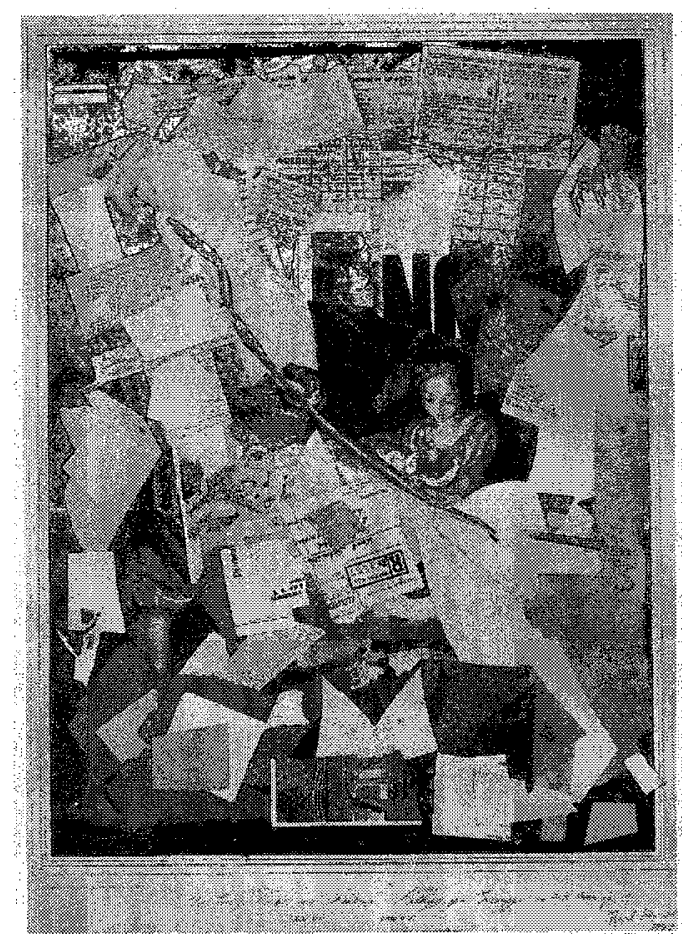

Fig. 33

Kurt Schwitters

Coreggio

1947

assemblage 


\section{Bibliography}

Bakhtin, Mikhail. Rabelais and His World, trans. Helene Iswolsky. Bloomington IN: Indiana University Press, 1965

Ball, Hugo. Flight out of Time: A Dada Diary. ed. John Elderfield, trans. Ann Raimes. New York: The Viking Press, 1974

Barron, Stephanie ed. Degenerate Art: The Fate of the Avant-Garde in Nazi Germany, Los Angeles: Los Angeles County Museum of Art, 1991

Berger, James. After the End: Representations of the Post-Apocalypse. Minneapolis, MI: University of Minnesota Press, 1999

Berger, Peter L. A Rumour of Angels: Modern Society and the Rediscovery of the Supernatural, Baltimore, MD: Penguin Books, Inc. 1971

Bindman, David. William Blake: His Art and Times, Toronto: The Art Gallery of Toronto, 1983

Boehme, Jacob. The Signature of All Things, Cambridge: James Clark \& Co. Ltd, 1969

Brandt, Susanne. "Nagelfiguren: Nailing Patriotism in Germany 1914-18" in Matters of Conflict, ed. Nicholas J. Saunders, London: Routledge, 2004, 62-89

Caillois, Roger. Man, Play and Games, trans. Meyer Barash, New York: The Free Press, 1961

Cardinal, Roger. "Collecting and Collage-Making: The Case of Kurt Schwitters", in The Cultures of Collecting, ed. John Elsner and Roger Cardinal, London: Reaktion Books, 1994, 68-97

Chevalier, Jacques M. A Postmodern Revelation: Signs of Astrology and the Apocalypse, Toronto: University of Toronto Press, 1999

Cohen, Stanley and Laurie Taylor. Escape Attempts: The Theory and Practice of Resistance in Everyday Life, London: Allen Lane, 1976

Collins, Adela Yarbro. Crisis \& Catharsis: The Power of the Apocalypse. Philadelphia: The Westminster Press, 1984

Cork, Richard. A Bitter Truth: Avant-Garde Art and the Great War, New Haven, CT: Yale University Press, 1994

Coudert, Allison. Alchemy: The Philosopher's Stone, Boulder CO: Shambhala Publications Inc. 1980 
Deitrich, Dorothea. The Collages of Kurt Schwitters: Tradition and Innovation, New York: Cabridge University Press, 1993

Dickerman, Leah. Ed. Dada: Zurich, Berlin, Hannover, Cologne, New York, Paris, Washington, DC: National Gallery of Art, 2005

Dickerman, Leah, "Merz and Memory: On Kurt Schwitters," in The Dada Seminars, ed. Leah Dickerman and Matthew S Witkousky, Washington D.C.: The National Gallery of Art, 2005, 68-97

Douglas, Mary. Purity and Danger: An Analysis of Concept of Pollution and Taboo, London: Routledge, 1966

Eliade, Mircea. Myth and Reality, trans.Willard R. Trask. New York: Harper and Row Publishers, Inc. 1963

Eliade, Mircea. Myth of the Eternal Return, trans. Willard R. Trask. Princeton: Princeton University Press, 1954

Eliade, Mircea. Shamanism: Archaic Techniques of Ecstasy, trans. Willard R. Trask. New York: Pantheon Books, Inc. 1964

Eliade, Mircea. The Forge and the Crucible: The Origins and Structures of Alchemy, trans. Stephen Corrin. Chicago: The University of Chicago Press, 1962

Ernst, Max. "Some Data on the Youth of M.E." in View: Parade of the Avant-Garde, ed. Charles Henri Ford, New York: Thunder's Mouth Press, 1991, 42-46

Fox, Steven J. "Theoretical Implications for the Study of Interrelationships Between Ritual and Play" in Play and Culture, ed. Helen B. Schwartzman, West Point, NY: Leisure Press, 1980, 42-46

Freud, Sigmund. Jokes and Their Relationship to the Unconscious. Trans. James Strachey. New York: W.W. Norton \& Company Inc. 1963

Fuchs, Rudi. Conflicts with Modernism: Or The Absence of Kurt Schwitters. Berlin: Verlag Gachnang \& Springer, 1991

Gay, Peter. Weimar Culture: The Outsider as Insider, New York: Harper and Row, Publishers, 1968

Germundson, Curt. "Montage and Totality: Kurt Schwitters and his Relationship to "Tradition" and "Avant-Garde", in Dada Culture: Critical Texts on the Avant-Garde, ed. Dafydd Jones. Amsterdam: Rodopi, 2006, 156-183 
Gordon, Mel. Voluptuous Panic: The Erotic World of Weimar Berlin, Los Angeles: Feral House, 2000

Hamilton, Alaistair. The Apocryphal Apocalypse: The Reception of The Second Book of Esdras (4 Ezra) From the Renaissance to the Enlightenment, New York: Oxford University Press, 1999

Hobsbawm, E.J. Primitive Rebels, Manchester: Manchester University Press, 1959

Hofman, Werner. Caspar David Friedrich, New York: Thames \& Hudson, 2000

Huelsenbeck, Richard. Memoir of a Dada Drummer, trans. Joachum Neugroschel. Berkeley: University of California Press, 1969

Huener, Jonathan and Francis R. Nicosia. "Introduction" in Nazi Germany: Continuity, Conformity, Change. Eds. Jonathan Huener and Francis R. Nicosia, New York: Berghahn Books, 2006, 1-15

Huizinga, J. Homo Ludens: A Study of the Play-Element in Culture, Boston: Beacon Press, 1950

Humphrey, Robert L. "Play as Life: Suggestions for a Cognitive Study of the Mesoamerican Ball Game" in Play as Context, ed. Alyce Taylor Cheska, West Point NY: Leisure Press, 1981, 134-148,

Hyde, Lewis. Trickster Makes this World: How Disruptive Imagination Creates Culture, New York: Canongate, 1998

James, William. The Varieties of Religious Experience: A Study in Human Nature, New York: Simon \& Schuster Inc. 1997

Janco, Marcel. "Dada at Two Speeds" Dadas On Art: Tzara, Arp, Duchamp and Others, ed. Lucy R. Lippard, Englewood Cliffs, NJ: Prentice-Hall, 1971

Janecke, Christian. "Schwitters and Chance", in Kurt Schwitters: Merz - a Total Vision of the World, eds. Müller, Annja and Heinz Stahlhut. Bern: Benteli Publishers, 2004, 3265

Josephon, Matthew. Life Among the Surrealists: A Memoir, New York: Holt, Rinehart and Winston, 1962

Jung, Carl G. \& M.-L von Franz eds. Man and his Symbols, London: Aldus Books Ltd, 1964

Kandinsky, Wassili. Concerning the Spiritual in Art, trans. M.T. H. Sadler, New York: Dover Publications, Inc. 1977 
Kozloff, Max. Cubism/Futurism, New York: Chaterhouse, 1973

Kuenzli, Rudolph E. "The Semiotics of Dada Poetry", in Dada Spectrum: The Dialectics of Revolt, ed. Stephen C. Foster and Rudolph E. Kuenzli, Iowa City, IA: The University of Iowa, 1979, 51-70

Kuspit, Donald, "Collage: The Organizing Principle of Art in the Age of the Relativity of Art", in Relativism in the Arts, ed. Betty Craig,Athens GA: The University of Georgia Press, 1983, 123-147

Kuspit, Donald, "Tart Wit, Wise Humour", in Artforum International, Vol 13, Issue 1 (January 1991) 123-147

La Fave, Lawrence and Jay Haddad and William A. Maesen. "Superiority, Enhanced Self-Esteem, and Perceived Incongruity Humour Theory" Humour and Laughter: Theory, Research and Appolication, eds. Antony J Chapman and Hugh C. Foot. Toronto: John Wiley \& Sons, 1976. 63-92

Lefcourt, Herbert M. Humour: The Psychology of Living Buoyantly, New York: Plenum Publishers, 2001

Levine, Frederick S. The Apocalyptic Vision: The Art of Franz Marc as German Expressionism, New York: Harper \& Row, Publishers, 1979

Marinetti, F.T. Critical Writings, trans. Doug Thompson, ed. Gunter Berghaus, New York: Farrar, Straus and Giroux. 2006

Mezler, Annabelle. Latest Rage the Big Drum: Dada and Surrealist Performance, Baltimore, MD: John Hopkins University Press, 1976

Motherwell, Robert ed. The Dada Painters and Poets, Cambridge MS: The Belknap Press of Harvard University, 1979

Nill, Annegreth. "Rethinking Kurt Schwitters: An Interpretation of Grünfleck" Arts Magazine, Vol 55, Issue 5 (January 1981) 112-25

Nordeau, Max. Degeneration, Lincoln, Nebraska: University of Nebraska Press, 1993

O'Leary, Stephen D. Arguing the Apocalypse: A Theory of Millennial Rhetoric, New York: Oxford University Press, 1994

Öhlenbach, Melanie "The Influence of Jacob Böhme's Theosophical Ideas on the 'Farbentheorie' by Phillip Otto Runge" Masonic and Esoteric Heritage ed. Den Jaag: OVN, 2005. 57-67 
Orchard, Karin, "Kurt Schwitters' Spatial Growths", in Kurt Schwitters: Merz - a Total Vision of the World, eds. Müller, Annja and Heinz Stahlhut. Bern: Benteli Publishers, 2004, 32-65

Panikos Panayi, "Continuities and Discontinuities in German History, 1919-1945", in Weimar and Nazi Germany: Continuities and Discontinuities, ed. Panikos Panayi, Essex, UK: Pearson Education Limited, 2007, 32-65

Paracelsus, "From The Nature of Things and Paracelsus His Aurora", in The Alchemy Reader: From Hermes Trismegistus to Issac Newton, ed. Stanton J. Linden. Cambridge: Cambridge University Press, 2003, 151-170

Parker, Derek and Julia Parker, A History of Astrology, (London: Andre Deutsch Limited, 1983)

Peterson, Elmer. Tristan Tzara: Dada and Surrational Theorist, New Brunswick, NJ: Rutgers University Press, 1971

Reichardt, Jasia. "Introduction" Raoul Hausmann \& Kurt Schwitters and the Story of Pin, London: Gaberbochus Press, 1962

Rickets, Mac Linscott, "The Shaman and the Trickster", in Mythical Trickster Figure: Contours, Contexts and Criticisms, eds. William J Hines and William G. Doty, Tuscaloosa AB: University of Alabama Press, 1993, 85-105

Robinson, John J. Born in Blood: The Lost Secrets of Freemasonry, Toronto: M. Evans, 1989

Schmalenbach, Werner. Kurt Schwitters, New York: Harry N. Abrams, Inc. 1967

Schwitters, Kurt. "Der Zweibel", in PPPPPP: Poems Performance Pieces Proses Plays Poetics, eds \& trans. Jerome Rothenberg \& Pierre Joris, Cambridge, MA: Exact Change, 2002, 121-127

Schwitters, Kurt “Ur Sonate”, in PPPPPP: Poems Performance Pieces Proses Plays Poetics, eds \& trans. Jerome Rothenberg \& Pierre Joris, Cambridge, MA: Exact Change, 2002, 52-79

Seitz, William C. The Art of Assemblage, (New York: The Museum of Modern Art, 1962)

Seligmann, Kurt. The History of Magic, New York: Pantheon Books Inc. 1948

Sheppard, Richard. Modernism - Dada - Postmodernism, Evanston, IN: Northwestern University Press, 2000 
Solnit, Rebecca. Wanderlust: A History of Walking, New York: Viking, 2000

Smith, Jeffrey R. "The First World War and the Public Sphere in Germany", inWorld War I and the Cultures of Modernity. eds. Douglas Mackaman and Michael Mays. Jackson, MI: University of Mississippi, 2000, 68-80

Taut, Bruno. "26 December, 1919", in The Crystal Chain Letters: Architectural Fantasies by Bruno Taut and his Circle ed. Iain Boyd Whyte, Cambridge MA: The MIT Press, 1985,25

Trompf, G.W. ed. Cargo Cults and Millenarian Movements: Transoceanic Comparisons of New Religious Movements, New York: Mouton de Gruyter, 1990

Tuchman, Maurice. "Hidden Meaning in Abstract Art" The Spiritual in Art: Abstract Painting 1890-1985 ed. Maurice Tuchman Los Angeles: Los Angeles County Museum of Art, 1986, 17-63

Umland, Anne and Adrian Sudhalter with Scott Gerson, eds. Dada: In the Collection of the Museum of Modern Art, New York: The Museum of Modern Art, 2008

Vatlin, Jan. Out of the Night, Oakland, CA: AK Press, 2004

Waldhorn, Herbert F. M.D. and Bernard D. Fine M.D. eds. Trauma, Symbolism, New York: International Universities Press, Inc. 1974

Wadley, Nicholas. Kurt Schwitters in Exile: The Late Work, 1937-1948 London: Marlborough Fine Art, 1981

Washton-Long, Rose Carol. "Expressionism, Abstraction, and the Search for Utopia" The Spiritual in Art: Abstract Painting 1890-1985 ed. Maurice Tuchman, Los Angeles: Los Angeles County Museum of Art, 1986, 201-217

Weber, Eugen. Apocalypses: Prophecies, Cults and Millennial Beliefs Through the Ages Toronto: Random House of Canada, 1999

Webster, Gwendolen. Kurt Merz Schwitters: A Biographical Study, Cardiff: University of Wales Press, 1997

Weitz, Eric D. Weimar Germany: Promise and Tragedy, Princeton, NJ: Princeton University Press, 2007

Willieford, William, The Fool and His Scepter: A Study in Clowns and Jesters and Their Audience, Northwestern University Press, 1969 